AUTARQUIA ASSOCIADA À UNIVERSIDADE DE SÃO PAULO

FUNCIONALIZAÇÃO DA SUPERFÍCIE DE METAIS ATRAVÉS DA PRODUÇÃO DE NANOESTRUTURAS PERIÓDICAS PRODUZIDAS POR LASER PULSADO DE FEMTOSSEGUNDO

Leandro Gusmão da Silva

Dissertação apresentada como parte dos requisitos para obtenção do Grau de Mestre em Ciências na Área de Tecnologia Nuclear - Materiais

Orientador:

Prof. Dr. Wagner de Rossi 
INSTITUTO DE PESQUISAS ENERGÉTICAS E NUCLEARES

Autarquia associada à Universidade de São Paulo

FUNCIONALIZAÇÃO DA SUPERFÍCIE DE METAIS ATRAVÉS DA PRODUÇÃO DE NANOESTRUTURAS PERIÓDICAS PRODUZIDAS POR LASER PULSADO DE FEMTOSSEGUNDO

Leandro Gusmão da Silva

Dissertação apresentada como parte dos requisitos para obtenção do Grau de Mestre em Ciências na Área de Tecnologia Nuclear - Materiais

Orientador:

Prof. Dr. Wagner de Rossi

Versão Original

São Paulo

2017 
Dedico esse trabalho ao Leandro Gusmão da Silva de 2014, que o iniciou com a esperança de um dia escrever essas palavras. 


\section{AGRADECIMENTOS}

Agradeço meu orientador, Dr. Wagner de Rossi, que desde o começo de nossa parceria demonstrou extrema confiança, compreensão, dedicação e amizade.

Ao Dr. Marcus Paulo Raele, que me auxiliou em diversas caracterizações fundamentais para o trabalho.

À todos do Centro de Lasers e Aplicações, que por mais indireta que fosse, auxiliaram de forma fundamental a execução desse trabalho.

Ao IPEN/CNEN por ceder as instalações para a realização desse trabalho.

À Empresa Açovisa, que não impediu, nem dificultou a conclusão desse trabalho.

Aos colegas Cristhiano da Costa Herrera, Denilson de Camargo Mirim, Eduardo Spinelli Oliveira, do Centro de Lasers e Aplicações e Bruno Pizzol Invernize do Centro de Ciência e Tecnologia dos Materiais pela colaboração e amizade.

Aos amigos Daniela Messias Francisco e Rodolfo Dal Alva Pinto, que nunca me deram a sensação de estar sozinho e sem propósito.

À meus pais, que sempre confiaram e se orgulharam de minhas decisões e metas, além de terem me apoiado quando poucos o fizeram. 
"Só conheço uma liberdade, e essa é a liberdade do pensamento"

Antoine de Saint-Exupéry 


\title{
FUNCIONALIZAÇÃO DA SUPERFÍCIE DE METAIS ATRAVÉS DA PRODUÇÃO DE NANOESTRUTURAS PERIÓDICAS PRODUZIDAS POR LASER PULSADO DE FEMTOSEGUNDO
}

\author{
Leandro Gusmão da Silva
}

\section{RESUMO}

Neste trabalho, foram realizados diversos experimentos para a criação controlada de nanoestruturas superficiais produzidas por Laser pulsado de femtossegundo em Titânio e em aço inoxidável, ambos utilizados para fins cirúrgicos e industriais. Os parâmetros alterados nos experimentos foram a Fluência do laser, a taxa de sobreposição de pulsos, polarização do feixe e atmosfera de processamento. A vantagem na utilização do laser de femtossegundo para essas aplicações é a possibilidade de ser criar tais estruturas sem que haja aquecimento crítico do material, evitando assim, a criação de óxidos ou nitretos superficiais, já que esses a formação desses materiais superficiais pode afetar o desempenho industrial e cirúrgico dos materiais. Após o entendimento dos parâmetros de irradiação na formação das nanoestruturas, foram propostas três aplicações possíveis para a superfície resultante do processamento com laser: Superfícies coloridas, que podem ser utilizadas em personalização de peças; Superfícies escuras, que podem ser utilizadas na marcação e tipagem de peças; e um Micro Aquecedor, que pode ser utilizado no controle de temperaturas dentro de circuitos microfluídicos.

Palavras-chave: Femtossegundo, Laser, Superfície Colorida. 


\title{
FUNCTIONALIZATION OF THE METALS SURFACE THROUGH THE PRODUCTION OF PERIODIC NANO-STRUCTURES PRODUCED BY FEMTOSECOND LASER PULSES
}

\begin{abstract}
In this work, several experiments were carried out for the controlled creation of surface nanostructures produced by femtosecond laser pulses in Titanium and stainless steel, both used for surgical and industrial purposes. The altered parameters in the experiments were the laser Fluence, the overlap pulses rate, the beam polarization and processing atmosphere. The advantage of using femtosecond laser for such applications is the possibility of creating the nanostructures without critical heating of the material, thus avoiding the creation of surface oxides or nitrides, since the formation of such surface materials may affect the industrial and surgical materials performance. After the understanding of the irradiation parameters in the formation of the nanostructures, three possible applications were proposed for the surface resulting from the laser processing: Colored surfaces, which can be used in personalization of parts; Dark surfaces, which can be used in parts marking; and a Micro Heater, which can be used to control temperatures inside microfluidic circuits.

Keywords: Femtosecond, Laser, Colored Surfaces.
\end{abstract}




\section{SUMÁRIO}

Página

1. INTRODUÇÃO

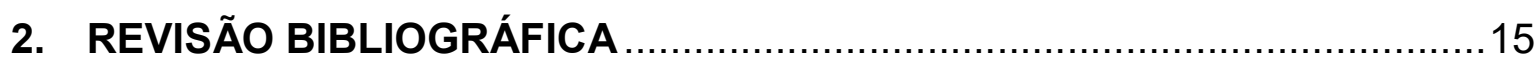

2.1. Interação do Laser de Femtossegundo com a Matéria ............................15

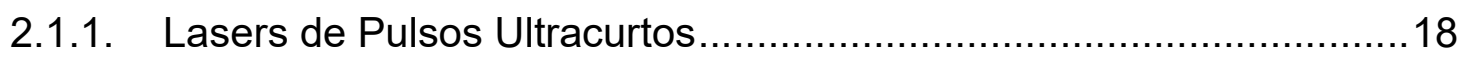

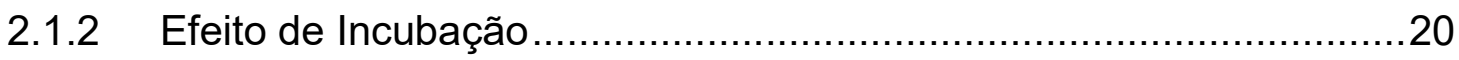

2.2. Estruturas Periódicas Superficiais Produzidas por Laser........................21

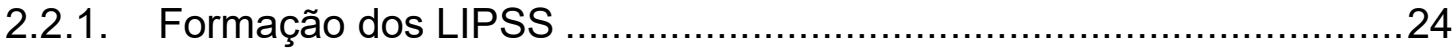

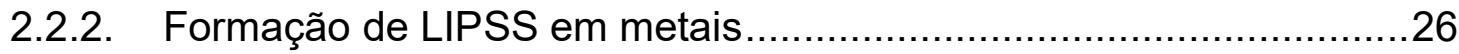

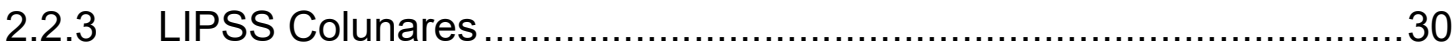

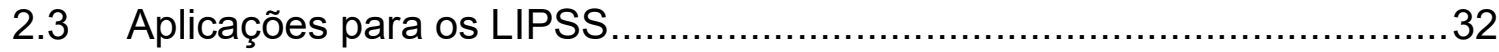

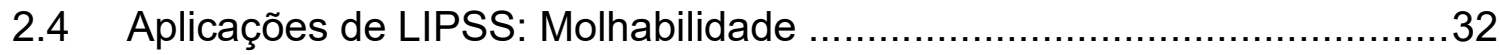

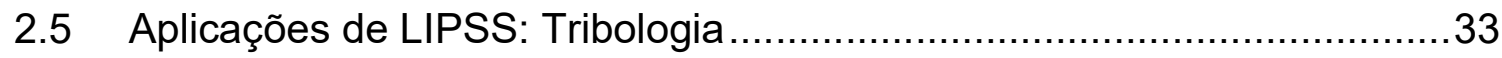

2.6 Aplicações de LIPSS: Propriedades Ópticas ..........................................34

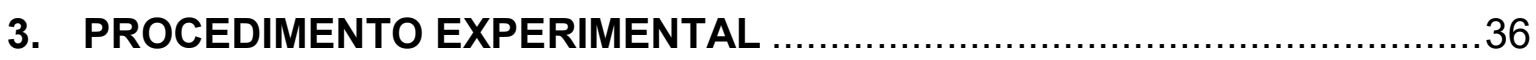

3.1. Influência da Energia na formação dos LIPSS ........................................38

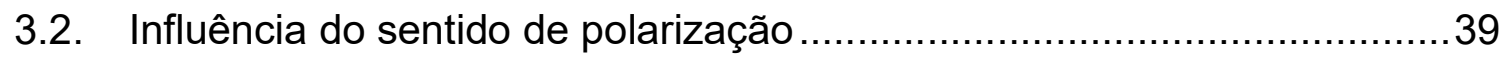

3.3. Influência dos gases de proteção …………….....................................40

3.4. Análise da relação entre a fluência e a morfologia dos LIPSS.................42

3.5. Investigação da técnica de escurecimento do metal................................43

3.6. Elaboração do Dispositivo de Aquecimento ...........................................46

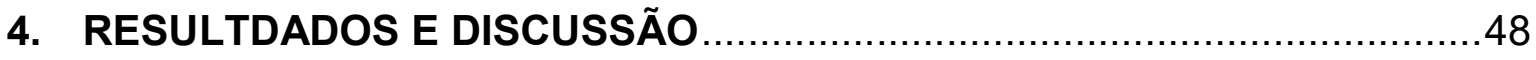

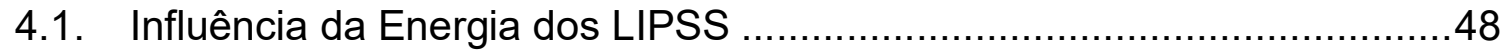

4.2. Influência do sentido de polarização na formação dos LIPSS .................52

4.3. Análise da influência de gases de proteção...........................................54

4.4. Análise da relação entre a fluência e a morfologia dos LIPSS.................57 
4.5. Investigação da técnica de escurecimento do metal...........................69

4.6. Avaliação de Dispositivo de Aquecimento ....................................... 75

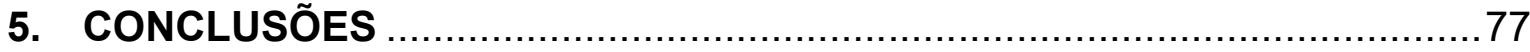

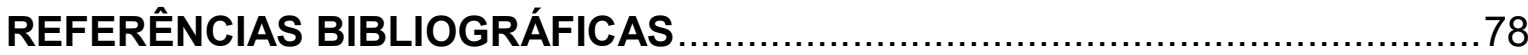




\section{LISTA DE FIGURAS}

FIGURA 1 - Esquema representativo desde a incidência do laser à ablação em laser de pulsos longos.

FIGURA 2 - Esquema representativo desde a incidência do laser à ablação em lasers de pulsos ultracurtos..

FIGURA 3 - Limiar de ablação (Fth) em função do número de pulsos sobrepostos (N) obtido na execução dos traços no aço inoxidável austenítico ASTM F 138 nas larguras temporais de 25 fs (MIRIM, 2016).

FIGURA 4 - LSFL obtidos em MEV no aço inoxidável austenítico ASTM F138. A seta indica a direção de polarização do feixe.

FIGURA 6 - Geometria da luz incidente em uma superfície rugosa (SIPE et al., 1983) .. 26

FIGURA 7- Etapas de formação dos LIPSS utilizando laser de femtossegundo.

FIGURA 8 - Desenvolvimento da superfície de Titânio após (a) 0 pulso, (b) 2 pulsos, (c) 10 pulsos e (d) 40 pulsos (VOROBYEV; GUO, 2013).

FIGURA 10 - (a) Cor em alumínio após irradiação com laser de femtossegundo para criação de LIPSS visualizado em diferentes ângulos. (b) LIPSS visualizados através de

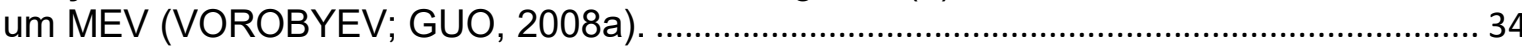

FIGURA 11 - Arranjo do sistema óptico de entrega do feixe .................................................. 37

FIGURA 12 - Localização e quantidade de passes das regiões irradiadas........................... 40

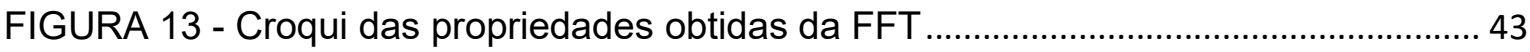

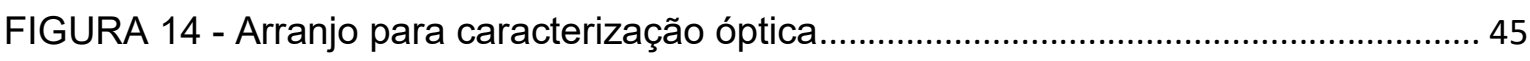

FIGURA 15 - Amostra irradiada para a criação do aquecedor ................................................ 46

FIGURA 16 - Aparato para medição da temperatura do dispositivo aquecedor. (A):

Amostra, (B): Termopar, (C): Lente focalizadora do feixe Laser ......................................... 47

FIGURA 17 - Detalhe do feixe laser atingindo o dispositivo (Seta) .................................. 47

FIGURA 18 - Fotografia das linhas executadas conforme Tabela 1 ....................................... 48

FIGURA 19 - Traço 6 com 3000x de aumento. As setas indicam as regiões onde foram formados LIPSS contínuos. Na região central do traço os LIPSS aparecem intermitentes e irregulares.

FIGURA 20 - Traços horizontais 13, 14 e 15 com ampliação de 3000x (a, c, e) e 8000x (b, $\mathrm{d}, \mathrm{f}$ ). As duplas setas indicam o sentido de polarização (perpendicular à direção do maior traço). 
FIGURA 25 - Análise EDS da (A) borda dos LIPSS e (B) região central dos LIPSS ......... 55

FIGURA 27 - Análise EDS dos LIPSS fabricados com atmosfera de Argônio.

FIGURA 28 - Micrografias das regiões irradiadas com taxa de sobreposição de 4 com

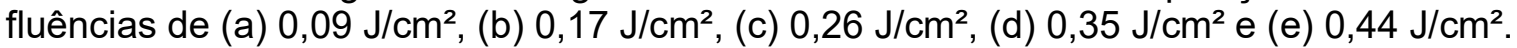

FIGURA 29 - Micrografias das regiões irradiadas com taxa de sobreposição de $16 \mathrm{com}$

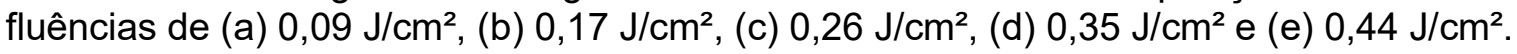

FIGURA 30 - Micrografias das regiões irradiadas com taxa de sobreposição de 64 com

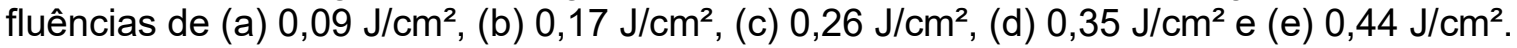

FIGURA 31 - Micrografias das regiões irradiadas com taxa de sobreposição de $256 \mathrm{com}$

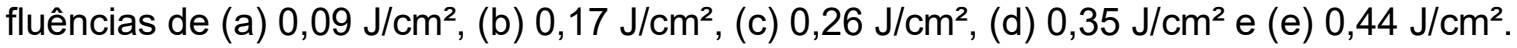

FIGURA 32 - FT das regiões irradiadas com taxa de sobreposição de 4 com fluências de (a) $0,09 \mathrm{~J} / \mathrm{cm}^{2}$, (b) $0,17 \mathrm{~J} / \mathrm{cm}^{2}$, (c) $0,26 \mathrm{~J} / \mathrm{cm}^{2}$, (d) $0,35 \mathrm{~J} / \mathrm{cm}^{2}$ e (e) $0,44 \mathrm{~J} / \mathrm{cm}^{2}$. 62

FIGURA 33 - - FFT das regiões irradiadas com taxa de sobreposição de 16 com fluências de (a) $0,09 \mathrm{~J} / \mathrm{cm}^{2}$, (b) $0,17 \mathrm{~J} / \mathrm{cm}^{2}$, (c) $0,26 \mathrm{~J} / \mathrm{cm}^{2}$, (d) $0,35 \mathrm{~J} / \mathrm{cm}^{2}$ e (e) $0,44 \mathrm{~J} / \mathrm{cm}^{2}$.

FIGURA 34 - FFT das regiões irradiadas com taxa de sobreposição de 64 com fluências

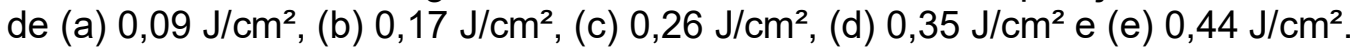
66

FIGURA 35 - FFT das regiões irradiadas com taxa de sobreposição de 256 com fluências de (a) $0,09 \mathrm{~J} / \mathrm{cm}^{2}$, (b) $0,17 \mathrm{~J} / \mathrm{cm}^{2}$, (c) $0,26 \mathrm{~J} / \mathrm{cm}^{2}$, (d) $0,35 \mathrm{~J} / \mathrm{cm}^{2}$ e (e) $0,44 \mathrm{~J} / \mathrm{cm}^{2}$. 68

FIGURA 36 - Retângulos coloridos sobre a superfície do aço inoxidável austenítico ASTM F138 produzidos pela formação de LIPSS. O parâmetro de processo variado foi a sobreposição $\mathrm{N}$ de pulsos, regiões 1 a 8 .

FIGURA 37 - Microscopia eletrônica das regiões irradiadas. Quanto menor a taxa de sobreposição de pulsos, mais linearmente os LIPSS são criados (regiões 1, 2, 3 e 4). Ao aumentar a taxa de sobreposição os LIPSS perdem a linearidade adquirindo características granulares (regiões 5, 6, 7 e 8).

FIGURA 38 - Amostras utilizadas para análise de reflexão / absorção. As amostras (A), (B) e (C) foram irradiadas utilizando os parâmetros das Regiões 1, 4 e 8, respectivamente, da Tabela 4.

FIGURA 39 - Espectro de reflexão nas regiões 1, 4 e 8. Nota-se que na região com maior taxa de sobreposição de pulsos a absorção de luz alcança $5 \%$.

FIGURA 40 - Comparação da emissão em função da taxa de sobreposição de pulsos... 75

FIGURA 41 - Gráfico de Temperatura x Tempo obtido durante a utilização do dispositivo de aquecimento. Ponto $(A)$ : Início da incidência do Laser He-Ne, ponto (B): Término da incidência do Laser He-Ne. 


\section{INTRODUÇÃO}

O processamento de materiais utilizando a interação da luz com a matéria cresceu consideravelmente desde a invenção do laser na década de 1960 (NOLTE, 2003). Dentre as aplicações em processamento de materiais pode-se destacar a microusinagem, soldagem e texturização de superfície.

A usinagem utilizando, ao invés de uma ferramenta de corte convencional, da energia disponível em um feixe laser para a remoção do material tem a vantagem de não haver desgastes ou quebras de ferramentas, possuir fácil automação e flexibilidade de seus parâmetros (NOLTE, 2003)

A soldagem a laser vem se destacando no meio de tradicionais processos de união como uma ótima alternativa quando a quantidade de energia necessária para a soldagem deve ser bem controlada (SILVA, 2013).

Por último há a texturização de superfícies, onde através de micro ou nano canais na superfície do material busca-se alguma alteração em suas propriedades ópticas e tribológicas (BONSE et al., 2015).

Grande parte dessas aplicações utiliza lasers pulsados, onde a energia total do laser é dividida em pequenos "pacotes" (pulsos) que atingem a superfície do material em uma determinada frequência. Esses pulsos, muitas vezes, podem causar certos efeitos térmicos e mecânicos indesejados (alta taxa de fusão, formação de rebarbas e trincas, mudanças microestruturais, etc.) (NOLTE et al., 1997). Esses efeitos estimularam fortemente pesquisas com o intuito de diminuir o dano que é causado, particularmente em texturizações precisas, pela difusão térmica natural de processos que utilizam lasers. 
Como resultado dessas pesquisas surge a tecnologia de diminuição da largura temporal de cada pulso, o que normalmente variava na faixa de alguns microssegundos $\left(10^{-3} \mathrm{~s}\right)$ ou nanossegundos $\left(10^{-9} \mathrm{~s}\right)$, passa a ser utilizado na escala de femtossegundo $\left(10^{-15} \mathrm{~s}\right)$. Surgem então os chamados lasers de pulso ultracurtos que se mostraram uma ótima ferramenta para micro fabricação e texturização de metais, semicondutores, dielétricos e até mesmo polímeros (SAMAD et al., 2012).

Quando aplicados em metais e dielétricos com baixa fluência, os lasers de pulsos ultracurtos podem induzir a formação de estruturas periódicas com períodos próximos ao comprimento de onda do laser utilizado, chamadas de Estruturas Periódicas superficiais Induzidas por Laser (Laser Induced Periodic Surface Structures, ou simplesmente LIPSS). Essas estruturas podem alterar as propriedades ópticas (agindo como uma grade de difração) (VOROBYEV; GUO, 2008a), tribológicas (diminuindo a superfície de contato) (BONSE et al., 2015) e a molhabilidade (controlando a rugosidade) do material (CUNHA et al., 2013).

A produção de cores nas superfícies dos materiais é normalmente realizada através de técnicas de pintura, revestimentos emulsivos, ou oxidação eletrolítica.

Existem dois principais métodos de mudança de cor por laser. $\mathrm{O}$ primeiro utiliza o laser como uma fonte de calor que provoca oxidação da superfície metálica, esse óxido pode assumir um comportamento de filme fino, ou seja, a luz incidente interfere tanto com a camada de óxido quanto com o substrato metálico causando o efeito de mudança de cor, ou ainda, o próprio óxido pode se formar na coloração desejada. Na segunda técnica, a cor é obtida na superfície dos metais através dos LIPSS, que apesar de serem conhecidos 
desde a década de 1960, foi com o advento do laser de femtossegundo que sua utilização prática em materiais começou a ser explorada. As primeiras constatações desses efeitos foram obtidas em Alumínio, cujas cores do metal foram alteradas para tonalidades desde preto até dourado (VOROBYEV; GUO, 2008a).

Outra demanda para os processos a laser é a marcação de materiais com o objetivo de identificação e rastreabilidade. Processos mecânicos utilizados para esses fins, apesar de mais baratos e demandarem menor mão de obra técnica, deixam um baixo contraste e afetam demasiadamente a superfície dos materiais (QI; WANG; ZHU, 2003). Nesse cenário, os lasers de pulsos longos se encaixaram muito bem com a precisão dimensional, formação de marcações com alto contraste e grande velocidade de processo. Como desvantagem, há a alta incidência de calor no material sendo processado, que pode ocasionar mudanças microestruturais e formação de óxidos indesejados, principalmente em componentes que precisam ser livres de contaminação, como os implantes (CUNHA, 2015). No entanto, com a utilização de lasers com pulsos ultracurtos (na faixa de femtossegundos, por exemplo) grande parte dos efeitos deletérios acima citados são eliminados (OLIVEIRA; CUNHA; VILAR, 2010). Por meio do controle da formação dos LIPSS, é possível a criação de estruturas absorvedoras de luz que proporcionam um alto grau de contraste visual com a vantagem de que o aquecimento provocado por esse tipo de laser é praticamente nulo, não favorecendo à formação de óxidos indesejáveis (OU; HUANG; ZHAO, 2016). A supressão de efeitos térmicos com a não formação de óxidos torna as aplicações de laser de femtossegundo em materiais (principalmente metais) importante para 
que se consiga alta confiabilidade em componentes de segurança e implantes cirúrgicos.

O objetivo deste trabalho é estudar os efeitos ópticos dos LIPSS produzidos por laser de pulsos ultracurtos na superfície de Titânio Grau 2 e assim avaliar a influência dos parâmetros de processamento, influência da polarização do laser e utilização de gases de proteção. É também objetivo promover o escurecimento do aço inoxidável austenítico ASTM F 138 para aplicação em um micro aquecedor utilizado em sistemas microfluídicos. 


\section{REVISÃO BIBLIOGRÁFICA}

\subsection{Interação do Laser de Femtossegundo com a Matéria}

Segundo (NOLTE et al., 1997) os lasers com largura temporal de pulso da ordem de femtossegundos depositam energia em uma velocidade muito alta, $\mathrm{e}$ por isso as interações da luz com a matéria que ocorrem com a utilização desse tipo de laser são diferentes se comparada à interação proveniente de lasers com pulsos longos, ou seja, da ordem de nanossegundos e picossegundos, como pode ser visto na FIG 1.

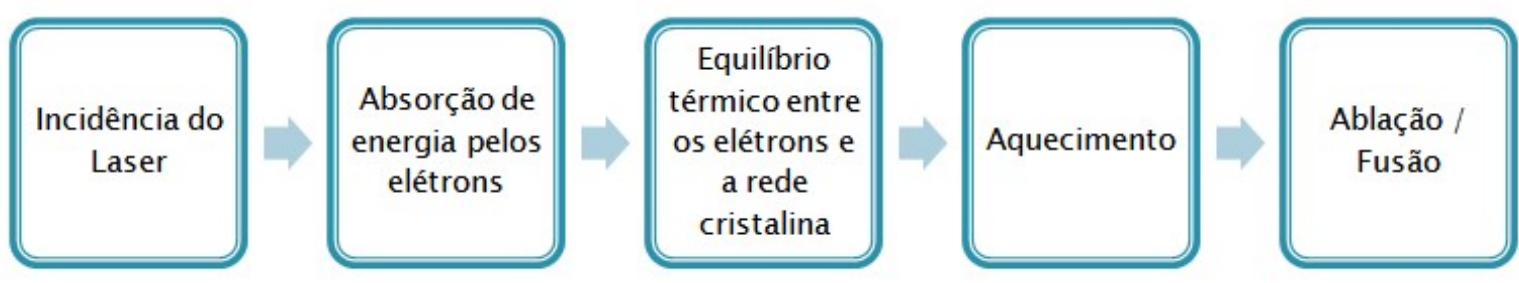

FIGURA 1 - Esquema representativo desde a incidência do laser à ablação em laser de pulsos longos.

Enquanto a transferência de energia com lasers de pulsos longos é um processo que ocorre em equilíbrio térmico, a irradiação de um material com pulsos ultracurtos causa um forte desequilíbrio entre as temperaturas dos elétrons e da rede. Em pulsos ultracurtos, nos metais, a radiação laser é absorvida, no início, por elétrons livres dentro de uma camada muito superficial. A excitação destes elétrons leva a uma ionização da superfície com consequente ejeção de material por efeito Coulomb. Antes da ionização, contudo, os elétrons excitados adquirem temperaturas extremamente altas, assim, antes da transferência do calor para a rede, existe um desequilíbrio de temperatura muito alto, onde os 
elétrons excitados apresentam temperaturas de milhares de graus e a rede permanece à temperatura ambiente (FIG 2).

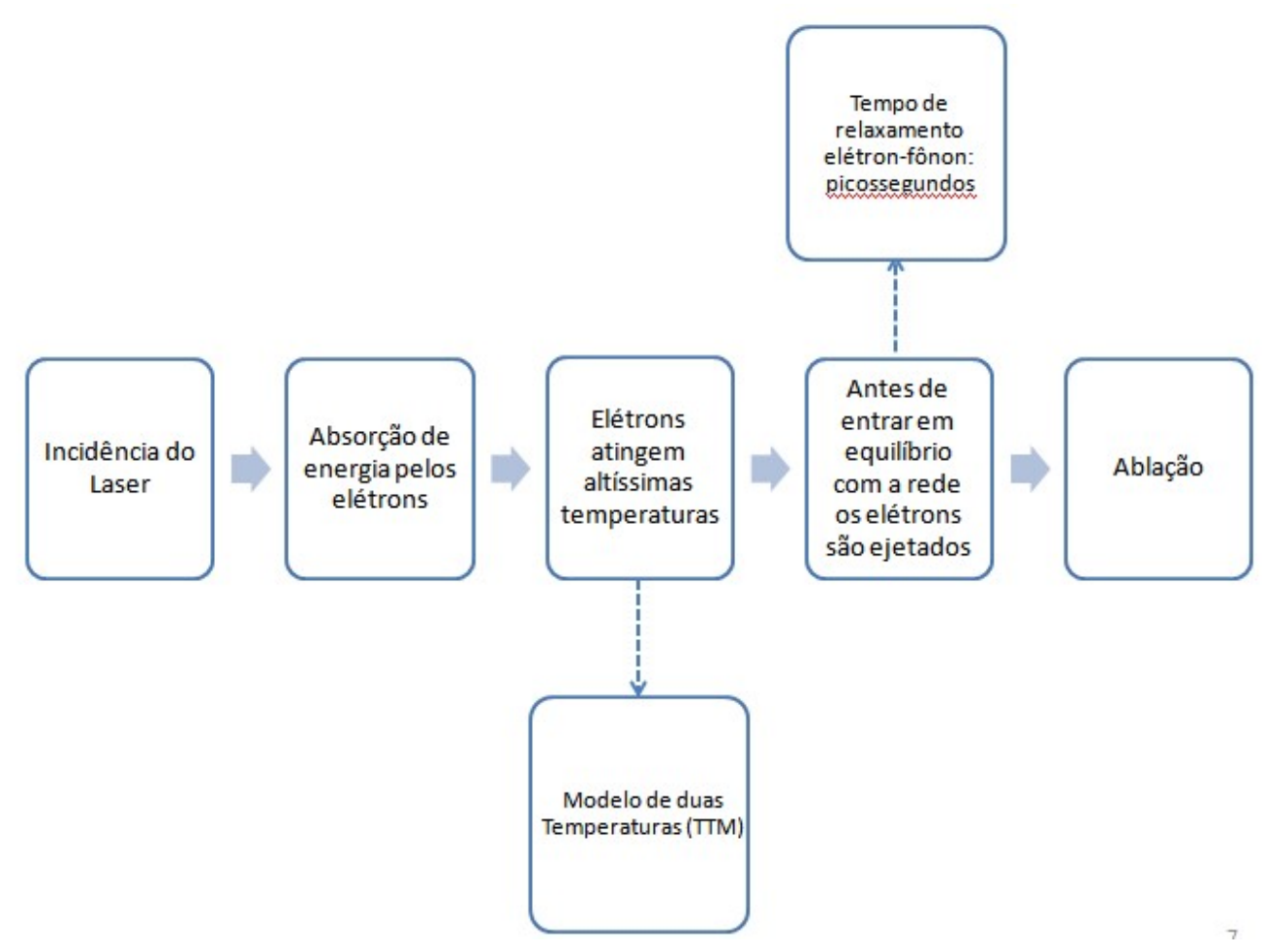

FIGURA 2 - Esquema representativo desde a incidência do laser à ablação em lasers de pulsos ultracurtos.

Esta situação, chamada de modelo de duas temperaturas (TTM, em inglês: Two Temperature Model) (NOLTE, 2003), permanece durante um tempo inferior ao tempo necessário à transferência de calor elétron-íon, que é geralmente da ordem de picossegundos. Como o pulso laser incidente tem uma duração muito inferior a este tempo, todo o processo que leva à ejeção de elétrons ocorre antes que o calor seja transferido para a rede. Assim, o material é ejetado e o processo de usinagem ocorre com transferência mínima de calor para o metal.

Em dielétricos e semicondutores, onde a existência de elétrons livres é muito pequena, uma etapa anterior ainda ocorre. Nestes casos, a alta intensidade do feixe focalizado é suficiente para absorção multifotônica dos 
elétrons ligados, os quais são levados em grande quantidade à banda de condução, criando assim (e também por um processo subseqüente de ionização por avalanche) uma situação localizada semelhante à de um metal, permitindo que o processo descrito acima comece a ocorrer (ZAYATS; SMOLYANINOV, 2003).

No caso dos dielétricos, o transporte do calor do elétron para o meio é fortemente suprimido. Em metais o transporte de calor dos elétrons é permitido, porque os elétrons aquecidos que se movem no meio podem ser substituído por elétrons frios da região adjacente.

Em qualquer caso, a absorção da radiação é seguida por um rápido relaxamento de energia dentro do subsistema eletrônico, seguido de transferência de energia por difusão térmica para a rede devido ao acoplamento do par elétronfônon. A evolução espacial e temporal das temperaturas dos elétrons e da rede ( $T_{e}$ e $T_{i}$, respectivamente) em uma fina camada de superfície com subsequente expansão do material é descrita pelas Equações 1 e 2.

$$
\begin{gathered}
C_{e} \frac{\partial T_{e}}{\partial t}=-\frac{\partial Q(x)}{\partial x}-\gamma\left(T_{e}-T_{i}\right)+S \\
C_{i} \frac{\partial T_{i}}{\partial t}=\gamma\left(T_{e}-T_{i}\right)
\end{gathered}
$$

Onde $C_{e}$ e $C_{i}$ são as capacidades caloríficas do elétron e da rede, respectivamente. A direção perpendicular para a superfície designada é x. O parâmetro $\gamma$ caracteriza a interação elétron-rede, $Q(x)=-k_{e}\left(T_{e}\right) \partial T_{e} / \partial x$, é o fluxo de calor, e $S=I(t) A \alpha \exp (-\alpha x)$ é o termo de fonte da energia laser. $\mathrm{k}_{\mathrm{e}}$ é a 
condutividade térmica do elétron, A é a absortividade (índice que caracteriza a capacidade de absorção de radiação) da superfície, a é o coeficiente de absorção do material, e I (t) é a intensidade do pulso laser.

Se a duração do pulso laser é maior que o tempo de aquecimento da rede $\left(\tau_{\mathrm{i}}=\mathrm{C}_{\mathrm{i}} / \gamma\right.$, que é da ordem de $\left.\tau_{\mathrm{i}} \approx 0,01-1 \mathrm{~ns}\right)$ o equilíbrio térmico, entre $\mathrm{o}$ subsistema de elétrons e o meio material, se dá durante o pulso laser. Neste caso, os elétrons e a rede podem ser caracterizados por uma temperatura comum $\mathrm{T}=\mathrm{T}_{\mathrm{e}}=\mathrm{T}_{\mathrm{i}}$ e a Equação (1 e a Equação (2 ficam reduzidas à bem conhecida equação de difusão de calor unidimensional que descreve o aquecimento com laser de pulsos longos.

\subsubsection{Lasers de Pulsos Ultracurtos}

Para pulsos laser de femtossegundo, a condução de calor e a transferência de energia para a rede durante o pulso podem ser negligenciadas em uma primeira aproximação. Neste caso simplificado, a taxa de ablação e o limiar de ablação só dependem da profundidade de penetração óptica $\delta$ (CHICBKOV, MOMMA, NOLTE, YON ALVENSLEBEN, 1996). Porém, a interação de troca de energia entre elétrons e o meio e a difusão de calor têm consequências importantes, até mesmo para a ablação com pulsos ultracurtos.

Quando a capacidade de calor, a condutividade térmica e a difusão térmica do elétron são tratadas como constantes, pode-se encontrar a distribuição de temperatura de equilíbrio para os elétrons e para a rede após relaxamento térmico através da relação demonstrada na Equação (NOLTE et al., 1997): 


$$
T_{i} \approx \frac{F_{a}}{C_{i}}\left(\frac{1}{\ell^{2}-\delta^{2}}\right)\left[\ell \exp \left(\frac{-x}{\ell}\right)-\partial \exp \left(\frac{-x}{\partial}\right)\right]
$$

Dois casos podem ser distinguidos: a profundidade ótica de penetração é superior ao comprimento de difusão térmica, $\delta>I$, e vice-versa, $1>\delta$. Para estes casos, as Equações 4 e 5 para as temperaturas de equilíbrio podem ser obtidas:

$$
\begin{aligned}
& T_{i} \approx{\frac{F_{a}}{C_{i} \delta}} \exp \left(\frac{-x}{\delta}\right)_{(\delta>\ell)}
\end{aligned}
$$

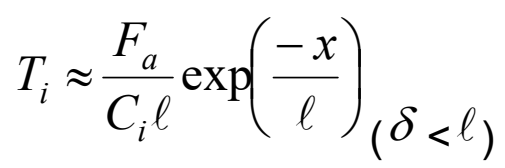

Neste modelo simplificado de ablação, algo significativo acontece quando a energia da rede $C_{i} / T_{i}$ (por unidade de volume) excede certo valor de limiar. Este valor de limiar pode ser calculado, em uma primeira aproximação, como o calor de evaporação $\rho \Omega$, onde $\rho$ é a densidade e $\Omega$ é o calor específico de evaporação por unidade de massa.

A condição para ablação significativa, $C_{i} T_{i} \geq \rho \Omega$, pode ser escrita como:

$$
\begin{aligned}
& F_{a} \geq F_{t h}^{\delta} \exp \left(\frac{x}{\delta}\right), F_{t h}^{\delta} \sim \rho \Omega \delta(\delta>\ell) \\
& F_{a} \geq F_{t h}^{\ell} \exp \left(\frac{x}{\ell}\right), F_{t h}^{\delta} \sim \rho \Omega \ell(\delta<\ell)
\end{aligned}
$$

Onde $F_{\text {th }}^{\delta}$ (fluência de profundidade óptica) e $F_{\text {th }}^{\ell}$ (fluência de difusão térmica), são os limiares de ablação para as correspondentes fluências laser absorvidas. As profundidades da ablação podem ser derivadas da Equação 4 e 5, obtendo-se: 


$$
\begin{aligned}
& L \approx \delta \ln \left(\frac{F_{a}}{F_{t h}^{\delta}}\right)_{(\delta>\ell)} \\
& L \approx \ell \ln \left(\frac{F_{a}}{F_{t h}^{\ell}}\right)_{(\delta<\ell)}
\end{aligned}
$$

Isto significa que são obtidas duas relações em escala logarítmicas no modelo de duas temperaturas - TTM. Com relação à equação (8) e à equação (9), estas duas relações logarítmicas podem ser atribuídas à profundidade de penetração óptica e a condução de calor eletrônico, respectivamente.

\subsubsection{Efeito de Incubação}

O limiar de ablação de um dielétrico depende da energia de ligação dos elétrons de valência. Essa energia, por sua vez, pode ser alterada pela presença de defeitos, impurezas, dopantes, etc. (SAMAD et al., 2012). Esses defeitos podem tanto criar níveis eletrônicos intermediários quanto modificar a densidade eletrônica local. Como resultado, elétrons livres são criados mais facilmente do que em um material ideal, portanto a energia necessária para que ocorra a ablação do material se torna menor.

Esses defeitos nem sempre são intrínsecos ao material e podem ser criados pelo próprio processo de irradiação com laser. Por exemplo, quando o material é irradiado por vários pulsos sobrepostos, tais mudanças são induzidas na proporção que os pulsos atingem o material, em energias abaixo do limiar natural de ablação $\left(F_{\text {th }}\right)$, e isso faz com que o $F_{\text {th }}$ dessas regiões diminua pelo acúmulo de defeitos na região irradiada. Essa propriedade é chamada de Efeito de Incubação (SAMAD et al., 2012). 
Mirim (2016) fez uma série de medições do limiar de ablação de um aço inoxidável austenítico ASTM F138 similar ao que foi utilizado nesse trabalho fazendo uso da técnica conhecida como Diagonal-Scan (D-Scan). Na FIG. 3 é possível ver a dependência da taxa de sobreposição de pulsos no limiar de ablação, comprovando o efeito de incubação.

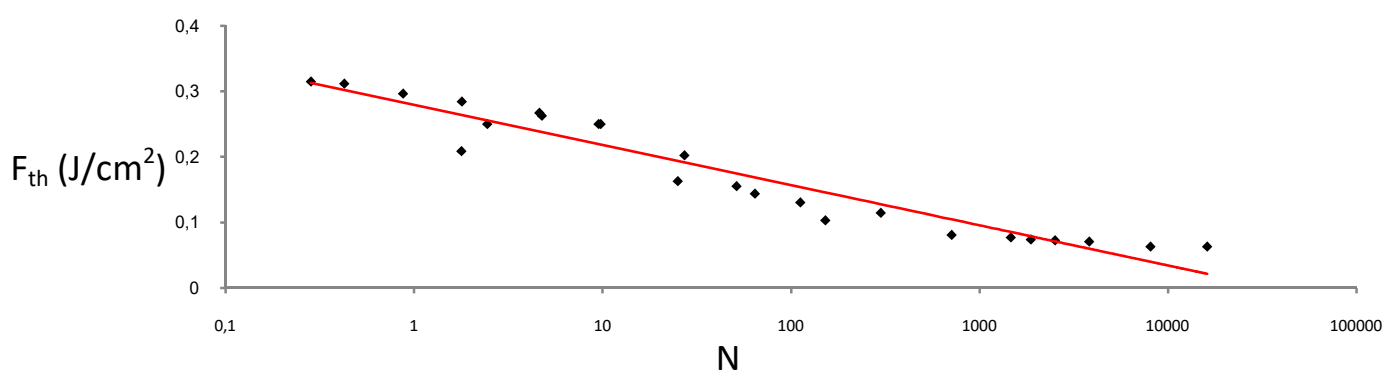

FIGURA 3 - Limiar de ablação (Fth) em função do número de pulsos sobrepostos (N) obtido na execução dos traços no aço inoxidável austenítico ASTM F 138 nas larguras temporais de 25 fs (MIRIM, 2016).

\subsection{Estruturas Periódicas Superficiais Produzidas por Laser}

Há pelo menos quarenta anos (BIRNBAUM, 1965), os danos periódicos e regulares causados por laser em sólidos vêm sendo estudados, tanto na busca por aplicações, como na descoberta de uma teoria física por trás do fenômeno. Esse interesse aumentou na última década com a utilização de lasers de pulsos ultracurtos, que trouxeram para a escala micro/nanométrica tais efeitos na superfície dos materiais que interagem com esse tipo de laser (HUANG et al., 2009).

As Estruturas Periódicas Superficiais Produzidas por Laser (do inglês Laser Induced Periodic Surface Structures, ou simplesmente LIPSS) são danos superficiais nanométricos causados na superfície dos materiais atingidos por pulsos de lasers em regimes de fluência próximo ao limiar de ablação do dado material. Podem ser paralelos ou perpendiculares à direção de polarização do 
feixe e possuem períodos aproximadamente iguais ao comprimento de onda do laser. Tais estruturas já foram reportadas em metais (YAO et al., 2012) e dielétricos (BONSE et al, 2009).

A periodicidade e a orientação dos LIPSS variam de acordo com os parâmetros do processo (comprimento de onda do feixe e energia do feixe, ângulo de incidência, polarização do laser etaxa de sobreposição de pulsos) (EICHSTDT et al, 2013; OKAMURO et al, 2010), dos materiais irradiados (rugosidade e limiar de ablação) (SAVOLAINEN et al, 2011; UPADHYAY et al., 2008; YOUNG et al., 1983) e da atmosfera em que o processo de irradiação é realizado. Os LIPSS podem ser classificados em dois tipos: Baixa freqüência espacial (Low Spatial Frequency LIPSS - LSFL) e Alta freqüência espacial (High Spatial Frequency LIPSS - HSFS). Os LIPSS do tipo LSFL (FIG. 4) foram os primeiros a serem observados e possuem como características principais a periodicidade aproximadamente igual ao comprimento de onda $\lambda$ do feixe. São produzidos com fluências próximas ou levemente superiores ao limiar de ablação do material. Os HSFL (FIG. 5

) foram encontrados recentemente e, até o momento, apenas em semicondutores. O período dos HSFL é da ordem de $1 / 6$ à 1/4 do comprimento de onda do laser e possuem orientação perpendicular à polarização do feixe laser. 


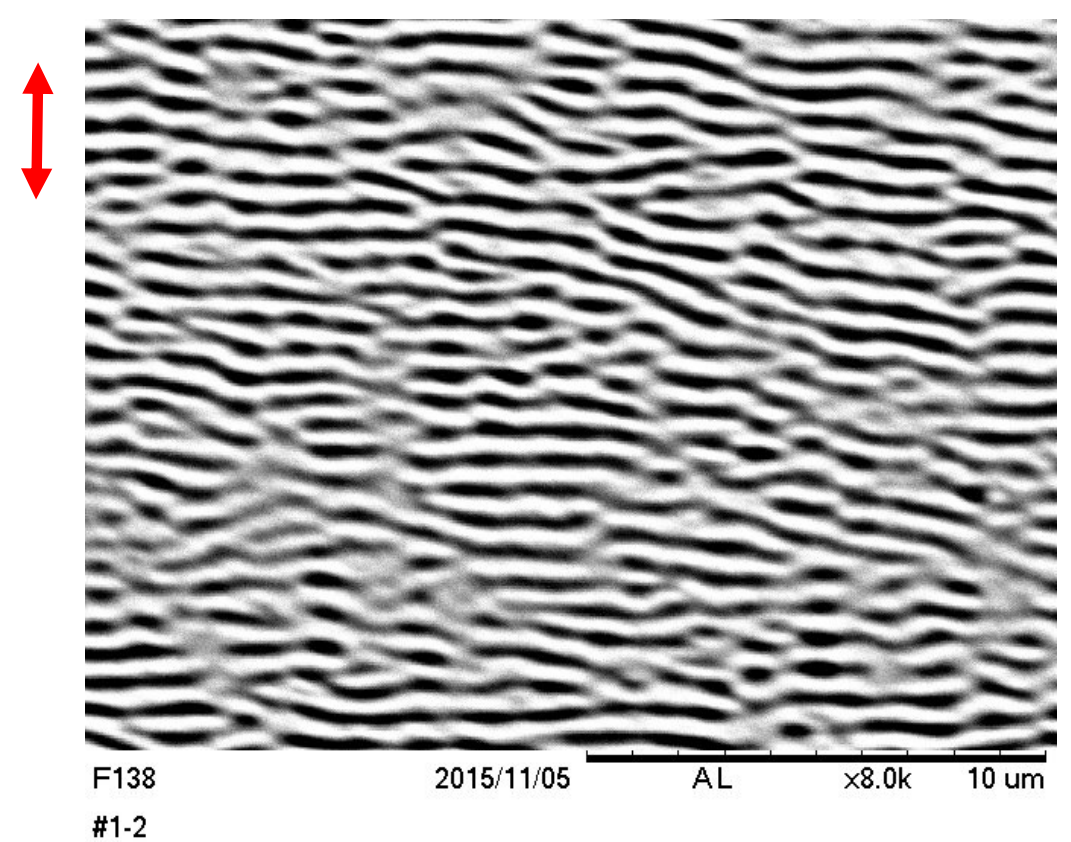

FIGURA 4 - LSFL obtidos em MEV no aço inoxidável austenítico ASTM F138. A seta indica a direção de polarização do feixe.

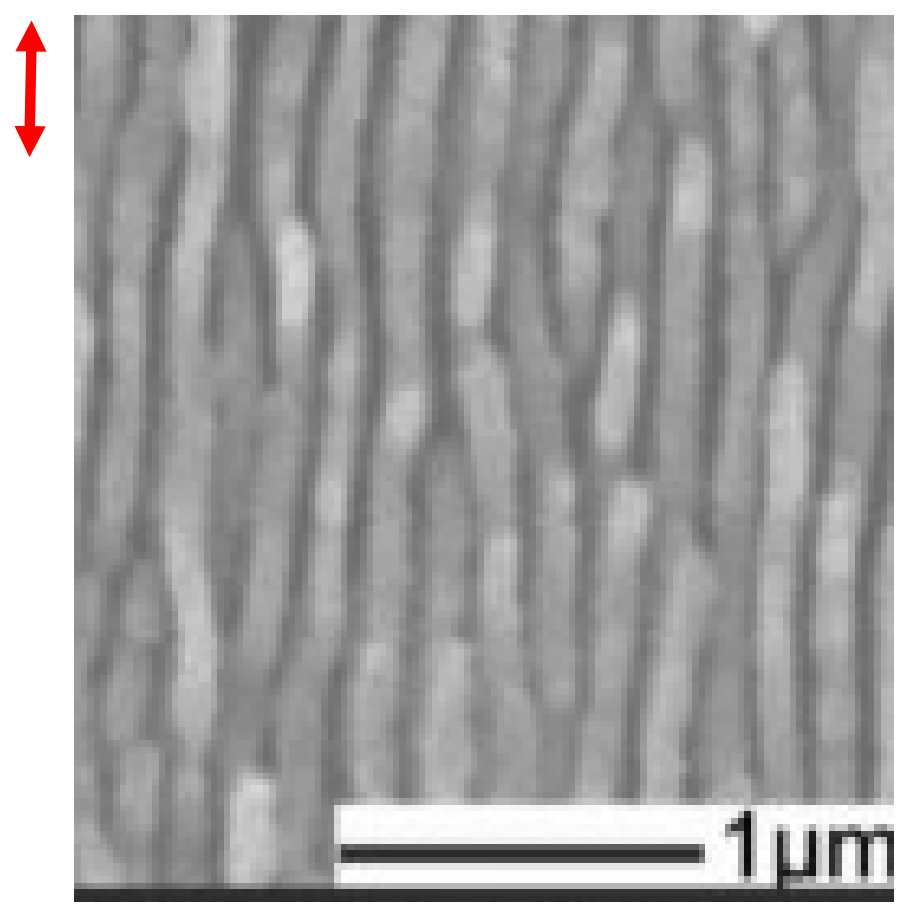

FIGURA 5 - HSFL obtidos em MEV no aço inoxidável ASTM F138. A seta indica a direção de polarização do feixe 


\subsubsection{Formação dos LIPSS}

A primeira observação de LIPSS foi feita por Birnbaum em 1965 que encontrou padrões regulares em superfícies polidas de semicondutores após irradiação com laser contínuo (cw) de ruby. Birnbaum atribuiu a formação desses padrões a efeitos de difração que poderiam ocorrer na lente (BIRNBAUM, 1965).

Posteriormente, em 1973, Emmony et al. encontraram linhas paralelas com periodicidade de 10,6 m, após irradiar Germânio com laser de $\mathrm{CO}_{2} \mathrm{TEA}$, que possuía os mesmos $10,6 \mu \mathrm{m}$ de comprimento de onda. Os autores atribuíram tal efeito a um mecanismo de interferência das ondas laser com um espalhamento que ocorre na lente em virtude de defeitos ou partículas que ali estejam. Essas partículas funcionariam como centros de espalhamentos levando à ocorrência da interferência. Os autores demonstraram ainda que os padrões formados na superfície do material seguiam a Equação 10 (EMMONY, 1973):

$$
d=\frac{\lambda}{(1 \pm \sin \theta)}
$$

Onde o sinal representa a direção de propagação da onda espalhada.

Keilmannet e Bai (1982) introduziram uma nova explicação à formação dos LIPSS em experimentos realizados em quartzo com laser de $\mathrm{CO}_{2}$. Segundo os autores, tais ondulações representam um carimbo holográfico da propagação das ondas eletromagnéticas de superfície, tais ondulações são chamadas de plasmons polaritrons superficiais (PPS). Plasmons Polaritrons Superficiais são ondas eletromagnéticas que se propagam na interface metal-dielétrico, ou metalar. Os experimentos dos autores mostraram que os LIPSS não são formados com polarização circular e que a rugosidade superficial da amostra interfere fortemente 
na formação das estruturas, pois atuam como obstáculos na propagação dos polaritrons de superfície.

Posteriormente, Sipe et al. (1983) elaboraram uma nova teoria que considera os efeitos da rugosidade superficial no campo eletromagnético. A teoria, conhecida como "Teoria do fator de eficácia" ou "Teoria n”, considera uma absorção heterogênea de energia das ondas eletromagnéticas linearmente polarizadas pelo plano e, portanto, os LIPSS se formam nas regiões em que essa absorção de energia é maior. A teoria de Sipe é baseada na interferência do feixe laser incidente com uma espécie de onda eletromagnética refletida na superfície do material. Tal teoria prediz que os vetores de onda $k$ paralelos à superfície do

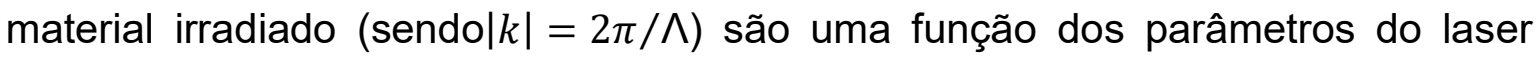
[ângulo de incidência $\theta$, direção de polarização, vetor de onda da radiação incidente $k_{L}$ (com $\left.\left|k_{L}\right|=2 \pi / \Lambda\right)$ e propriedades do material (constante dielétrica e rugosidade superficial), conforme representação na FIG. 6 . Nesse estudo, Sipe concluiu ainda que o uso da Transformada de Fourier da microscopia obtida da região irradiada fornece informações sobre as estruturas formadas que não eram conhecidas anteriormente. A técnica da utilização da transformada de Fourier para caracterização dos LIPSS foi utilizada no presente trabalho. 


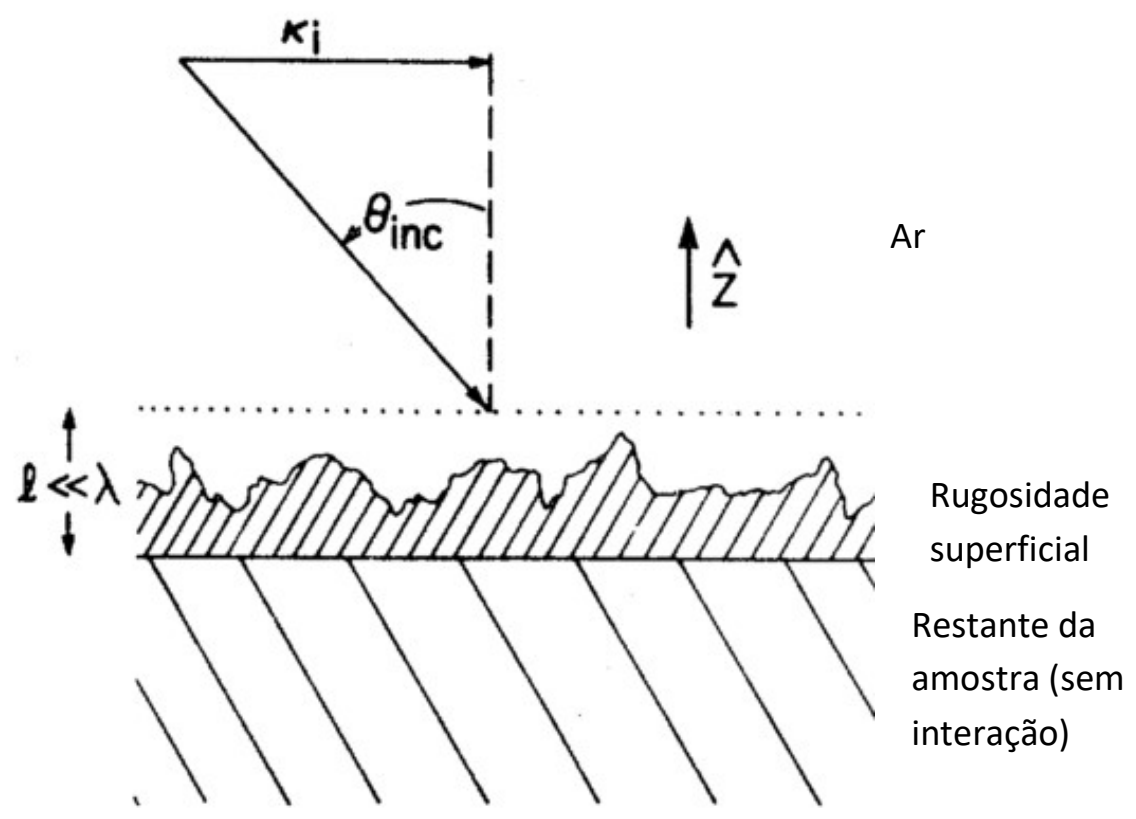

FIGURA 6 - Geometria da luz incidente em uma superfície rugosa (SIPE et al., 1983).

\subsubsection{Formação de LIPSS em metais}

Com o advento do laser de femtossegundos, a formação dos LIPSS em semicondutores e metais vem sendo estudada profundamente. Os LIPSS formados por lasers de femtossegundos são comumente produzidos por múltiplos pulsos em um regime de fluência levemente superior ao limiar de ablação (BOROWIEC; HAUGEN, 2003; REIF et al., 2015).

Há duas grandes diferenças entre os LIPSS estudados por Sipe e os LIPSS formados por lasers de femtossegundo. A primeira é a absorção do feixe de luz pelo material, que ocorre em condições de desequilíbrio térmico entre os elétrons e a rede, conforme explicado no item 2.1.1 deste trabalho. A segunda diferença é que as estruturas periódicas são impressas no material após o 
término do pulso em femtossegundo, conforme etapas demonstradas na FIG. 7 (VOROBYEV; GUO, 2013).

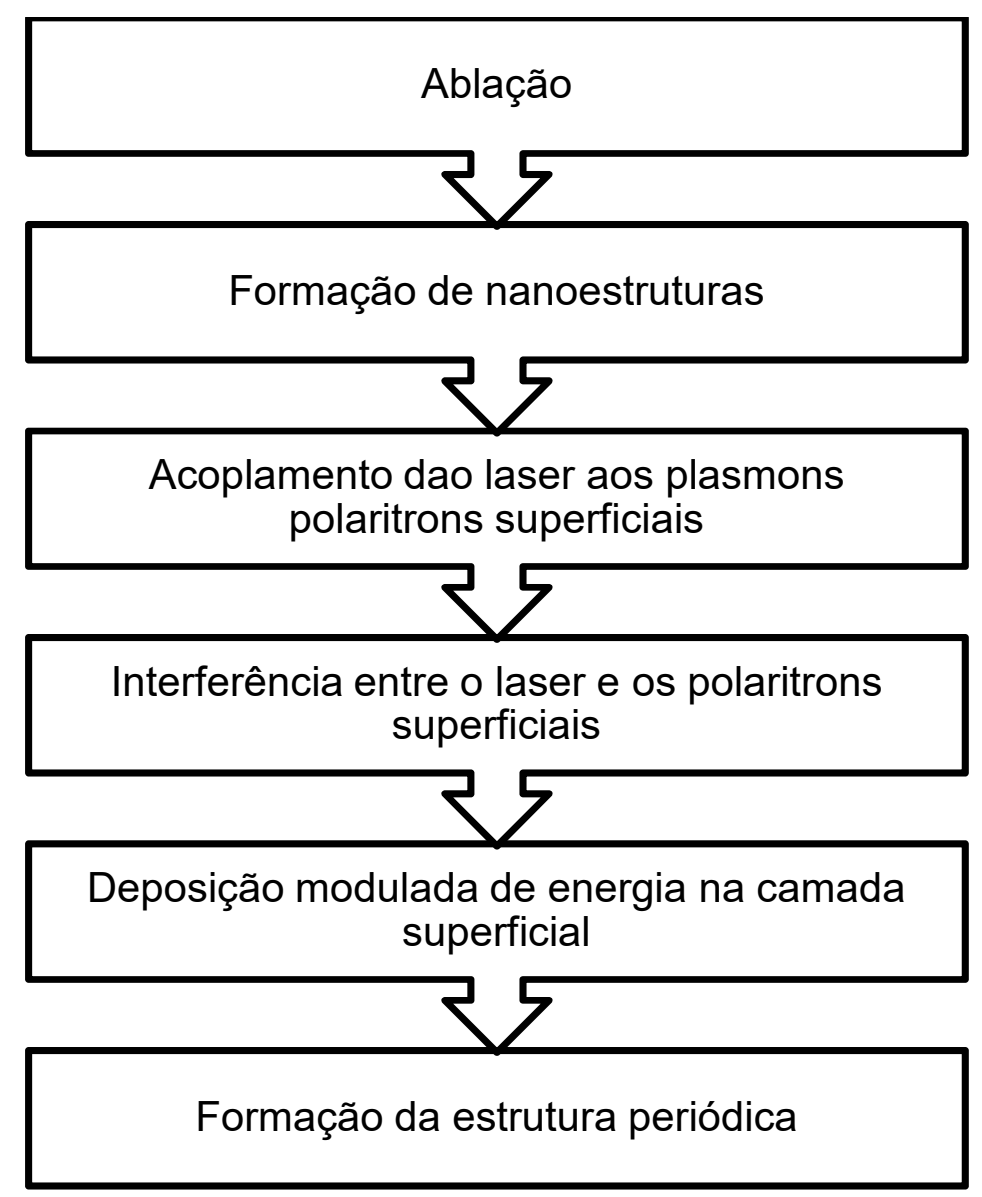

FIGURA 7- Etapas de formação dos LIPSS utilizando laser de femtossegundo.

Vorobyev e Guo (2013) registraram passo-a-passo a formação de LIPSS em Titânio através do controle do número de pulsos. Com as imagens obtidas pelos autores (FIG. 8) é possível concluir que a formação de LIPSS não é um fenômeno que ocorre instantaneamente, e sim um conjunto de processos que possuem seu produto final as estruturas periódicas. 

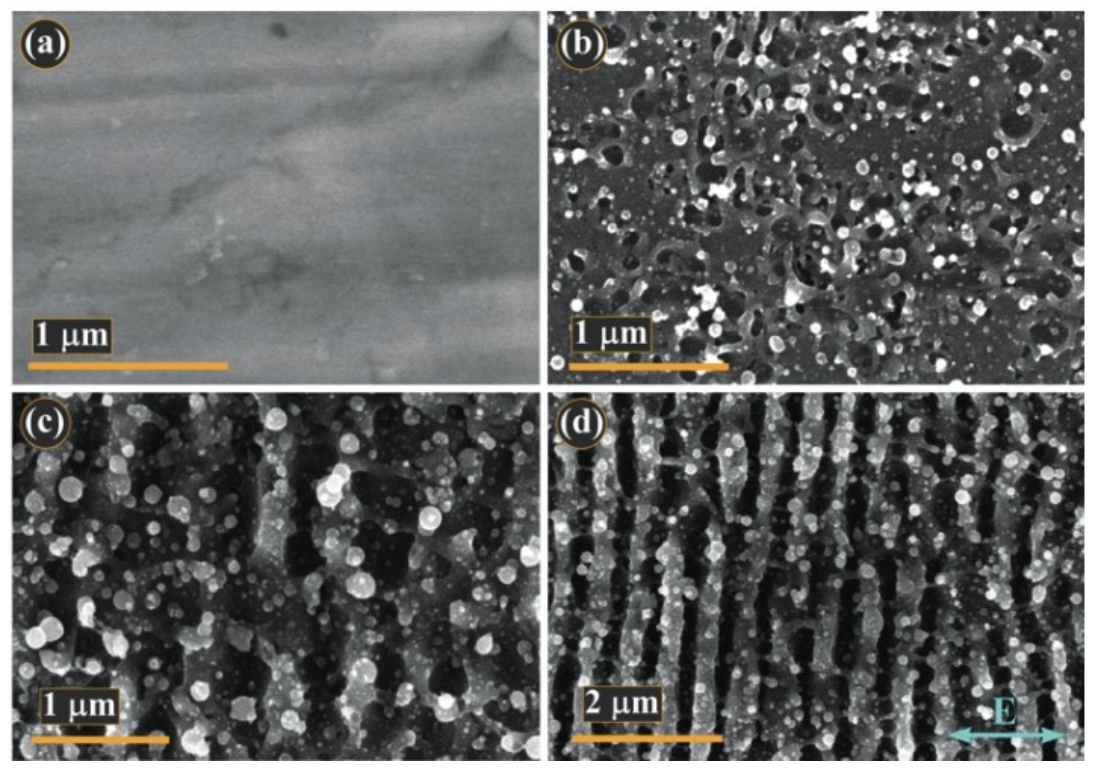

FIGURA 8 - Desenvolvimento da superfície de Titânio após (a) 0 pulso, (b) 2 pulsos, (c) 10 pulsos e (d) 40 pulsos (VOROBYEV; GUO, 2013).

Conforme pode ser visto nas microscopias, os primeiros pulsos criam uma nanoestrutura aleatória. A rugosidade superficial em uma superfície metálica pode gerar espaços livres para acoplar os plasmons polaritrons superficiais (PPS) por difração. Entretanto, os pulsos lasers seguintes interferem com os PPS's através dessas nanoestruturas criadas com os primeiros pulsos. Essa interferência entre o feixe laser polarizado e os PPS's causam uma modulação espacial periódica de energia na superfície da amostra (VOROBYEV; MAKIN; GUO, 2007) o que acarreta em um aquecimento modulado da superfície do material, esse aquecimento conduz também à uma pequena fusão, conforme demonstrado em (CANGUEIRO; VILAR, 2016). Com esses processos térmicos formam-se então as estruturas periódicas.

Os LIPSS formados por pulsos curto possuem, assim como os gerados com pulsos longos, sua direção perpendicular à polarização do laser. Porém, há duas diferenças entre os LIPSS formados por pulsos longos em comparação aos 
formados por pulsos ultracurtos. A primeira é que os LIPSS formados por pulsos ultracurtos são cobertos por nanoestruturas, diferentemente dos LIPSS lisos produzidos por pulsos longos. A segunda diferença está no período nas estruturas, sendo que nas estruturas formadas por pulsos ultracurtos o período é cerca de $25 \%$ menor em comparação às estruturas produzidas com pulsos longos (que possuem período aproximadamente igual ao comprimento de onda do laser). Essa diminuição no período pode ser explicada por uma mudança no índice de refração efetivo da interface metal-ar quando as estruturas estão sendo formadas e isso afeta a propagação dos PPS's (VOROBYEV; et al, 2007).

Em muitas aplicações, é importante o controle do período dos LIPSS. A equação 8 mostra que esse período pode ser alterado mudando o comprimento de onda do laser, o ângulo de incidência do feixe ou a parte real do índice de refração efetivo. A relação entre o comprimento de onda e o período dos LIPSS foi demonstrado em (VOROBYEV; GUO, 2008b) onde os autores fabricaram estruturas periódicas em tungstênio utilizando laser com comprimento de onda de $400 \mathrm{~nm}$ e $800 \mathrm{~nm}$ sendo produzidas estruturas com períodos de $289 \mathrm{~nm}$ e $542 \mathrm{~nm}$ respectivamente.

O efeito do ângulo de incidência no período dos LIPSS foi averiguado em (HWANG; GUO, 2010) onde os autores produziram LIPSS em metais utilizando diversos ângulos de incidência. Esse estudo mostrou que os períodos obtidos com diferentes ângulos de incidência são diferentes dos períodos teóricos obtidos pela equação (8) uma vez que a equação parte da premissa de que o material irradiado é totalmente liso, porém, como fora demonstrado em (VOROBYEV et al, 2007) os LIPSS formados por lasers de femtossegundos são cobertos com por nanoestruturas. Essas nanoestruturas que estão presentes na 
superfície dos LIPSS alteram a constante dielétrica efetiva do meio e, consequentemente, o período dos LIPSS em função do ângulo de incidência. Diante disso, o período dos LIPSS foram significantemente alterados, variando de $600 \mathrm{~nm}$ à $2800 \mathrm{~nm}$ em ouro e de $600 \mathrm{~nm}$ à $3700 \mathrm{~nm}$ em platina, com os ângulos de incidência do feixe controlados entre $0^{\circ}$ e $80^{\circ}$.

\subsubsection{LIPSS Colunares}

Estruturas colunares, cônicas e em formato de agulha são outras formas encontradas de danos causados pela irradiação do material por laser.

Essas estruturas constituem-se de densas regiões cobertas com algum dos tipos geométricos citados acima, com razão de aspecto de pelo menos 2:1 (CUNHA, 2015) e são desenvolvidas com fluências maiores dos que as utilizadas na formação dos LIPSS convencionais. Além da fluência outras propriedades que alteram o formato e as características dessas estruturas são: a quantidade de pulsos sobrepostos, o material irradiado e as condições ambientais (principalmente a pressão atmosférica).

Recentemente, Kalsoom et al. (2012) avaliaram os efeitos de diferentes condições ambientais na formação dessas estruturas em um aço inoxidável. Foi utilizado vácuo e oxigênio com pressão de 133 mbar. Os autores observaram que os LIPSS lineares se formaram em todas as condições ambientais, entretanto as estruturas em formato de cones foram formadas apenas em condições de vácuo.

Também utilizando vácuo, Tsibidiset al. (2015) irradiaram diversos materiais com vários pulsos em um só ponto e observaram que na mesma região, pode haver a presença de várias estruturas diferentes como: ripples, estrutura granular e colunar. 
A fabricação de microestruturas colunares em metais por ablação direta foi demonstrada em (VOROBYEV; GUO, 2007)onde foram encontrados diversos formatos e tamanhos de estruturas colunares que podem ser controlados através dos parâmetros do laser.

Estruturas cônicas foram criadas em Titânio, Alumínio, Cobre e Aço Inoxidável (NAYAK; GUPTA; KOLASINSKI, 2008) através de alterações nos parâmetros do laser como fluência, número de pulsos sobrepostos e atmosfera. Foi demonstrado em (VARLAMOVA, 2013) que as estruturas cônicas, colunares e granulares são progressões que se formam com o aumento do número de pulsos sobrepostos em uma mesma região. Esse fato foi demonstrado através da incidência de múltiplos pulsos em uma mesma região, tomando proveito da característica gaussiana da distribuição de energia no feixe laser, foi possível constatar a evolução das estruturas da periferia ao centro do pulso (FIG. 9).

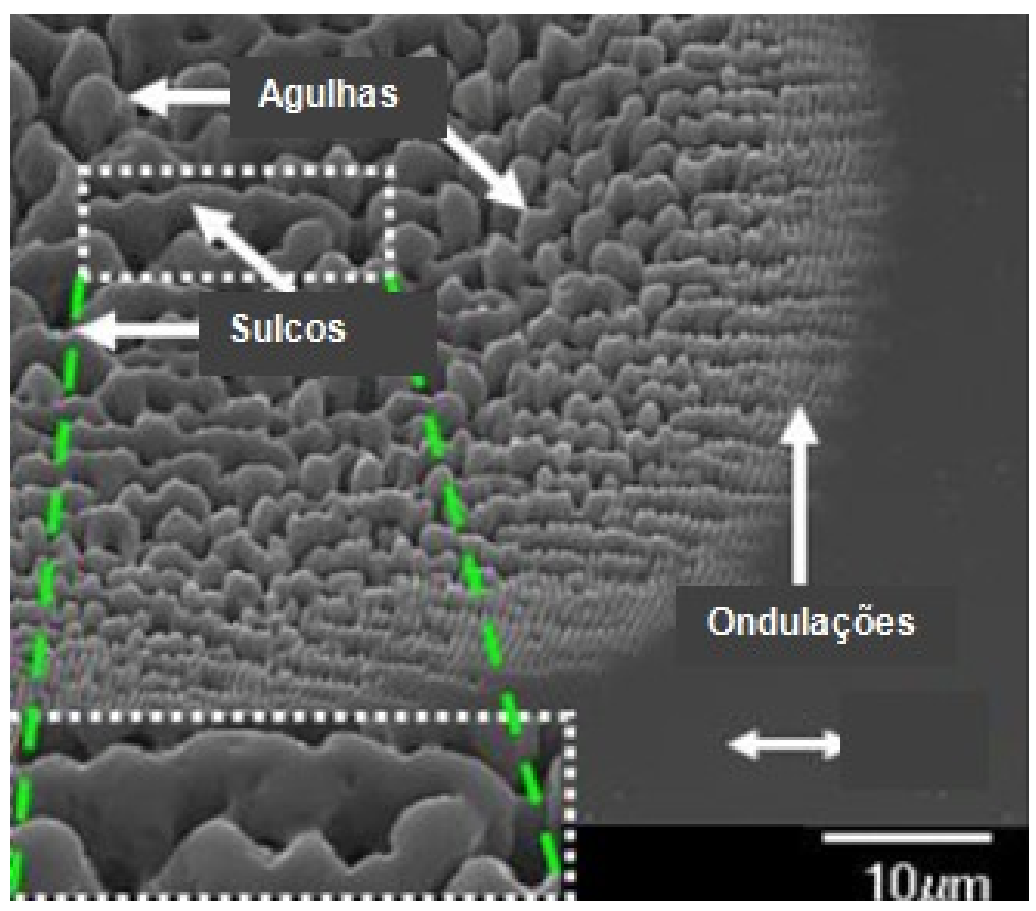

FIGURA 9 - Evolução das estruturas formadas em vácuo. Nota-se que os ripples tendem a se formar nas regiões com menores fluências, enquanto as estruturas colunares na região de maior intensidade. Imagem retirada de (TSIBIDIS et al, 2015) 


\subsection{Aplicações para os LIPSS}

Enquanto o entendimento a respeito da formação dos LIPSS continua em debate, muitas são as aplicações para tais nanoestruturas.

Por ser um efeito visual e perceptível imediatamente, alterações ópticas se tornaram naturalmente as primeiras aplicações que justificaram a produção de LIPSS. Metais coloridos (AHSAN et al., 2011; DUSSER et al., 2010; LI et al., 2014b; OU; HUANG; ZHAO, 2014; VOROBYEV; GUO, 2008a) ou mesmo absorvedores de luz(GUO; VOROBYEV, 2010; OU; HUANG; ZHAO, 2016) foram criados recentemente graças à fabricação de LIPSS por meio de lasers de femtossegundo sem que houvesse a formação de camadas superficiais como óxidos ou nitretos e, talvez mais importante, sem que haja mudança microestrutural dos metais.

\subsection{Aplicações de LIPSS: Molhabilidade}

Modificações na molhabilidade de metais e semicondutores através da irradiação do material com laser de femtossegundo é um campo de pesquisa recente, se comparado com outras aplicações que a técnica oferece.

A técnica básica para o controle da molhabilidade se baseia nas teorias de Wenzel (1936) e Cassie-Baxter (1944). Segundo Wenzel, o ângulo de contato da água com a superfície do material irá aumentar com o aumento da rugosidade da superfície e consequentemente, irá diminuir com a diminuição dessa rugosidade. Tal situação é descrita pela Equação 11:

$$
\cos \alpha=r \cos \theta
$$


Onde a é o ângulo de contato aparente na superfície rugosa, e $\theta$ o ângulo de contato aparente na superfície lisa e $r$ é a rugosidade do material.

O uso dos LIPSS como meio rugoso, que criará o aumento da energia de superfície e consequentemente o ângulo de contato, proporciona vantagens como o fato de poder ser aplicado em diversos materiais e do processo não exigir um ambiente altamente controlado.

Vorobyev e Guo (2015) criaram superfícies super-hidrofóbicas e autolimpantes através da fabricação de LIPSS em metais. Tais superfícies também possuem aplicações anti-bactericidas, anti-congelantes e anti-corrosivas.

Cunha et al. (2013) avaliaram a utilização de superfícies com LIPSS em Titânio utilizado em implantes cirúrgicos. Os autores concluíram que essa técnica pode melhorar consideravelmente a adesão de células aos implantes.

\subsection{Aplicações de LIPSS: Tribologia}

Dentre as aplicações encontradas para os LIPSS, as que envolvem melhoria tribológica do material são as que possuem menos publicações, em comparação com os efeitos ópticos e de molhabilidade. Entretanto, os resultados obtidos nos primeiros trabalhos com essa finalidade são muito promissores Mizuno et al.(2006) constataram uma redução no coeficiente de atrito em filmes de DLC cobertos com LIPSS por meio de medições realizadas em um microscópio de força atômica. Em um trabalho mais recente (GNILITSKYI et al., 2016) foi observado redução no coeficiente de atrito do aço AISI 316 irradiado com laser de femtossegundo tanto à seco quanto lubrificado. Essa diminuição no coeficiente de atrito foi atribuída à capacidade das nanoestruturas de diminuírem 
a área de contato entre os materiais, uma vez que o atrito está ocorrendo apenas nos picos das estruturas.

\subsection{Aplicações de LIPSS: Propriedades Ópticas}

A utilização de laser de femtossegundo para alterações em propriedades ópticas é um campo de estudo amplo e explorado (IONIN et al., 2012; LI et al., 2014a; OU; HUANG; ZHAO, 2014; VOROBYEV; GUO, 2008a). A FIG. 10 mostra um dos trabalhos pioneiros nessa área onde os autores criaram estruturas de difração na superfície de alumínio, alterando sua coloração em função do ângulo de visualização e de incidência da luz (VOROBYEV; GUO, 2008a).

(a)
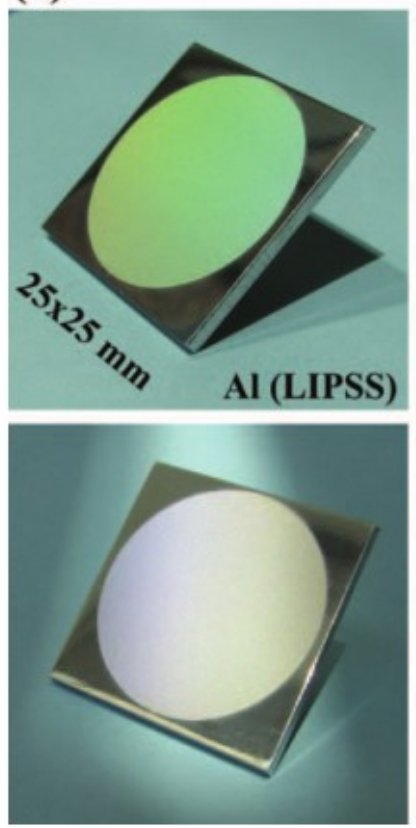
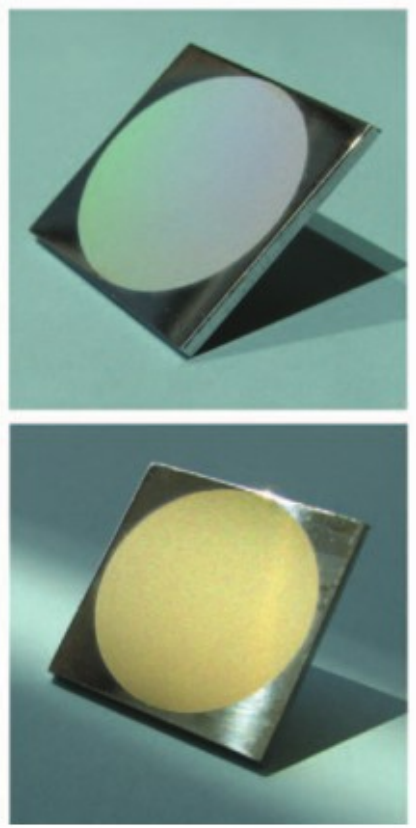

(b)

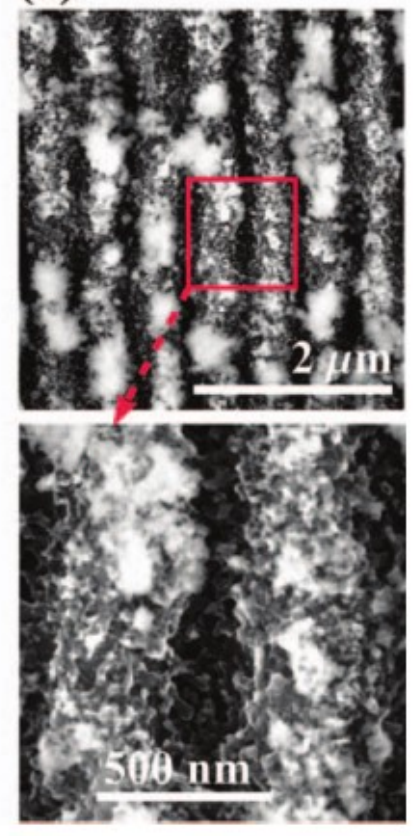

FIGURA 10 - (a) Cor em alumínio após irradiação com laser de femtossegundo para criação de LIPSS visualizado em diferentes ângulos. (b) LIPSS visualizados através de um MEV (VOROBYEV; GUO, 2008a). 
Uma característica das estruturas coloridas obtidas através desse processo é a grande dependência da polarização e do ângulo de visualização da amostra. Porém essa dependência foi muito bem aproveitada por Dusser et al. (2010) que desenvolveu uma técnica para obter diversas cores na superfície de um metal através da composição de LIPSS em diversos ângulos e direções. Com isso foi possível a criação de um retrato e de outros desenhos artísticos utilizando apenas o laser de femtossegundo.

Metais são materiais com alto nível de reflexão de luz, entretanto, existem aplicações (marcação, absorção de luz em células solares e sensoriamento) em que é necessário que o metal possua certo nível de contraste, ou seja, absorva radiação eletromagnética.

A produção de superfícies metálicas absorvedoras de luz foi demonstrada em (GUO; VOROBYEV, 2010), onde os autores aumentaram significantemente a absorção em metais através de estruturas superficiais produzidas com laser de femtossegundo.

Esse aumento na absorção de luz é explicado por meio de dois mecanismos simultâneos. O primeiro é o aprisionamento da luz incidente nas cavidades dos LIPSS, que dependendo dos parâmetros de produção, pode ter uma profundidade maior do que a luz visível incidente. O outro mecanismo diz respeito à contribuição da interferência destrutiva provocada pelos plasmonssuperficiais, provocando uma absorção em diversos comprimentos de onda do espectro visível (GUO; VOROBYEV, 2010; OU; HUANG; ZHAO, 2016). 


\section{PROCEDIMENTO EXPERIMENTAL}

Os experimentos que serão descritos nesse item foram realizados com o objetivo de, inicialmente, determinar a influência dos parâmetros do laser na formação dos LIPSS e, posteriormente, analisar a consequência dessas nanoestruturas nas propriedades ópticas dos metais estudados.

O experimentos foram realizados por meio de um sistema laser de Ti:Safira (Femtopower Compact Pro CE-Phase HP/HR de Femtolasers), conforme esquematizado na FIG. 11. O sistema emite pulsos com 25 fs de duração com comprimento de onda central de $790 \mathrm{~nm}$ e taxa de repetição de $4 \mathrm{kHz}$. Estes pulsos são gerados em uma sala distante 30 metros da estação de trabalho. Durante este percurso os pulsos são alargados temporalmente devido à dispersão espectral. Uma correção é feita através de uma pré-compensação no espectro de emissão original, resultando em uma largura temporal de aproximadamente $30 \mathrm{fs}$ na posição focal de trabalho.

A focalização do feixe se deu através de uma lente de $50 \mathrm{~mm}$ de comprimento focal. Os principais parâmetros alterados durante os experimentos foram a energia (fluência) e a taxa de sobreposição de pulsos. 


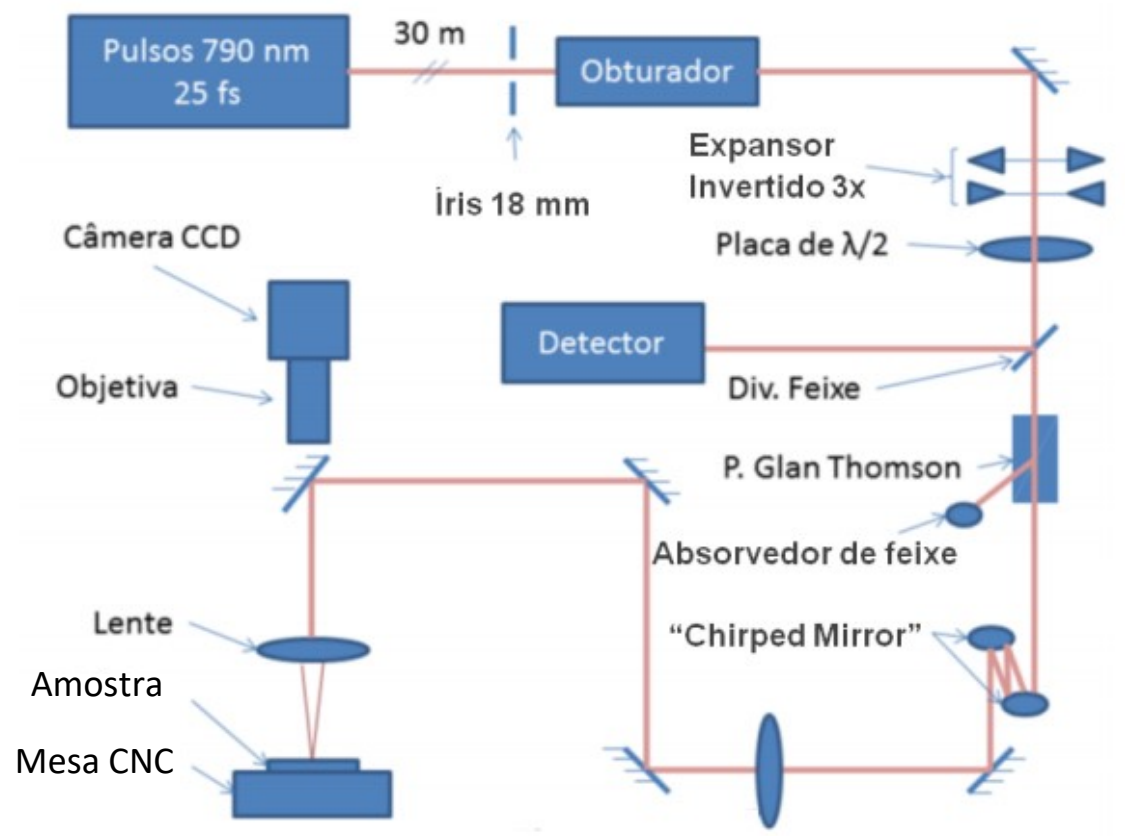

FIGURA 11 - Arranjo do sistema óptico de entrega do feixe

Foram utilizados dois tipos de metais: Titânio Grau 2 e o aço inoxidável austenítico ASTM F138 obtidos através de barras, das quais foram cortadas e sua superfície lixada em uma lixadeira politriz universal utilizando lixas da marca Carborudum com tamanho de grão entre 200 e 1200. Após o lixamento, as amostras foram polidas utilizando pastas de diamante Struers com tamanho granulometria entre $4 \mu \mathrm{m}$ e $0,5 \mu \mathrm{m}$. Os metais polidos foram fixados em uma mesa programável através de comandos CNC, com resolução de 0,001 mm, na qual foram irradiados por laser de femtossegundo.

Para a caracterização das amostras irradiadas, foi utilizado um Microscópio Eletrônico de Varredura Hitashi Tabletop TM3000. As propriedades ópticas foram caracterizadas por meio de uma câmera fotográfica convencional para o registro visual em ampliação real e,além disso, os espectros de reflexão da amostra após a incidência do laser foram obtidos por meio do espectrofotômetro AgilentCary 5000 e do espectrômetro Thorlabs CCS100. 


\subsection{Influência da Energia na formação dos LIPSS}

O primeiro experimento foi conduzido em uma amostra de titânio grau 2 com 20 mm x 15 mm cujos parâmetros estão descritos na TAB 1.

Foram irradiados 15 traços com $5 \mathrm{~mm}$ de comprimento na amostra. A largura dos traços de $17 \mu \mathrm{m}$ foi calculada através da Equação 12 (JOHNSTON JR., 1990). Os parâmetros alterados foram a fluência e o número de sobreposição de pulsos, conforme apresentado na .

$$
d_{\min .}=4 M^{2} \lambda f /\left(\pi \cdot d_{0}\right)
$$

Onde $d_{0}$ é o diâmetro na entrada da lente $(6 \mathrm{~mm}), d_{\text {min }}$ é o diâmetro no ponto focal , $\lambda$ é o comprimento de onda do laser $(0,79 \mu \mathrm{m})$,f é o comprimento focal da lente (50 mm) e $\mathrm{M}^{2}$ é a qualidade do feixe laser (2,6 em x e 1,4 em y).

TABELA 1 - Parâmetros do Experimento 1

\begin{tabular}{c|c|c}
\hline Traço & Fluência $\left(\mathbf{J} / \mathbf{c m}^{2}\right)$ & $\begin{array}{c}\text { Taxa N de } \\
\text { sobreposição de } \\
\text { pulsos }\end{array}$ \\
\hline 1 & 2,2 & 4 \\
\hline 2 & 2,2 & 8 \\
\hline 3 & 2,2 & 12 \\
\hline 4 & 1,3 & 4 \\
\hline 5 & 1,3 & 8 \\
\hline 6 & 1,3 & 12 \\
\hline 7 & 0,88 & 4 \\
\hline 8 & 0,88 & 8 \\
\hline 9 & 0,88 & 12 \\
\hline 10 & 0,44 & 4 \\
\hline 11 & 0,44 & 12 \\
\hline 12 & 0,44 & 4 \\
\hline 13 & 0,22 & 8 \\
\hline 14 & 0,22 & 12 \\
\hline 15 & 0,22 &
\end{tabular}


A taxa $\mathrm{N}$ de sobreposição de pulsos foi obtida pela relação entre a velocidade de varredura do laser, freqüência e diâmetro do feixe, através da equação 13.

$$
N=\frac{f d}{v}
$$

Onde, $\mathrm{N}$ é a taxa de sobreposição de pulsos, $\mathrm{d}$ o diâmetro do feixe e $\mathrm{v}$ a velocidade de propagação do laser e $f$ a frequência.

\subsection{Influência do sentido de polarização}

Outra variável que influencia a formação dos LIPSS é o sentido de polarização do feixe (SIPE et al., 1983). Foi então elaborado um experimento cujo objetivo era constatar e mensurar tal dependência.

Utilizando o mesmo material do experimento anterior (Titânio Grau 2), irradiou-se 6 regiões com polarizações distintas, conforme. Além da polarização, também foi analisada a influência da taxa $N$ de sobreposição de pulsos na formação dos LIPSS e na coloração final da amostra. A taxa $\mathrm{N}$ de sobreposição de pulsos foi modificada por meio da relação entre a taxa de repetição de pulsos, velocidade de varredura e do aumento da quantidade de vezes que o feixe laser irradiou a mesma região da amostra (quantidade de passes). $\mathrm{O}$ experimento foi conduzido utilizando fluência de $0,44 \mathrm{~J} / \mathrm{cm}^{2}$, que foi selecionado a partir dos resultados do experimento anterior. A FIG. 12 indica a localização das regiões irradiadas na amostra assim como a indicação do sentido de polarização empregado, representado pelas setas. 


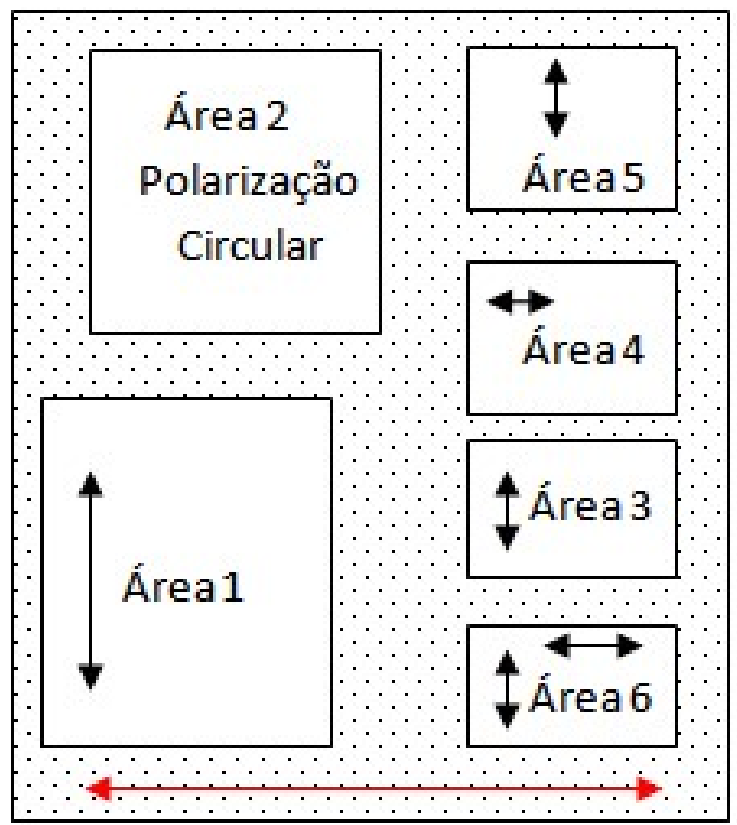

FIGURA 12 - Localização e quantidade de passes das regiões irradiadas.

Os testes foram configurados da seguinte forma:

- A área 1 foi irradiada com 1 passe $(\mathrm{N}=4)$ e polarização vertical;

- A área 2 com 1 passe (N=4) e polarização circular;

- A área 3 com 2 passes (N=8) e polarização vertical;

- A área 4 com 4 passes ( $N=16)$ e polarização vertical;

- A área 5 com 1 passe $(\mathrm{N}=4)$ e polarização horizontal;

- A área 6 com 1 passe $(N=4)$ e polarização vertical seguido de um passe com polarização horizontal.

Um passe representa um traço realizado pelo feixe laser na distância desejada e é diretamente proporcional à taxa de repetição de pulsos.

\subsection{Influência dos gases de proteção}

Uma das grandes vantagens no uso de laser de femtossegundo para irradiação e marcação em metais é a baixa transferência de energia que ocorre, 
proporcionando um aquecimento mínimo do material (NOLTE, 2003; SAMAD et al., 2012). Como consequência do baixo aquecimento está a possível não formação de camadas de óxidos e nitretos na superfície dos metais, naturalmente reativos. Porém, podem ser observados regiões irradiadas com laser de femtossegundo com uma provável camada de óxidos, principalmente nas extremidades das linhas irradiadas pelo laser, ou seja, na região com maior aporte energético. Essa maior quantidade de energia nas extremidades é explicada pelo efeito de aceleração e desaceleração do motor de passo que movimenta a mesa e com isso, há um aumento na taxa de sobreposição de pulsos. Segundo (MIRIM, 2016) o efeito de incubação leva a uma diminuição na fluência de limiar $F_{\text {th }}$ com o aumento de $N$. Nas extremidades dos traços, a velocidade deve diminuir até zero para depois acelerar até a velocidade normal no sentido de volta. Esta diminuição da velocidade acarreta então em um aumento muito grande em $\mathrm{N}$ (mas localizado), o que leva a uma diminuição em $\mathrm{F}_{\text {th. }}$ Nesta região, portanto, a fluência utilizada passa a ser muito maior que a de limiar. Assim, efeitos térmicos surgem nestas extremidades dos traços, e o calor produzido pode levar à oxidação do metal.

Para averiguar a presença desses óxidos, foi realizada irradiação de duas amostras de Titânio Grau 2 com fluência de $2,2 \mathrm{~J} / \mathrm{cm}^{2}$ e taxa de repetição de $4 \mathrm{kHz}$ com taxa $\mathrm{N}$ de sobreposição de pulsos igual a 4. Uma amostra foi irradiada sob atmosfera sem controle (ar) e outra amostra com a presença de argônio $(99,999 \%)$ na atmosfera. O argônio foi introduzido na área de irradiação do laser através de uma mangueira, que transportou o gás do cilindro soltando-o por meio de uma válvula com um orifício direcionado para a amostra. 
A utilização de argônio como gás protetivo é uma prática comum em soldagem e usinagens a laser, uma vez que, por se tratar de uma molécula inerte, ele impede que o oxigênio entre em contato com o material que se está sendo trabalhado, e consequentemente evita sua oxidação.

Após a irradiação das amostras, foi realizado microscopia eletrônica para detectar visualmente a presença de óxidos no material, em seguida, foi realizada uma análise química por EDS nas extremidades irradiadas das duas amostras e no centro da amostra irradiada sem argônio.

\subsection{Análise da relação entre a fluência e a morfologia dos LIPSS}

Para correlacionar a fluência do laser com a formação dos LIPSS foram irradiados 20 traços no material Titânio grau 2, alterando a fluência e a quantidade de passes (taxa de sobreposição) conforme demonstrado na TAB 2.

TABELA 2 - Parâmetros do experimento

\begin{tabular}{|c|c|c|c|}
\hline Traço & Energia por pulso $(\mu \mathrm{J})$ & Fluência $\left(\mathrm{J} / \mathrm{cm}^{2}\right)$ & Taxa de sobreposição N \\
\hline 1 & 1 & 0,44 & \multirow{5}{*}{4} \\
\hline 2 & 0,8 & 0,35 & \\
\hline 3 & 0,6 & 0,26 & \\
\hline 4 & 0,4 & 0,17 & \\
\hline 5 & 0,2 & 0,09 & \\
\hline 6 & 1 & 0,44 & \multirow{5}{*}{16} \\
\hline 7 & 0,8 & 0,35 & \\
\hline 8 & 0,6 & 0,26 & \\
\hline 9 & 0,4 & 0,17 & \\
\hline 10 & 0,2 & 0,09 & \\
\hline 11 & 1 & 0,44 & \multirow{5}{*}{64} \\
\hline 12 & 0,8 & 0,35 & \\
\hline 13 & 0,6 & 0,26 & \\
\hline 14 & 0,4 & 0,17 & \\
\hline 15 & 0,2 & 0,09 & \\
\hline 16 & 1 & 0,44 & \multirow{5}{*}{256} \\
\hline 17 & 0,8 & 0,35 & \\
\hline 18 & 0,6 & 0,26 & \\
\hline 19 & 0,4 & 0,17 & \\
\hline 20 & 0,2 & 0,09 & \\
\hline
\end{tabular}


A velocidade de varredura do laser utilizada foi de $960 \mathrm{~mm} / \mathrm{min}$, a largura temporal dos pulsos laser foi de 30 fs e a taxa de repetição foi de $4 \mathrm{kHz}$. Após a irradiação os traços foram analisados por microscopia eletrônica e as micrografias geradas foram processadas por meio da técnica de transformada rápida de Fourier (Fast Fourier Transform - FFT) para que se pudessem verificar com precisão pequenas variações na direção e período dos LIPSS. As medições das FFT foram realizadas conforme FIG. 13.

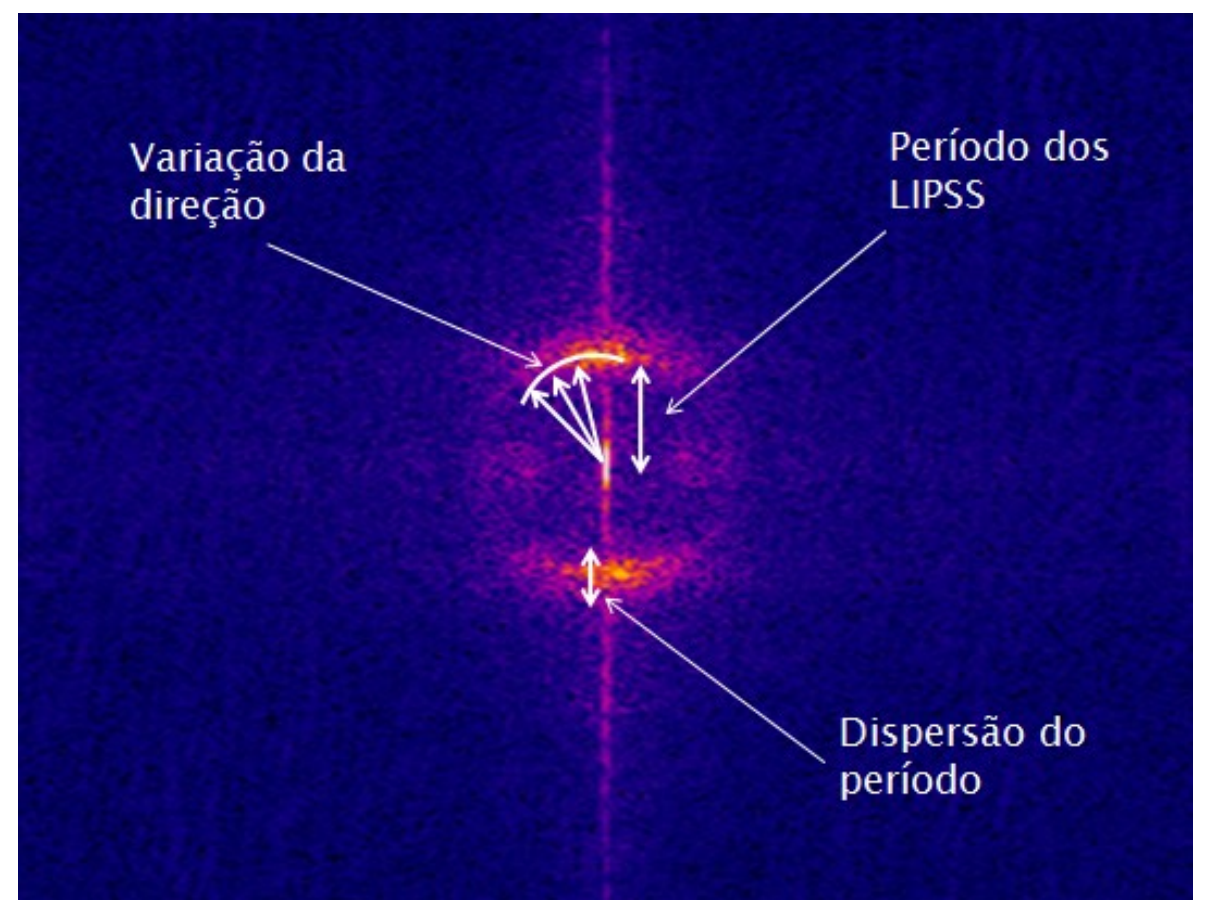

FIGURA 13 - Croqui das propriedades obtidas da FFT

\subsection{Investigação da técnica de escurecimento do metal}

Neste experimento, foi utilizado o aço inoxidável austenítico ASTM F138, que assim como o Titânio grau 2 utilizado nos testes anteriores, possui ampla aplicação cirúrgica e industrial.

Para isso, foram irradiados oito retângulos que se diferenciam pela velocidade de deslocamento do laser, ou seja, a taxa $\mathrm{N}$ de sobreposição de 
pulsos, conforme TAB 3. Foi utilizada energia de $1 \mu \mathrm{J}$ por pulso com taxa de repetição de 4 kHz e polarização horizontal.

TABELA 3 - Parâmetros do experimento de escurecimento do metal

\begin{tabular}{c|c|c}
\hline Região & Velocidade & $\begin{array}{c}\text { Taxa N de } \\
\text { sobreposição }\end{array}$ \\
\hline $\mathbf{1}$ & $960 \mathrm{~mm} / \mathrm{min}$ & 3,75 \\
\hline $\mathbf{2}$ & $768 \mathrm{~mm} / \mathrm{min}$ & 4,7 \\
\hline $\mathbf{3}$ & $576 \mathrm{~mm} / \mathrm{min}$ & 6,25 \\
\hline $\mathbf{4}$ & $384 \mathrm{~mm} / \mathrm{min}$ & 9,4 \\
\hline $\mathbf{5}$ & $192 \mathrm{~mm} / \mathrm{min}$ & 18,75 \\
\hline $\mathbf{6}$ & $96 \mathrm{~mm} / \mathrm{min}$ & 37,5 \\
\hline $\mathbf{7}$ & $50 \mathrm{~mm} / \mathrm{min}$ & 72 \\
\hline $\mathbf{8}$ & $25 \mathrm{~mm} / \mathrm{min}$ & 144 \\
\hline
\end{tabular}

Para analisar quantitativamente a reflexão que cada região irradiada proporciona, foram irradiadas outras três amostras com uma área maior, utilizando os parâmetros das regiões 1,4 e 8 , escolhida pelo fato de, teoricamente, possuírem a menor, intermediária e maior absorção entre as regiões. Essa análise de reflexão / absorção foi realizada por meio do Espectrofotômetro modelo Cary 5000, utilizando uma faixa de comprimentos de onda entre $350 \mathrm{~nm}$ e $800 \mathrm{~nm}$.

Foi também realizada a análise da intensidade dos comprimentos de onda refletidos em determinado ângulo por meio de um espectrômetro (FIG. 14). No arranjo montado foi utilizado um laser emissor de luz branca (A), um detector colimador (B) conectado ao espectrômetro por meio de uma fibra óptica e a amostra fixada em uma base com movimentos angulares (C). A amostra foi posicionada a um ângulo de $20^{\circ}$ em relação à normal do emissor de luz (ângulo 
de incidência) e o detector a um ângulo de $23^{\circ}$ em relação à linha paralela da face da amostra. Foram obtidas medidas na região cuja sobreposição $N$ de pulsos foi de 3,75 e na região com $\mathrm{N}=37,5$ pulsos.
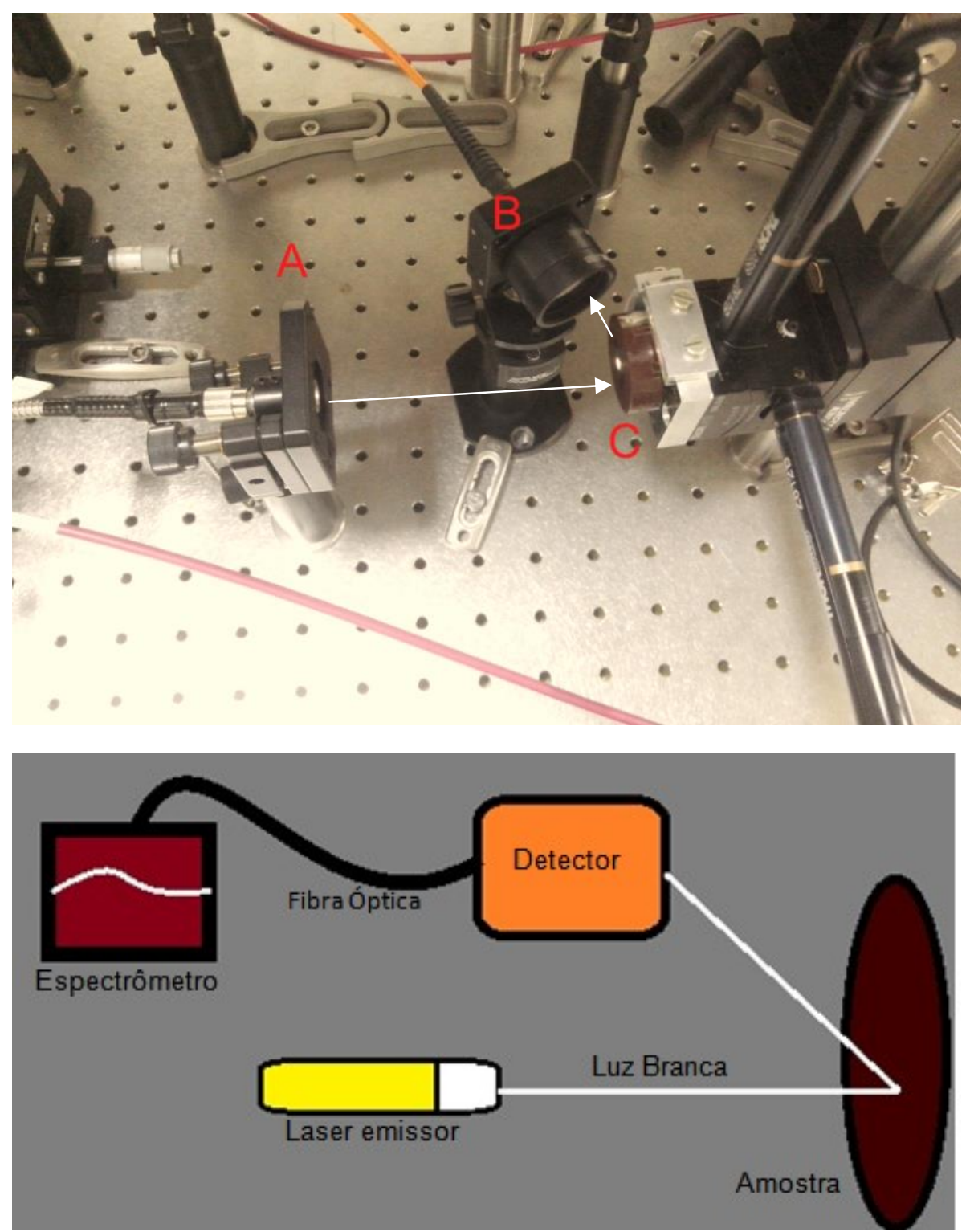

FIGURA 14 - Arranjo para caracterização óptica 


\subsection{Elaboração do Dispositivo de Aquecimento}

Foi elaborado um experimento para a avaliar a possibilidade de criação de um dispositivo de aquecimento utilizando-se as altas taxas de absorção que o material pode adquirir após a irradiação com laser de femtossegundo. Para isso, foi selecionada uma chapa metálica com $0,5 \mathrm{~mm}$ de espessura do material aço inoxidável austenítico ASTM F138, o mesmo utilizado nos experimentos anteriores. Os parâmetros de irradiação do metal foram os mesmos utilizados na região 8 da . Foi irradiada uma região de $6 \mathrm{~mm} \times 10 \mathrm{~mm}$, conforme FIG. 15.

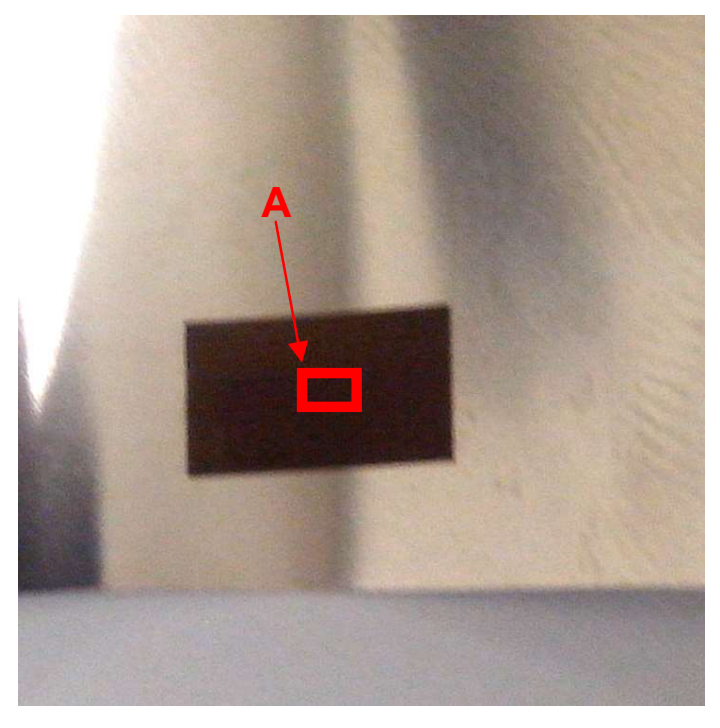

FIGURA 15 - Amostra irradiada para a criação do aquecedor

Após a irradiação, foi retirada uma amostra com $1 \mathrm{~mm} \times 1 \mathrm{~mm}$ (Região $A$ Figura 15) para a realização do experimento de aquecimento. Para esse experimento, foi utilizado um laser de He-Ne com potência máxima de saída de $25 \mathrm{~mW}$. Para a medição da temperatura do dispositivo foi utilizado um micro termopar tipo $\mathrm{k}$ com $0,3 \mathrm{~mm}$ de diâmetro unido à chapa metálica por meio de pasta térmica (FIG. 16 e 17). 


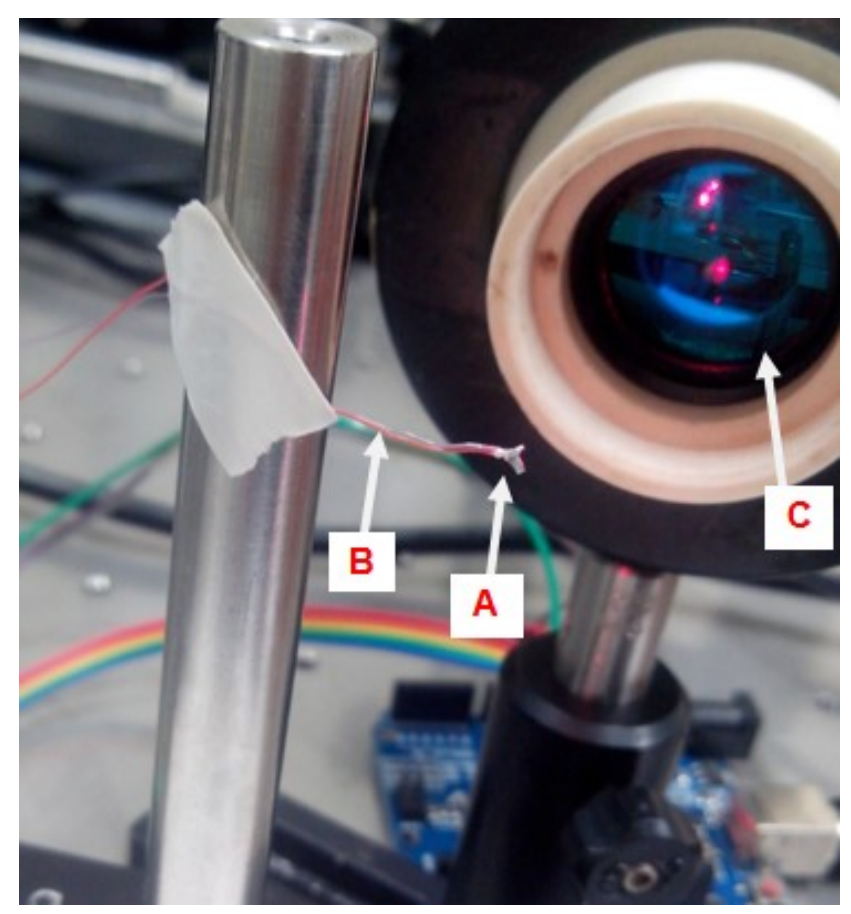

FIGURA 16 - Aparato para medição da temperatura do dispositivo aquecedor. (A): Amostra, (B): Termopar, (C): Lente focalizadora do feixe Laser

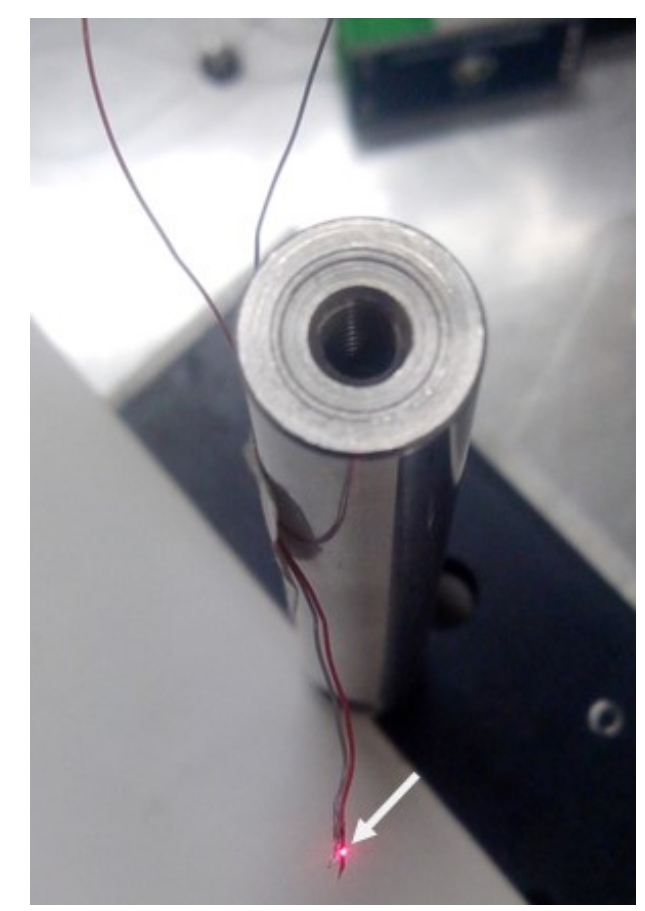

FIGURA 17 - Detalhe do feixe laser atingindo o dispositivo (Seta) 


\section{RESULTDADOS E DISCUSSÃO}

\subsection{Influência da Energia dos LIPSS}

Após a execução dos traços, o aspecto visual do material foi caracterizado por meio de uma câmera digital convencional para registro das alterações ópticas perceptíveis a olho nu (FIG. 18).

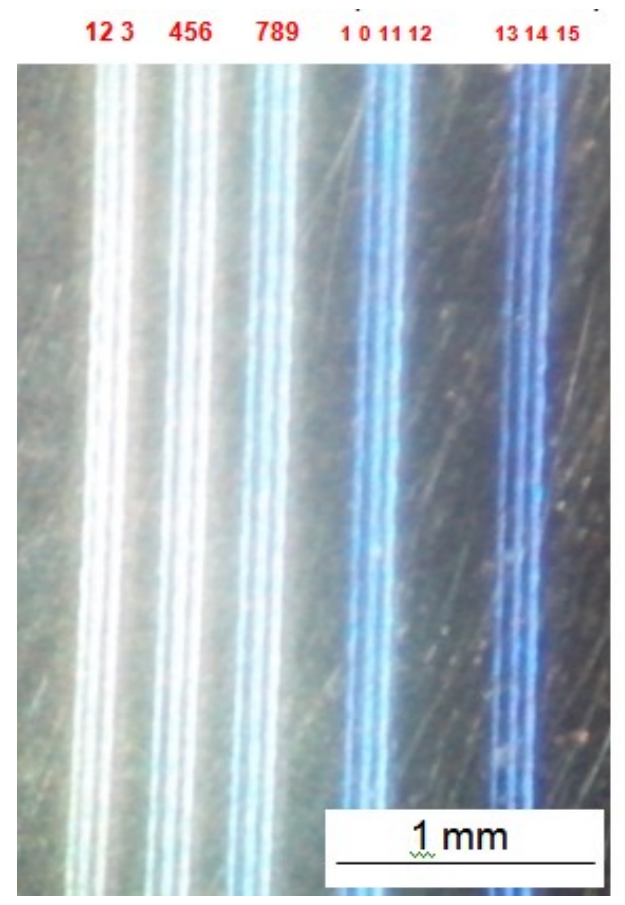

FIGURA 18 - Fotografia das linhas executadas conforme Tabela 1.

Para averiguar a influência dos diversos parâmetros na formação dos LIPPS a amostra foi analisada em ampliações maiores por microscopia eletrônica de varredura (FIG. 19 e 20). Pode-se constatar nas análises que nos traços de 1 a 9, com fluência variando entre $2,2 \mathrm{~J} / \mathrm{cm}^{2}$ e $0,88 \mathrm{~J} / \mathrm{cm}^{2}$, houve uma pequena remoção do material por meio de ablação, com formação de LIPSS nas regiões externas, onde a energia é menor em função da característica gaussiana do feixe. $\mathrm{Na}$ região central os LIPSS foram criados, porém, de forma descontínua, provocados pela alta energia na região (FIGURA 19), o que demonstra que essa faixa de fluência não é ideal para a formação dos LIPSS. Nos traços de números 
10 a 15 , com fluência variando entre $0,44 \mathrm{~J} / \mathrm{cm}^{2}$ e $0,22 \mathrm{~J} / \mathrm{cm}^{2}$, foi possível verificar a presença de LIPSS contínuos, o que explica a mudança da cor constatada na FIG. 18.

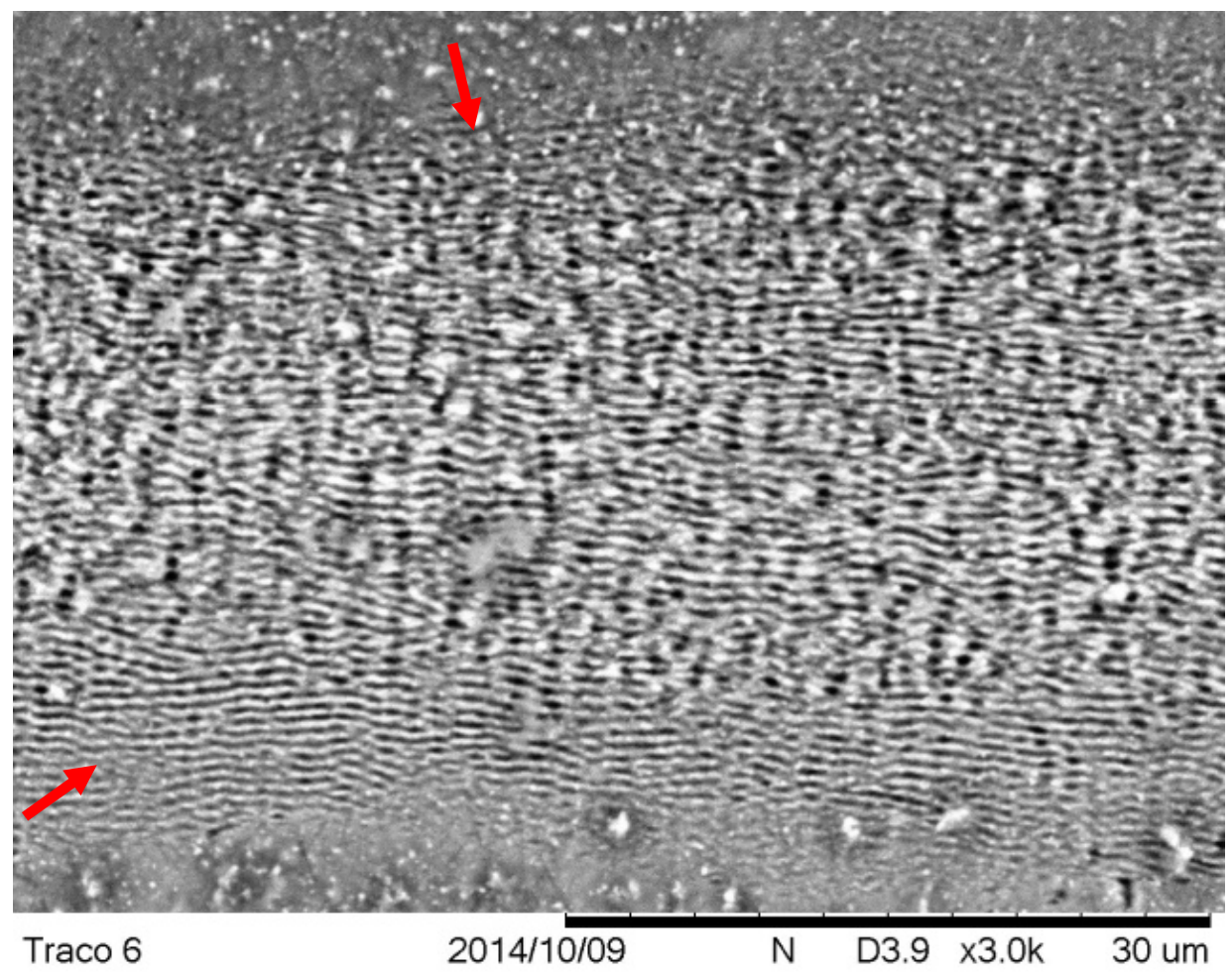

FIGURA 19 - Traço 6 com 3000x de aumento. As setas indicam as regiões onde foram formados LIPSS contínuos. Na região central do traço os LIPSS aparecem intermitentes e irregulares. 

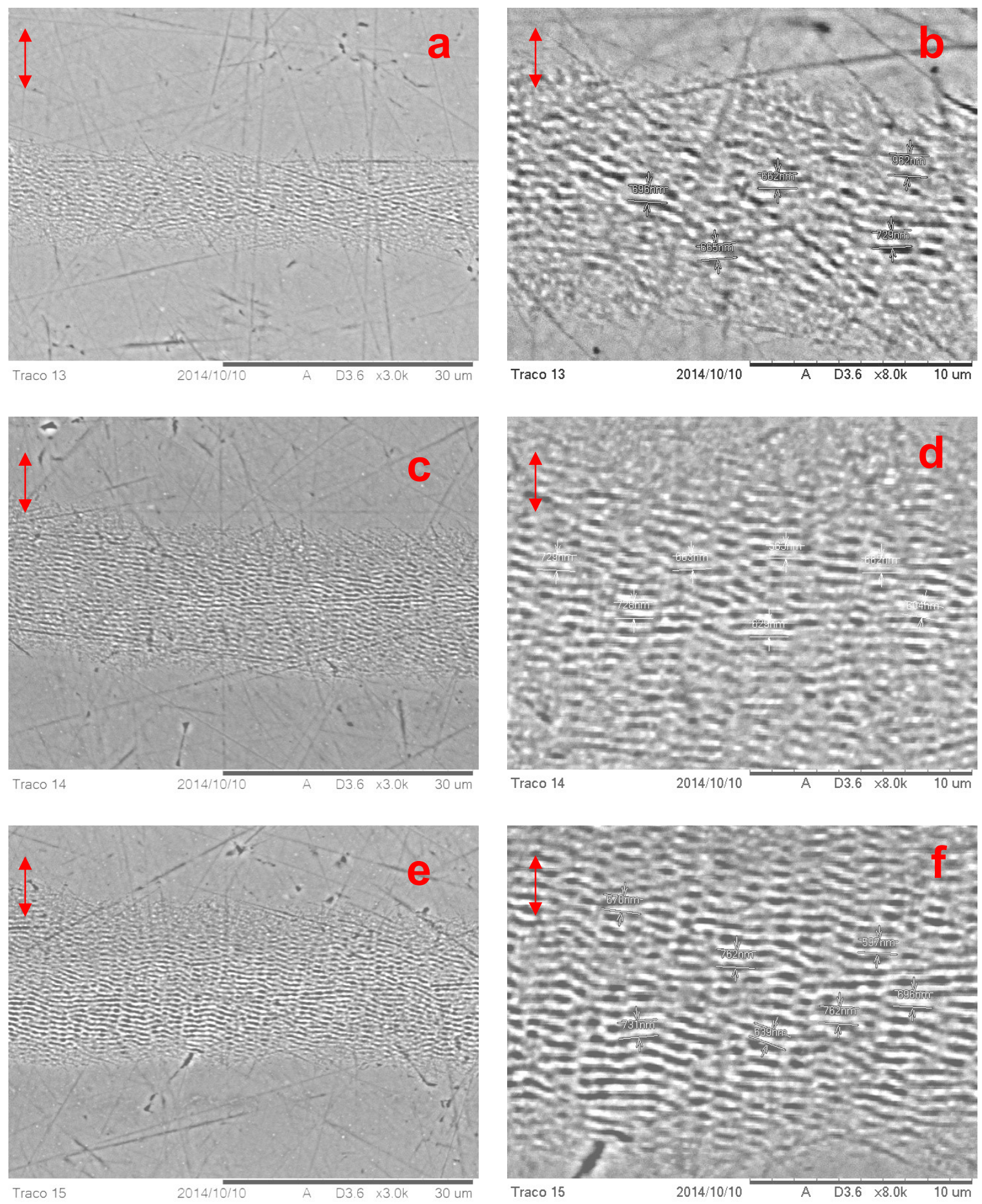

FIGURA 20 - Traços horizontais 13, 14 e 15 com ampliação de 3000x (a, c, e) e $8000 x(b, d, f)$. As duplas setas indicam o sentido de polarização (perpendicular à direção do maior traço).

O aspecto periódico e contínuo dos LIPSS explica o fenômeno de alteração visual da cor constatada na amostra, pois, tais nanoestruturas podem ser tratadas como uma grade de difração retangular, sendo possível aplicar a 
teoria da difração de ondas eletromagnéticas em grades periódicas (DUSSER et al., 2010). Com essa teoria tem-se que o comprimento de onda $\lambda$ refratado, que ocasiona o efeito visual de mudança de cor, pode ser calculado seguindo a Equação 14:

$$
m \lambda=d(\sin \alpha \cdot \sin \varphi+\sin \beta)
$$

Onde $m$ é a ordem de difração, que é um número inteiro. $\lambda$ é o comprimento de onda refratado, que no espectro visível varia entre $400 \mathrm{~nm}$ e $700 \mathrm{~nm}$. $d$ é o período dos LIPSS e a função $(\sin \alpha \cdot \sin \varphi+\sin \beta)$ é resultado dos ângulos de incidência, refração e direção dos LIPSS, conforme FIG. 21.

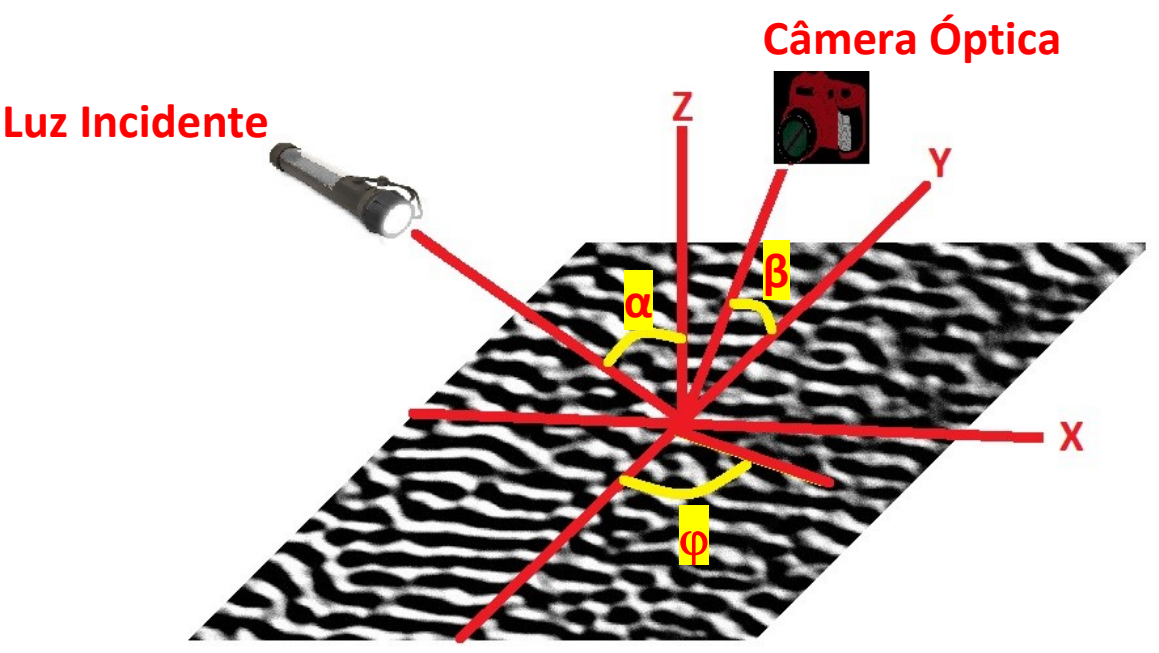

FIGURA 21 - Arranjo dos ângulos que influenciam na refração da luz

Com esse experimento, foi possível concluir que a formação de LIPSS contínuos e periódicos é possível dentro da faixa de fluência que varia de $0,22 \mathrm{~J} / \mathrm{cm}^{2}$ a $0,88 \mathrm{~J} / \mathrm{cm}^{2}$, independente das taxas $\mathrm{N}$ de sobreposição utilizadas. Acima dessa fluência, por conta da alta energia, as nanoestruturas não se formam de maneira contínua, dando lugar à uma cratera provocada pelo feixe laser, resultado da alta remoção de matéria da superfície do metal (MACHADO, 2012). 


\subsection{Influência do sentido de polarização na formação dos LIPSS}

Após a irradiação das regiões detalhadas no item 3.2, foi possível notar claramente a alteração na coloração das regiões 1, 3, 4, 5 e 6 em função do ângulo de visualização da amostra e do ângulo de incidência da luz (FIG 22). A região 2 não apresentou mudança na coloração, efeito esse justificado pela polarização circular utilizada,
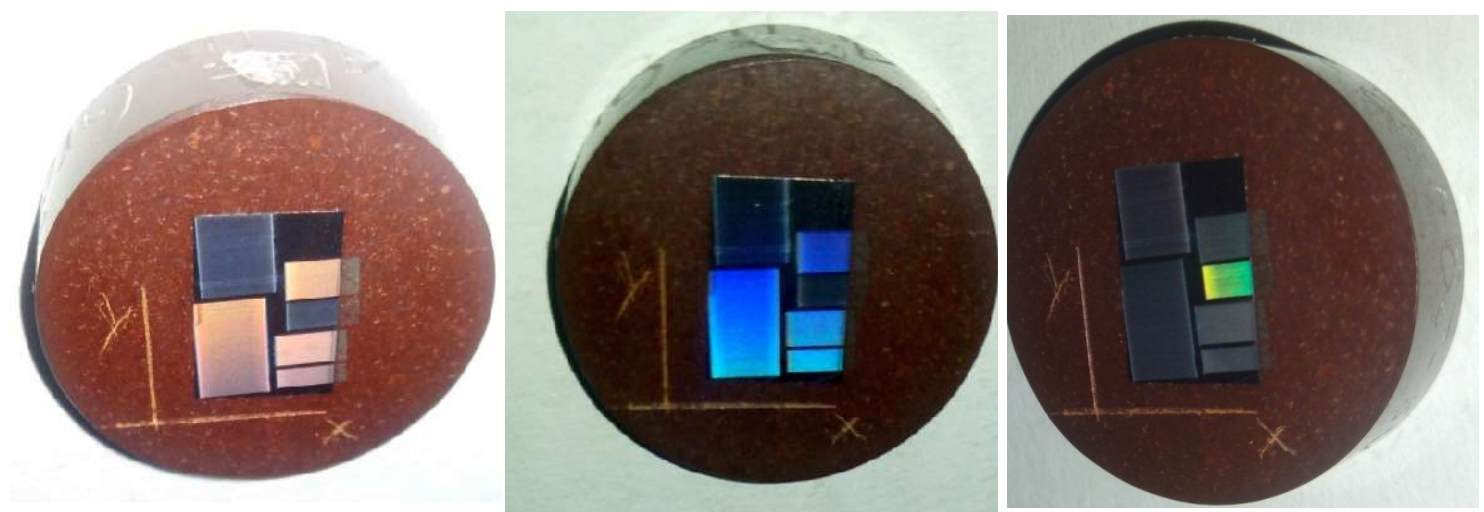

FIGURA 22 - Aspecto visual da amostra sob diferentes ângulos

A análise dos LIPSS por meio de microscopia eletrônica comprovou que a polarização do feixe laser tem influência direta no sentido de formação dos LIPSS, estando sempre perpendicular à direção da polarização do feixe, como pode ser constatado nas microscopias das regiões 4 e 5 (FIG. 23). As imagens obtidas por microscopia eletrônica foram utilizadas para que pudéssemos também analisar se há alguma influência das condições empregadas no experimento no período dos LIPSS. A TAB. 4 mostra os períodos medidos com os respectivos desvios encontrados. 
TABELA 4- Período dos LIPSS

\begin{tabular}{c|c|c|c|c}
\hline $\begin{array}{c}\text { Área } \\
\text { texturizada }\end{array}$ & $\begin{array}{c}\text { Período médio } \\
\text { dos LIPSS (nm) }\end{array}$ & $\begin{array}{c}\text { Desvio } \\
\text { Padrão } \\
\text { (nm) }\end{array}$ & $\begin{array}{c}\text { Número de } \\
\text { passes }\end{array}$ & Polarização \\
\hline 1 & 725 & 31 & 1 & Vertical \\
\hline 2 & - & - & 1 & Circular \\
\hline 3 & 674 & 115 & 2 & Vertical \\
\hline 4 & 665 & 77 & 4 & Vertical \\
\hline 5 & 622 & 27 & 1 & Horizontal \\
\hline 6 & 650 & 34 & 2 & $\begin{array}{c}\text { Vertical }+ \\
\text { Horizontal }\end{array}$ \\
\hline
\end{tabular}

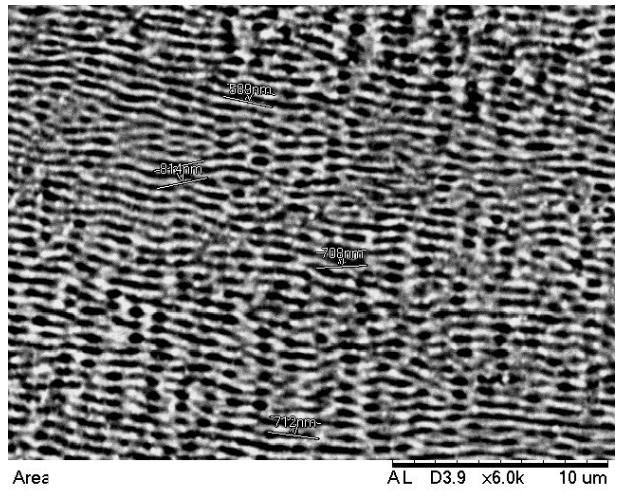

Região 4

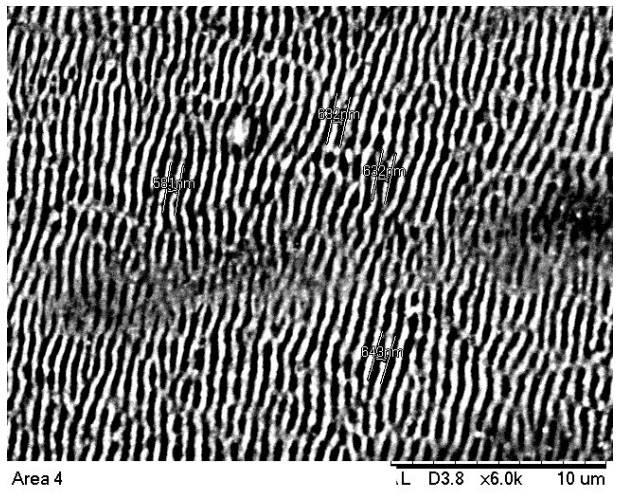

Região 5

FIGURA 23 - Microscopia em 6000x de aumento que mostra a influência do sentido de polarização do feixe na direção de formação dos LIPSS.

Com base no experimento compreendeu-se a influência da polarização do laser na formação dos LIPSS, tendo sido constatado que tal influência se da na direção das nanoestruturas, consequentemente na direção em que a luz será refletida por elas, o que abre grandes possibilidades na formação de figuras na superfície de materiais utilizando essa técnica, como foi demonstrado por Dusser (2010). Conclui-se também, que a polarização circular não favorece a formação dos LIPSS, assim como não há influência nos parâmetros utilizados no período das nanoestruturas, sendo essa uma propriedade que, como previsto por Sipe (1983), depende do comprimento de onda do laser e do ângulo de incidência do feixe. 


\subsection{Análise da influência de gases de proteção}

Após a irradiação das amostras de titânio grau 2com e sem a presença de argônio, foi realizada a análise por microscopia eletrônica, onde pode-se constatar que na amostra irradiada sem a presença de argônio, houve a formação de uma estrutura superficial que possui características de óxidos nas extremidades dos passes do laser (FIG. 24).

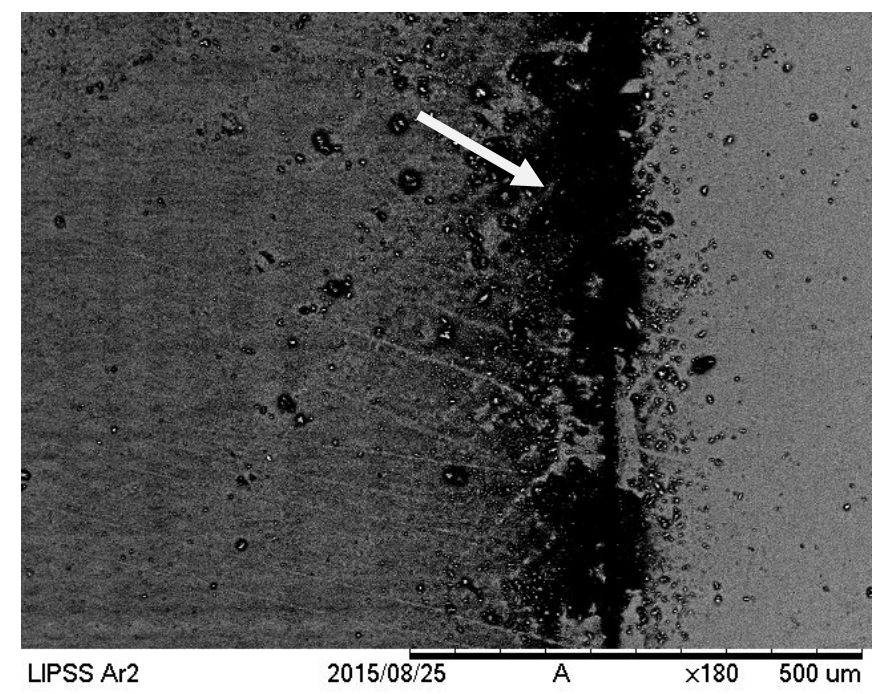

FIGURA 24 - Região de início e final dos passes laser mostra uma formação característica de óxidos (seta).

Para a confirmação de que se tratava de óxidos, foi realizada uma análise química da região por meio de um EDS acoplada ao MEV, cujo resultado mostrou a presença de $8,6 \%$ de oxigênio na região indicada pela seta da figura 18 contra $4 \%$ na região central irradiada (FIG. 25). 


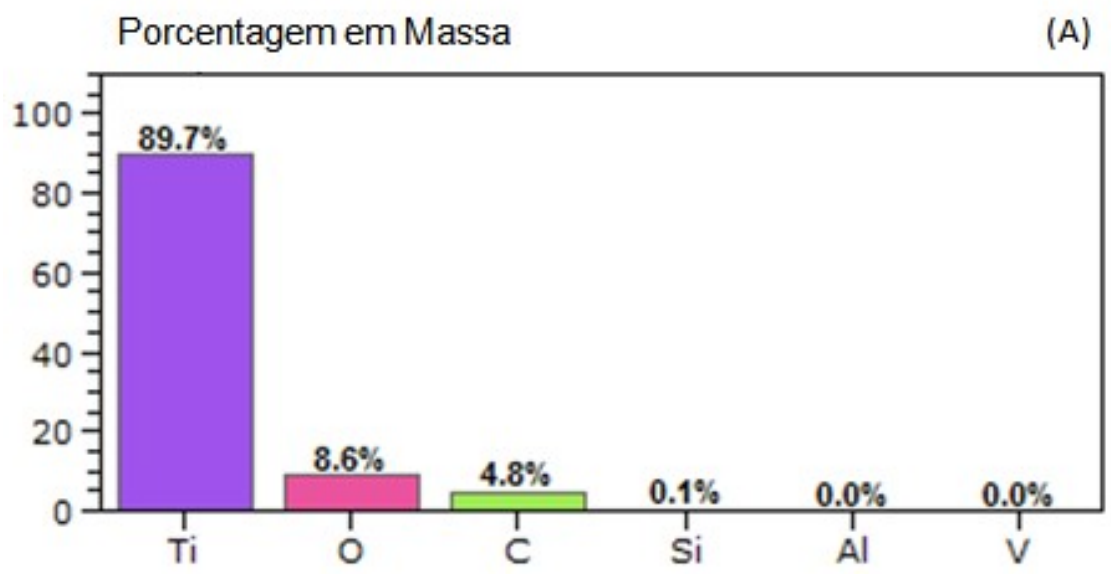

Porcentagem em Massa

(B)

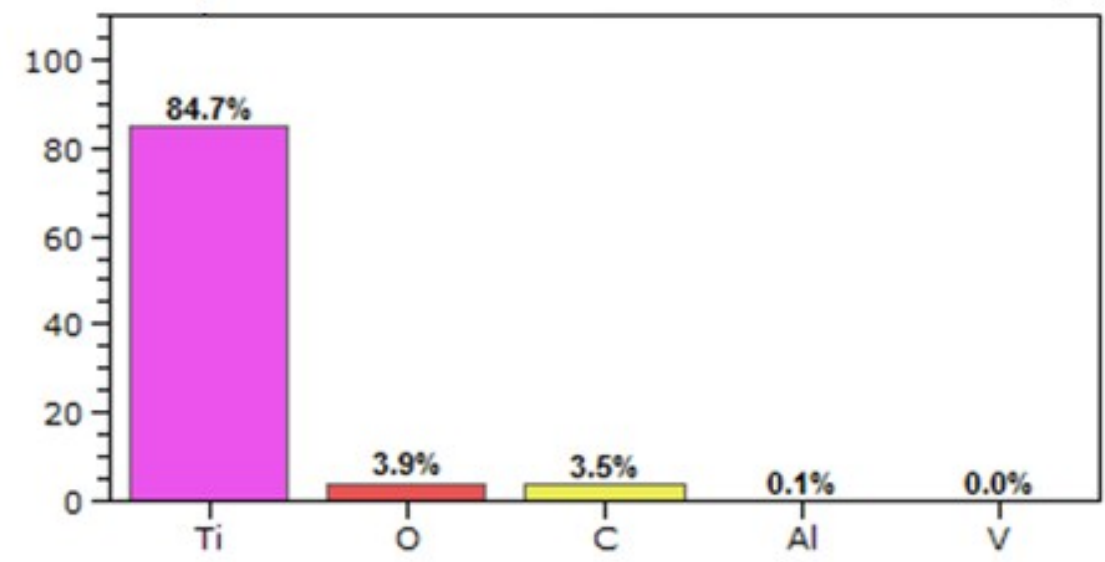

FIGURA 25 - Análise EDS da (A) borda dos LIPSS e (B) região central dos LIPSS

Na amostra irradiada com a presença do gás argônio não foram detectadas visualmente as presenças de óxidos nas extremidades dos passes do laser (FIG. 26). Da mesma forma, a análise química da região marginal dos passes laser demonstrou uma significante diminuição na presença do elemento oxigênio, onde foi encontrado em torno de 2\% (FIG. 27). 


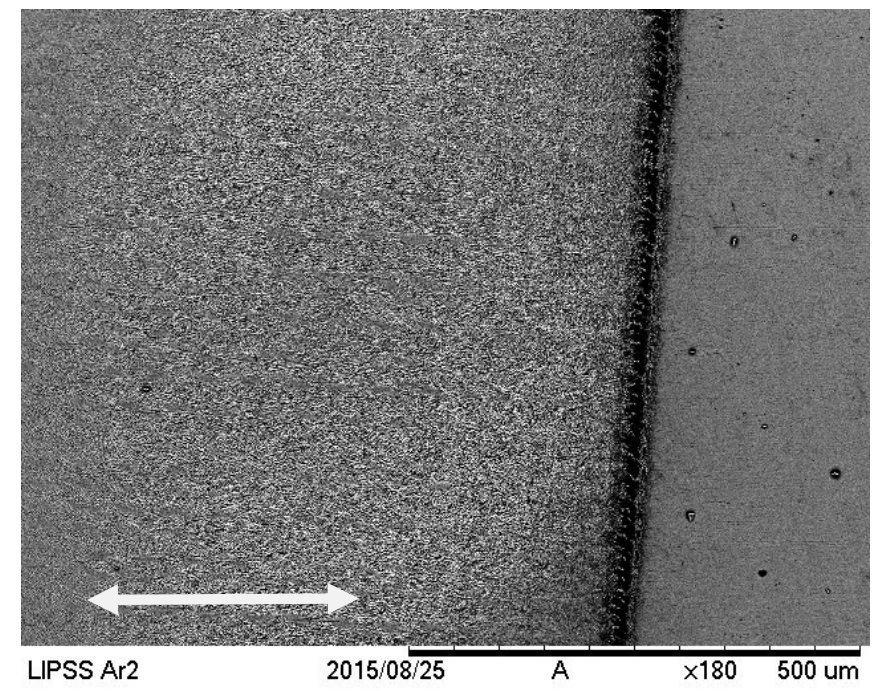

FIGURA 26 - Região de início e final dos passes laser. Não há evidencia visual da formação de óxidos. A dupla seta indica o sentido de varredura do laser.

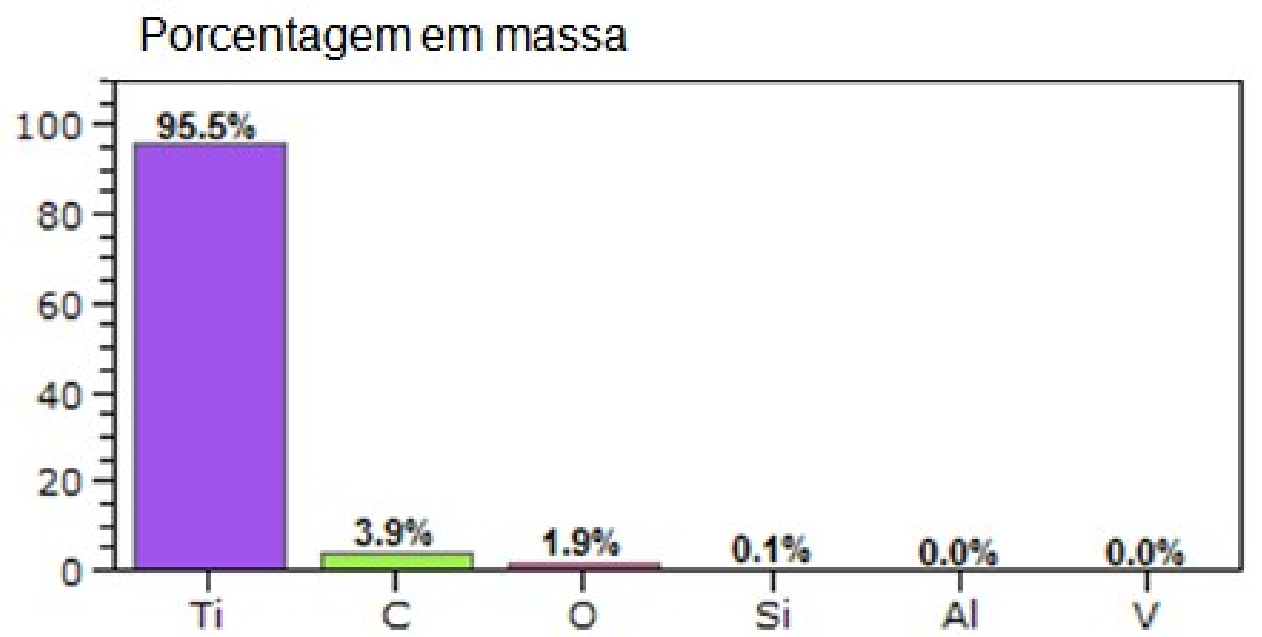

FIGURA 27 - Análise EDS dos LIPSS fabricados com atmosfera de Argônio.

Portanto, pode-se comprovar que, dependendo da taxa de sobreposição de pulsos, pode haver a formação de óxidos superficiais quando irradia-se Titânio Grau 2 com laser de femtossegundo. Todavia, tal formação pode ser suprimida com a irradiação do material em uma atmosfera de argônio $99,999 \%$. 
O efeito de formação de óxidos nas extremidades do passe laser não será levado em consideração nos experimentos seguintes por se tratar de uma região atípica no processo não valendo o custo absorvido pela utilização do gás de proteção.

\subsection{Análise da relação entre a fluência e a morfologia dos LIPSS}

Após a irradiação do material, os traços foram analisados em MEV com a finalidade de se caracterizar a morfologia dos LIPSS em função da fluência e da taxa de sobreposição utilizados em sua fabricação. Essas diferenças morfológicas podem ser constatadas nas FIG. 28, 29, 30 e 31 . 

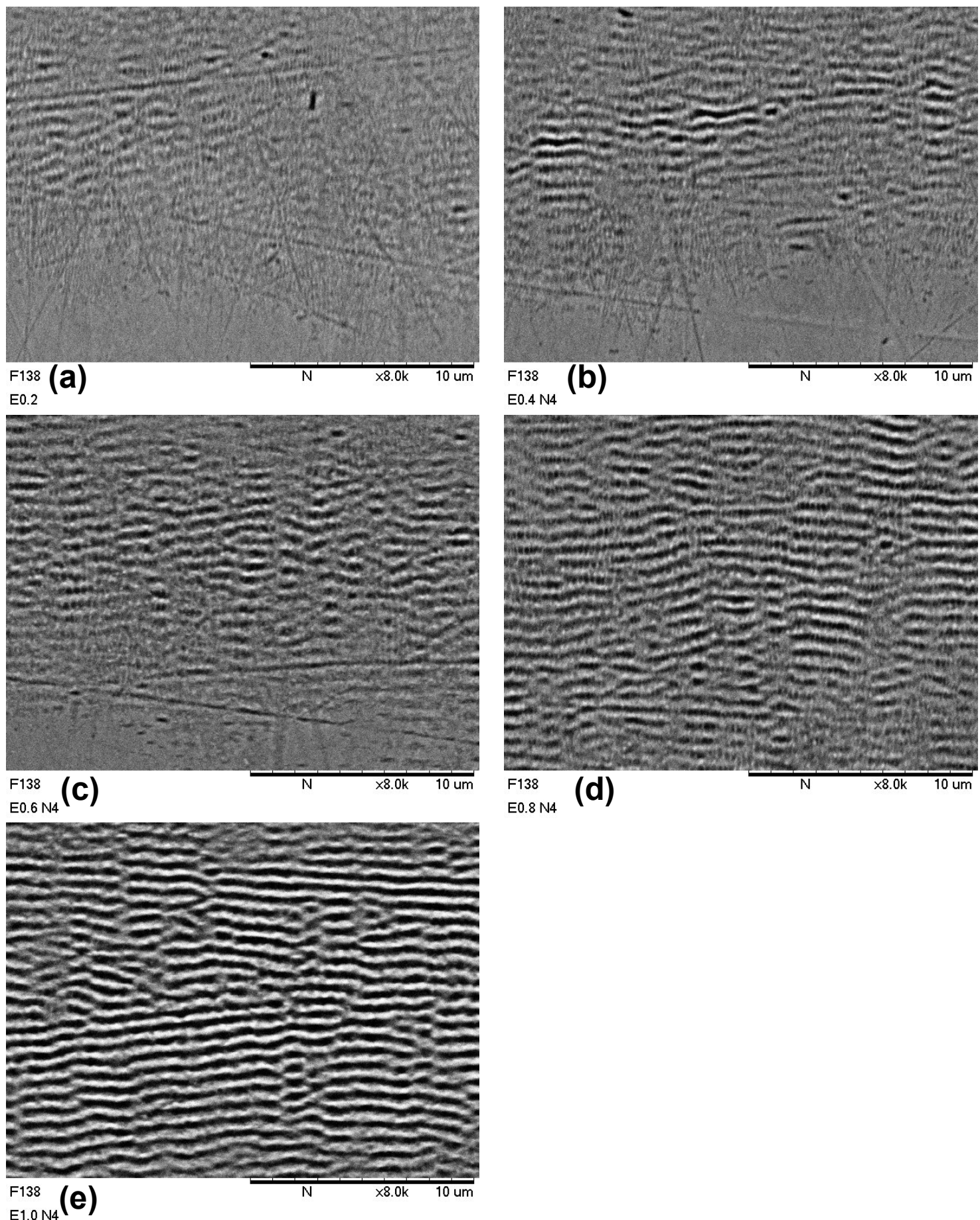

E08N4 (d)

FIGURA 28 - Micrografias das regiões irradiadas com taxa de sobreposição de 4 com fluências de (a) $0,09 \mathrm{~J} / \mathrm{cm}^{2}$, (b) $0,17 \mathrm{~J} / \mathrm{cm}^{2}$, (c) $0,26 \mathrm{~J} / \mathrm{cm}^{2}$, (d) $0,35 \mathrm{~J} / \mathrm{cm}^{2}$ e (e) $0,44 \mathrm{~J} / \mathrm{cm}^{2}$. 


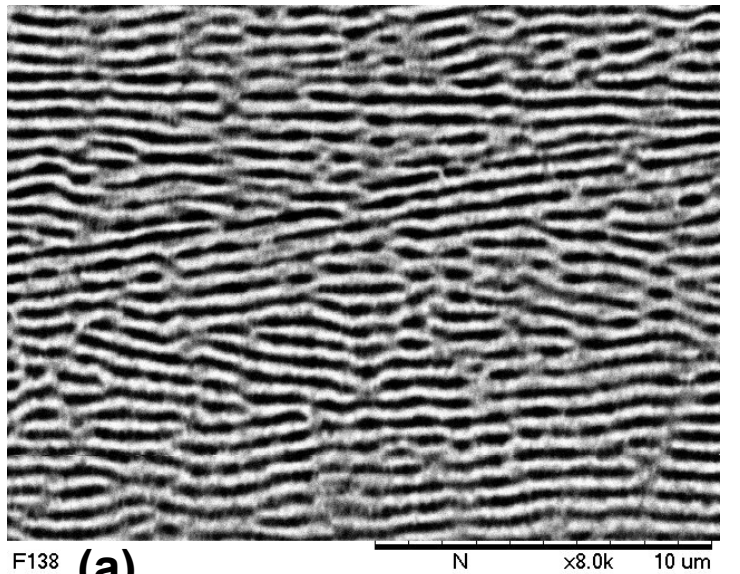

F138 (a)
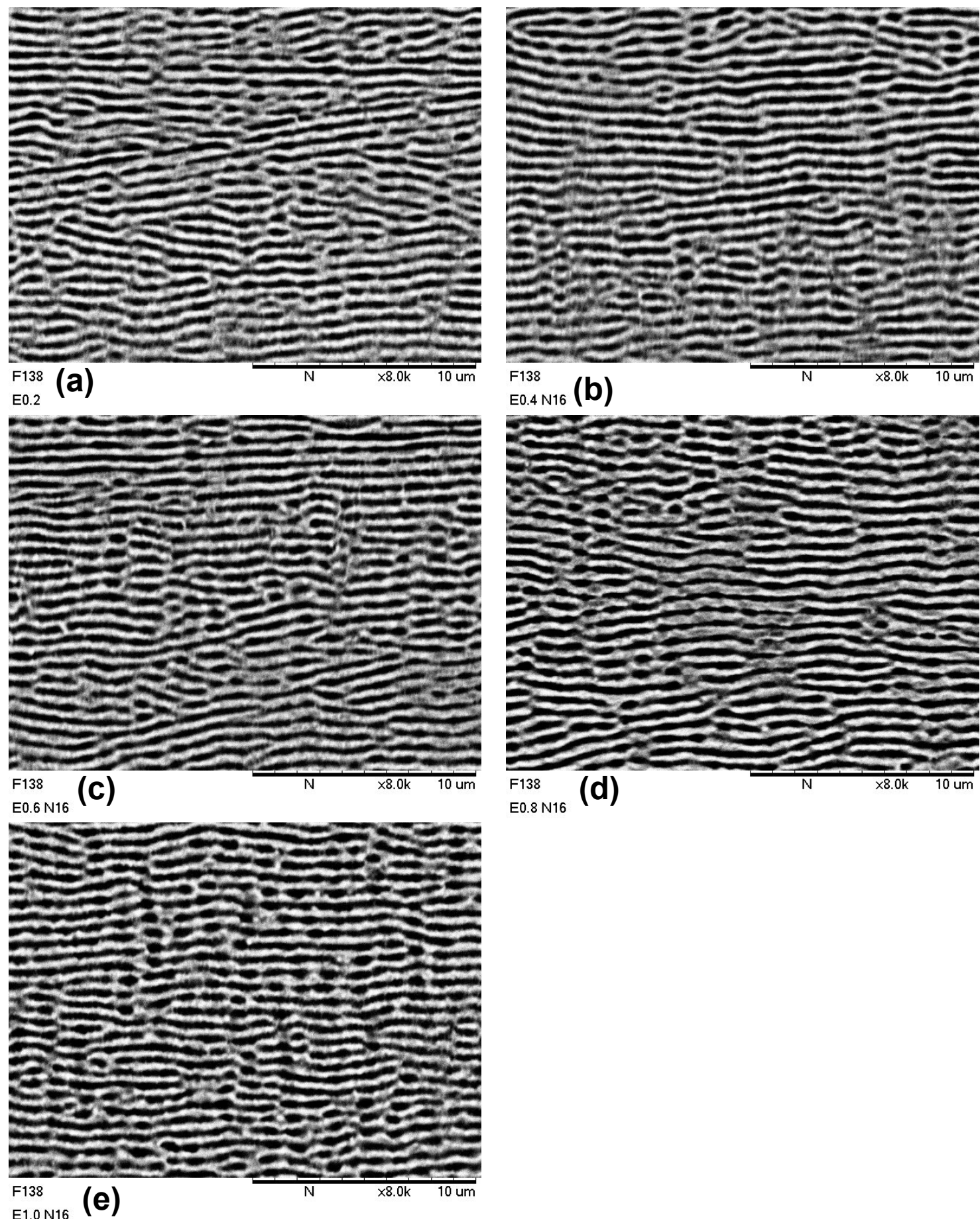

E0.8N16 (d)

FIGURA 29 - Micrografias das regiões irradiadas com taxa de sobreposição de 16 com fluências de (a) $0,09 \mathrm{~J} / \mathrm{cm}^{2}$, (b) $0,17 \mathrm{~J} / \mathrm{cm}^{2}$, (c) $0,26 \mathrm{~J} / \mathrm{cm}^{2}$, (d) $0,35 \mathrm{~J} / \mathrm{cm}^{2}$ e (e) $0,44 \mathrm{~J} / \mathrm{cm}^{2}$. 

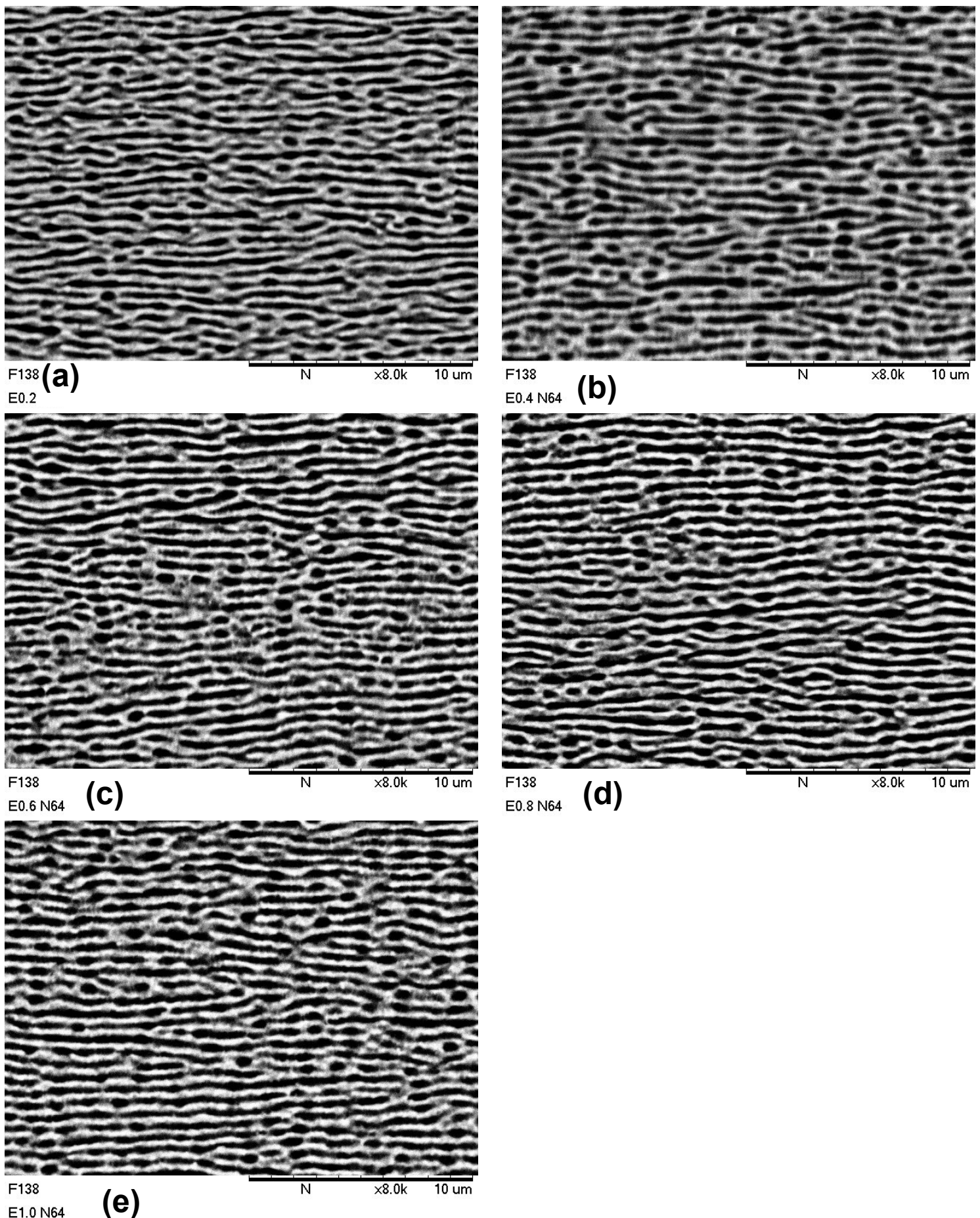

FIGURA 30 - Micrografias das regiões irradiadas com taxa de sobreposição de 64 com fluências de (a) $0,09 \mathrm{~J} / \mathrm{cm}^{2}$, (b) $0,17 \mathrm{~J} / \mathrm{cm}^{2}$, (c) $0,26 \mathrm{~J} / \mathrm{cm}^{2}$, (d) $0,35 \mathrm{~J} / \mathrm{cm}^{2} \mathrm{e}$ (e) $0,44 \mathrm{~J} / \mathrm{cm}^{2}$. 

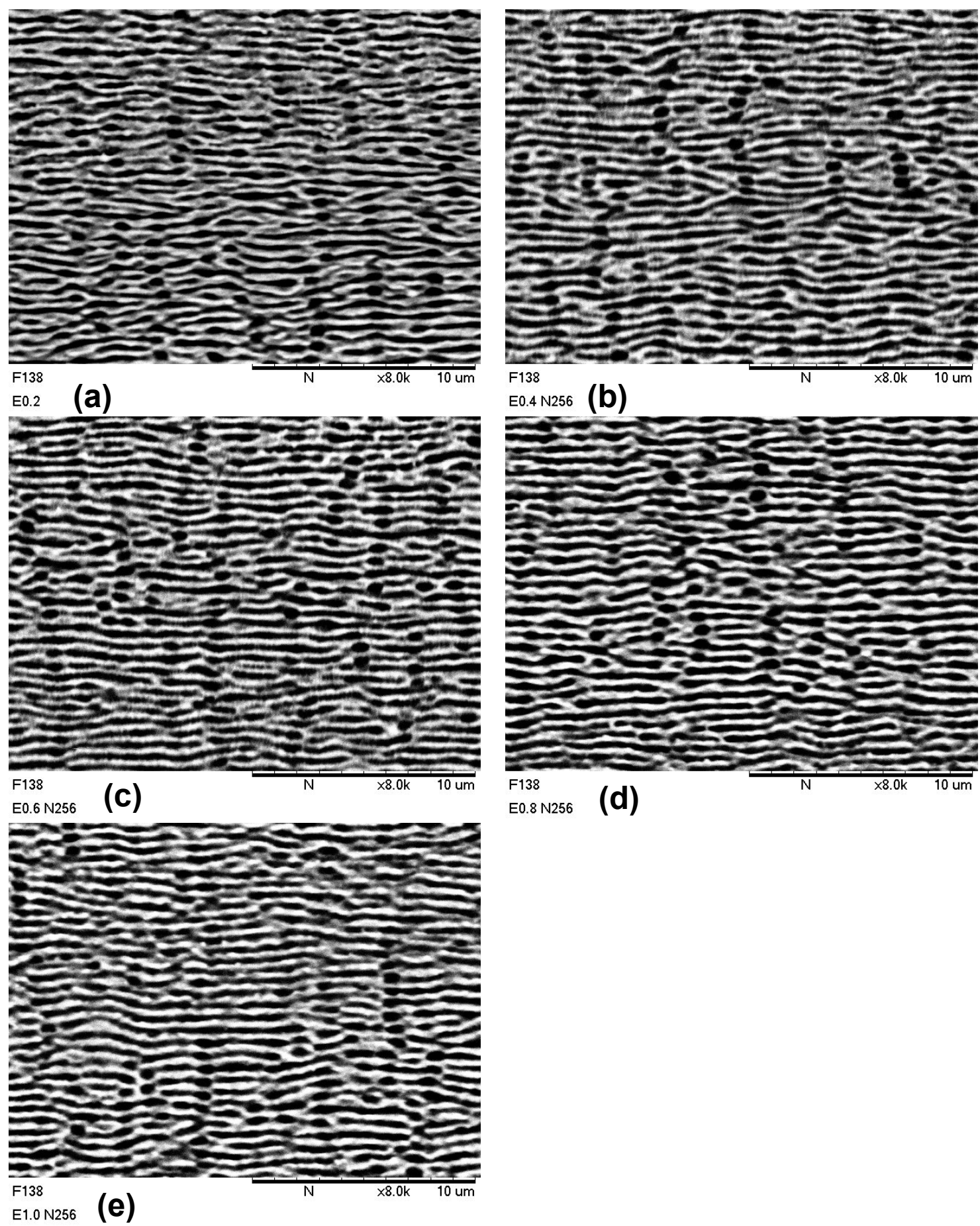

FIGURA 31 - Micrografias das regiões irradiadas com taxa de sobreposição de 256 com fluências de (a) $0,09 \mathrm{~J} / \mathrm{cm}^{2}$, (b) $0,17 \mathrm{~J} / \mathrm{cm}^{2}$, (c) $0,26 \mathrm{~J} / \mathrm{cm}^{2}$, (d) $0,35 \mathrm{~J} / \mathrm{cm}^{2}$ e (e) $0,44 \mathrm{~J} / \mathrm{cm}^{2}$.

As imagens obtidas foram processadas no software ImageJ para a obtenção de sua transformada rápida de Fourier (Fast Fourier Transform - FFT). Por meio das FFT, foi possível analisar detalhadamente a diferença na direção e 
paralelismo dos LIPSS, além de calcular, pelo software, seu período, conforme demonstrado nas figuras a seguir.
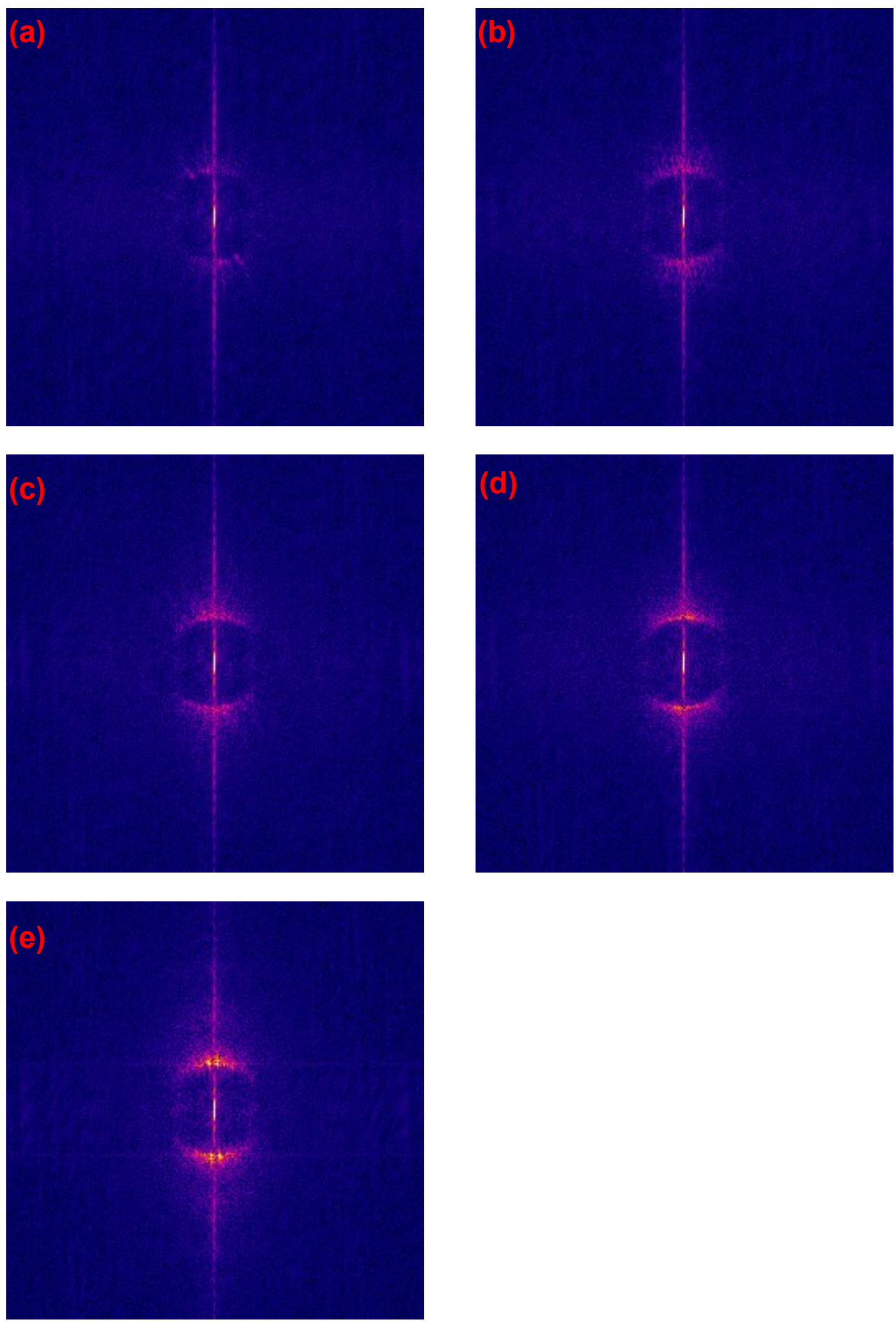

FIGURA 32 - FT das regiões irradiadas com taxa de sobreposição de $4 \mathrm{com}$ fluências de (a) $0,09 \mathrm{~J} / \mathrm{cm}^{2}$, (b) $0,17 \mathrm{~J} / \mathrm{cm}^{2}$, (c) $0,26 \mathrm{~J} / \mathrm{cm}^{2}$, (d) $0,35 \mathrm{~J} / \mathrm{cm}^{2}$ e (e) 0,44 $\mathrm{J} / \mathrm{cm}^{2}$. 
Estas figuras são representações do espaço recíproco da grade de difração real. Assim, a distância do centro da figura até o anel fornece o período da grade. A espessura do anel reflete a dispersão nos valores deste período. A abertura angular dos anéis estão associados à variação de direção das ranhuras da grade. Uma grade de difração perfeita teria uma figura de difração representada por um ponto na posição correspondente ao seu período (RODRÍGUEZ et al., 2015).

Nas figuras acima nota-se:

A variação angular total dos anéis parece não mudar com o aumento da fluência, contudo, há um aumento de intensidade concentrado no centro do semi-anel. O mesmo observa-se para a espessura do anel. 

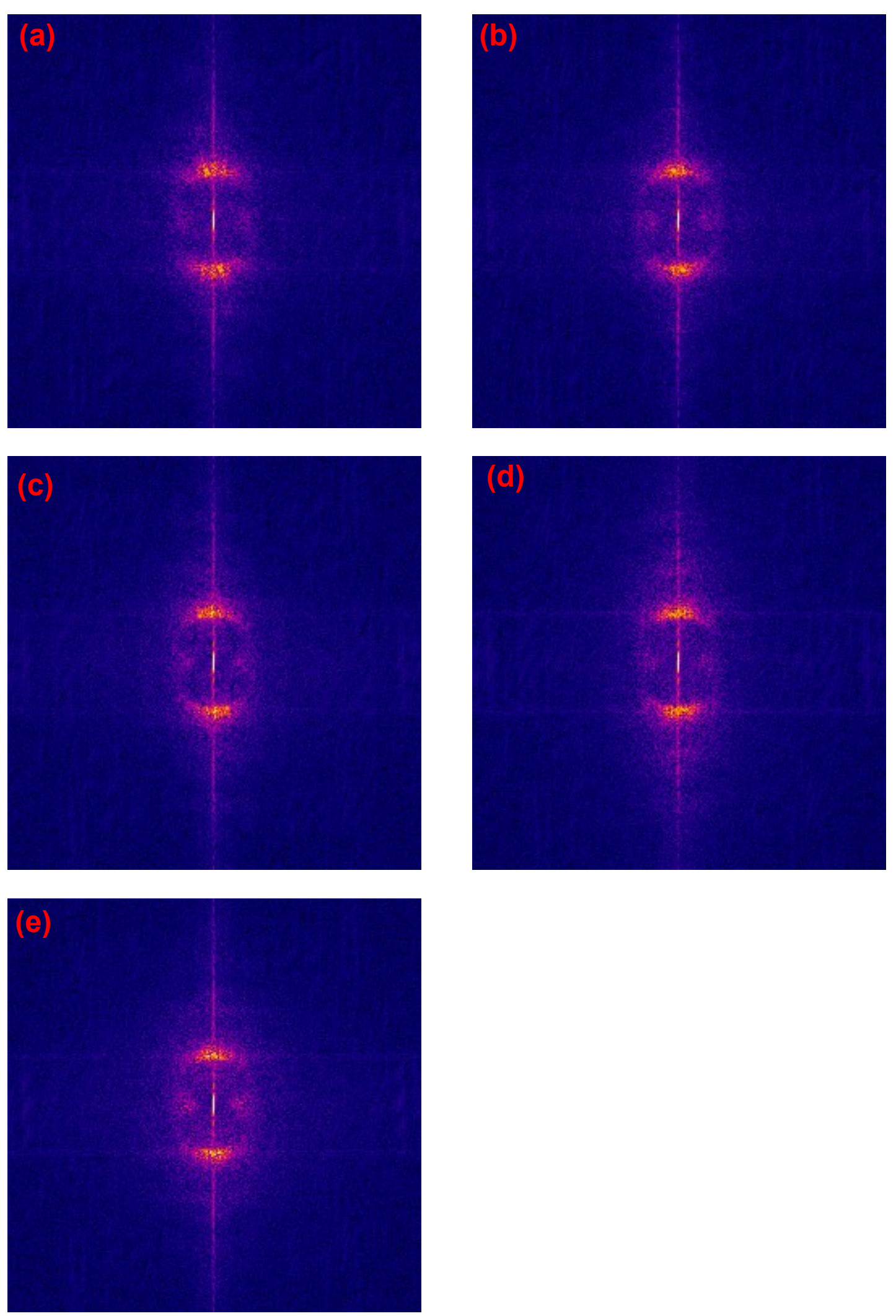

FIGURA 33 - - FFT das regiões irradiadas com taxa de sobreposição de 16 com fluências de (a) $0,09 \mathrm{~J} / \mathrm{cm}^{2}$, (b) $0,17 \mathrm{~J} / \mathrm{cm}^{2}$, (c) $0,26 \mathrm{~J} / \mathrm{cm}^{2}$, (d) $0,35 \mathrm{~J} / \mathrm{cm}^{2}$ e (e) 0,44 $\mathrm{J} / \mathrm{cm}^{2}$. 
O comportamento da figura de difração para a FIG. 32 é muito semelhante àquele da FIGURA 33 - - FFT das regiões irradiadas com taxa de sobreposição de $16 \mathrm{com}$ fluências de (a) $0,09 \mathrm{~J} / \mathrm{cm}^{2}$, (b) $0,17 \mathrm{~J} / \mathrm{cm}^{2}$, (c) 0,26 $\mathrm{J} / \mathrm{cm}^{2}$, (d) $0,35 \mathrm{~J} / \mathrm{cm}^{2}$ e (e) $0,44 \mathrm{~J} / \mathrm{cm}^{2}$.

A espessura dos anéis é um pouco maior que na FIGURA 32 - FT das regiões irradiadas com taxa de sobreposição de 4 com fluências de (a) 0,09 $\mathrm{J} / \mathrm{cm}^{2}$, (b) $0,17 \mathrm{~J} / \mathrm{cm}^{2}$, (c) $0,26 \mathrm{~J} / \mathrm{cm}^{2}$, (d) $0,35 \mathrm{~J} / \mathrm{cm}^{2}$ e (e) $0,44 \mathrm{~J} / \mathrm{cm}^{2}$. , mas a abertura angular não foi modificada.

Aqui, observa-se o aparecimento de difração em direção perpendicular aos anéis principais, com intensidade bem mais fraca, bem dispersa e correspondendo a um período maior que aquele associado aos LIPSS. 

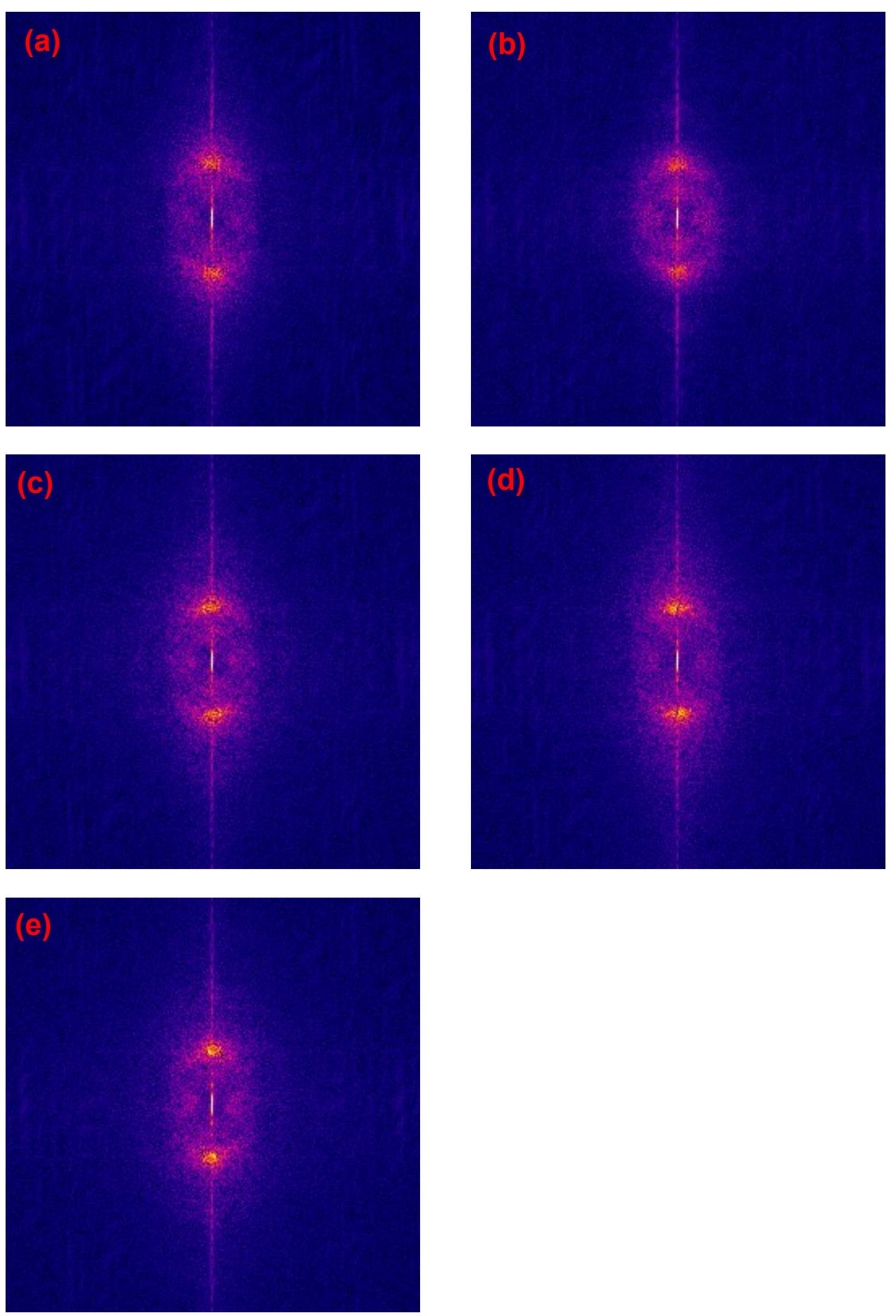

FIGURA 34 - FFT das regiões irradiadas com taxa de sobreposição de 64 com fluências de (a) $0,09 \mathrm{~J} / \mathrm{cm}^{2}$, (b) $0,17 \mathrm{~J} / \mathrm{cm}^{2}$, (c) $0,26 \mathrm{~J} / \mathrm{cm}^{2}$, (d) $0,35 \mathrm{~J} / \mathrm{cm}^{2}$ e (e) 0,44 $\mathrm{J} / \mathrm{cm}^{2}$. 
Na FIG. 34 a espessura dos anéis aumentou bastante, também com concentração de intensidade no centro do anel. A figura de difração perpendicular e mais central agora é mais acentuada e surge mesmo para as fluências mais baixas. Também se espalha para uma região angular maior. 

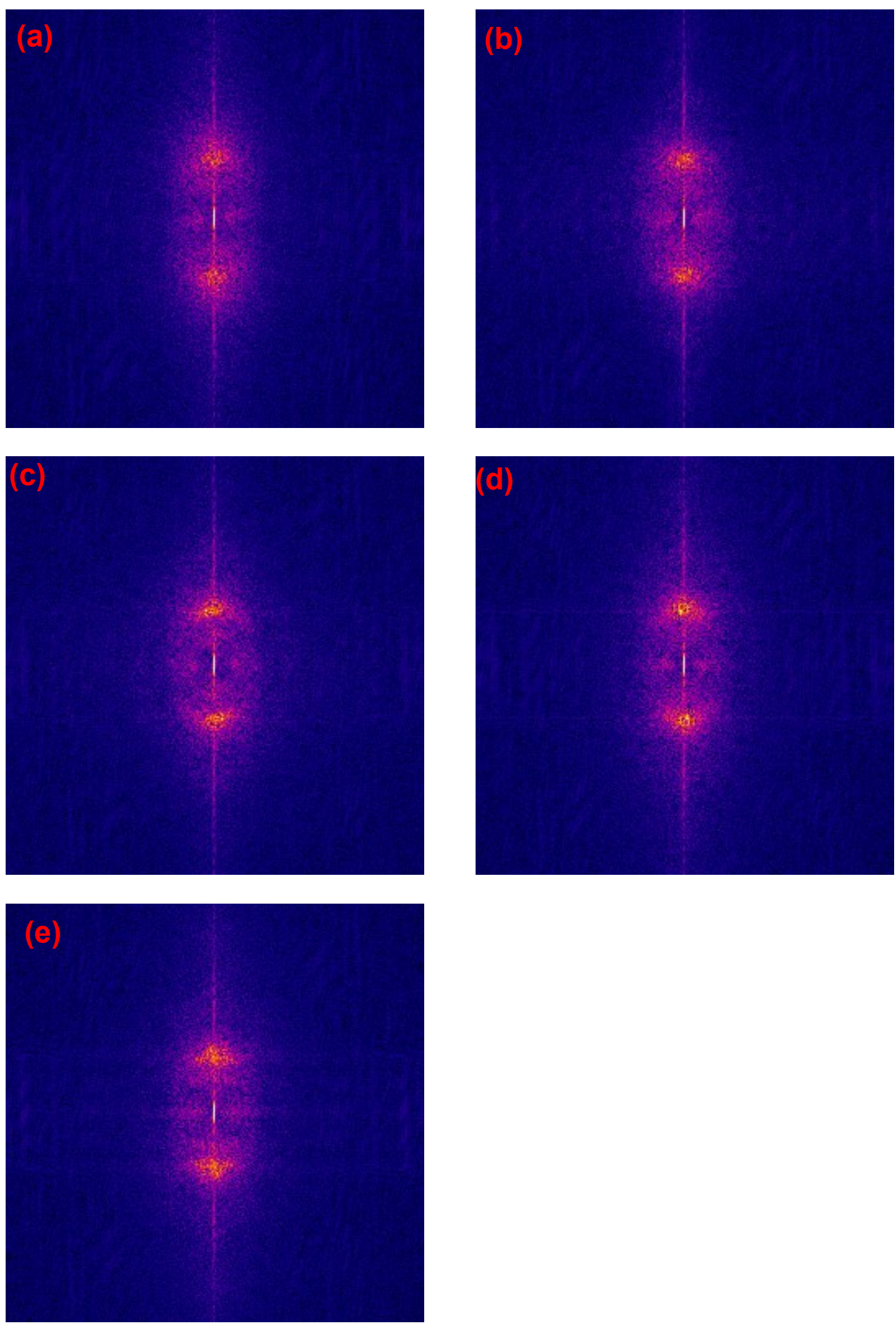

FIGURA 35 - FFT das regiões irradiadas com taxa de sobreposição de 256 com fluências de (a) $0,09 \mathrm{~J} / \mathrm{cm}^{2}$, (b) $0,17 \mathrm{~J} / \mathrm{cm}^{2}$, (c) $0,26 \mathrm{~J} / \mathrm{cm}^{2}$, (d) $0,35 \mathrm{~J} / \mathrm{cm}^{2}$ e (e) 0,44 $\mathrm{J} / \mathrm{cm}^{2}$. 
A FIGURA 35 - FFT das regiões irradiadas com taxa de sobreposição de 256 com fluências de (a) $0,09 \mathrm{~J} / \mathrm{cm}^{2}$, (b) $0,17 \mathrm{~J} / \mathrm{cm}^{2}$, (c) $0,26 \mathrm{~J} / \mathrm{cm}^{2}$, (d) 0,35 $\mathrm{J} / \mathrm{cm}^{2}$ e (e) $0,44 \mathrm{~J} / \mathrm{cm}^{2}$.

mostra um alargamento na espessura dos anéis. A parte central mais intensa dos anéis também está mais larga quando comparada àquelas da FIG. 34. A figura de difração perpendicular e mais central se aproxima do centro indicando um crescimento da estrutura correspondente a esta difração. Simultaneamente, ela abrange um ângulo bem maior, quase que completando todo o círculo.

A partir das imagens obtidas no MEV foi possível identificar que, em baixas fluências, a taxa de sobreposição de pulsos é um parâmetro importante na formação dos LIPPS, conforme pode ser visto na FIG. 28 (a) onde os LIPPS se formaram irregularmente. Entretanto, com a mesma fluência, mas com taxa de sobreposição N=256 (FIGURA 28 (e)), se pode notar o aumento na quantidade, linearidade e periodicidade das estruturas nanométricas.

Por meio das FFT foi possível concluir que os LIPSS não possuem lineariedade perfeita, ou seja, há outros fatores que influenciam a direção dos LIPSS além da polarização. Esses fatores, como demonstrados nas FFT por meio da mudança na abertura angular dos anéis, podem ser a própria fluência e a taxa de sobreposição. O efeito físico causador dessas diferenciações podem ser riscos provenientes da preparação da superfície do metal e/ou a rugosidade superficial, conforme já foi previsto em trabalhos anteriores (GUREVICH; GUREVICH, 2014; SIPE et al., 1983; YOUNG et al., 1983).

\subsection{Investigação da técnica de escurecimento do metal}


Após a comprovação da possibilidade de alteração da cor em metais nos experimentos anteriores, o próximo passo foi a obtenção de superfícies absorvedoras de luz, que causassem um efeito de escurecimento do metal. Tal escurecimento pode encontrar aplicações na área de marcação de metais a laser, ou seja, criação de logotipos, códigos de barras, códigos de rastreamento do material, etc.

Ou et al. (2014) obteve o escurecimento de metais através do controle da fluência do laser e obteve resultados de até $5 \%$ de reflectância. Neste trabalho, a fluência fixa foi mantida e variou-se a taxa $\mathrm{N}$ de sobreposição de pulsos, isso demanda menor ajustes no sistema laser, o que permite ter um ganho em produtividade. Em teoria, uma sobreposição maior acarreta em uma desfiguração dos LIPSS tradicionais, criando vazios mais espessos que aprisionam as ondas eletromagnéticas que, normalmente, seriam refletidas pelas nanoestruturas.

Após a incidência do feixe laser no aço, notaram-se alterações de sua coloração em função do ângulo de incidência da luz e o ângulo de visualização da amostra, conforme experimentos anteriores com titânio grau 2. Além disso, nas condições em que a velocidade de propagação do feixe é menor (i.e, maior taxa de sobreposição de pulsos) a região irradiada tornou-se preta, ou seja, absorvedora de luz (FIG. 36). 


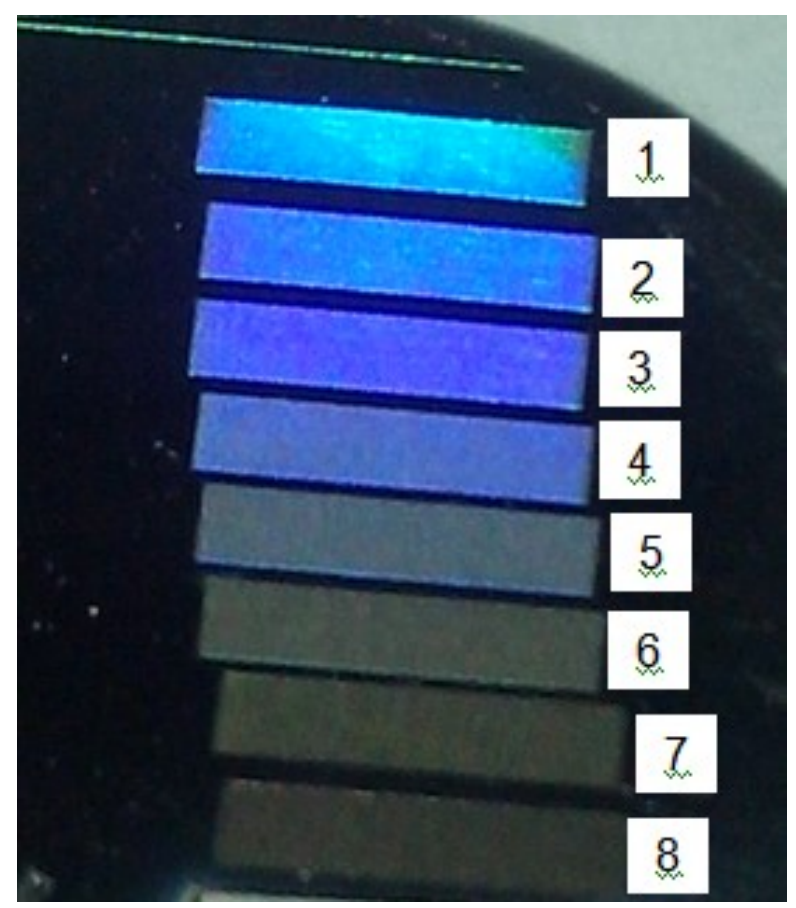

FIGURA 36 - Retângulos coloridos sobre a superfície do aço inoxidável austenítico ASTM F138 produzidos pela formação de LIPSS. O parâmetro de processo variado foi a sobreposição $\mathrm{N}$ de pulsos, regiões 1 a 8 .

Para entender o que causou essas mudanças na coloração do material, as regiões irradiadas foram analisadas em ampliações de 4000x. Em todas elas, como esperado, foram observadas as presenças de LIPSS. Pode-se notar que em maiores taxas de sobreposição as nanoestruturas tendem a perder a linearidade com tendência a formação de regiões granulares (FIG. 37 - regiões $6,7$ e 8$)$. 

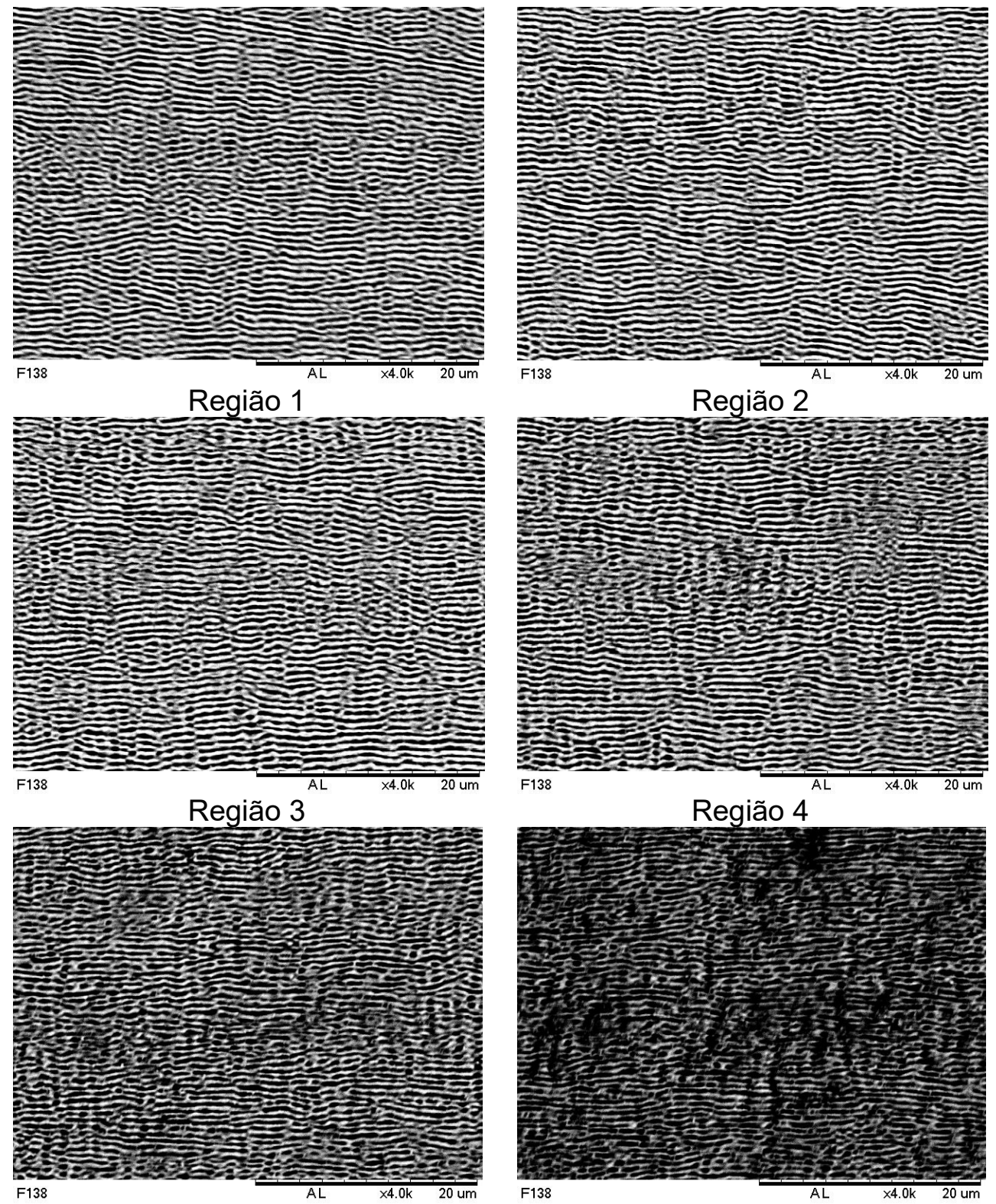

Região 5

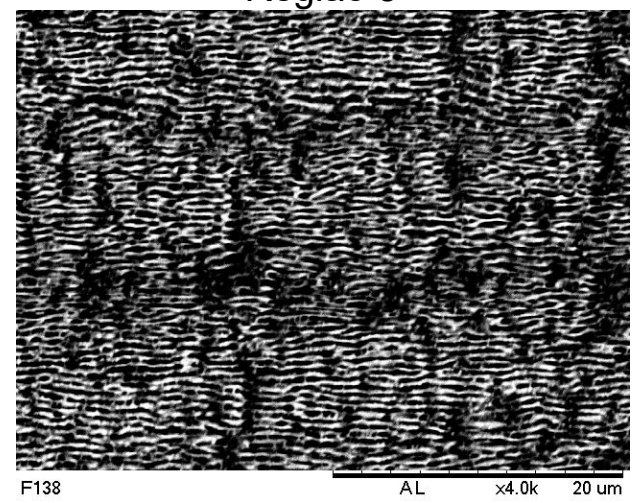

Região 7

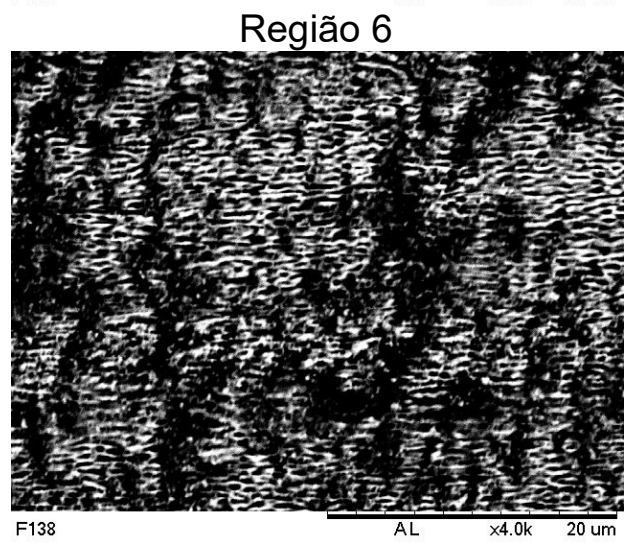

Região 8

FIGURA 37 - Microscopia eletrônica das regiões irradiadas. Quanto menor a taxa de sobreposição de pulsos, mais linearmente os LIPSS são criados (regiões 1, 2, 3 e 4). Ao aumentar a taxa de sobreposição os LIPSS perdem a linearidade adquirindo características granulares (regiões 5, 6, 7 e 8). 
Esse efeito de "quebra" dos LIPSS já foi observado por Oliveira et al. (2010) que demonstraram que as nanoestruturas, antes periódicas e lineares, tendem a assumir a forma colunar com o aumento da energia e da taxa de sobreposição de pulsos, o que justifica a ausência do efeito de mudança de cor nas condições com altas taxas de sobreposição de pulsos.

Na FIG. 38 são apresentadas as 3 amostras irradiadas com os parâmetros das regiões 1,4 e 8 , onde é possível observar que a amostra C alcançou maiores teores de absorção.

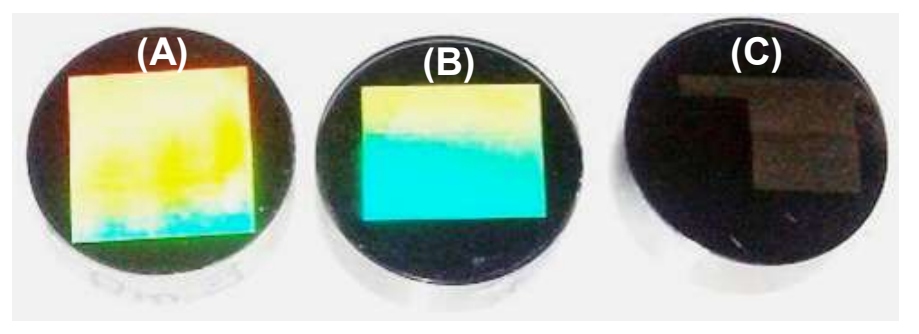

FIGURA 38 - Amostras utilizadas para análise de reflexão / absorção. As amostras (A), (B) e (C) foram irradiadas utilizando os parâmetros das Regiões 1, 4 e 8, respectivamente, da .

A FIG. 39 mostra o espectro de reflexão das 3 amostras, onde é possível constatar que a amostra (C) apresentou reflexão na faixa dos comprimentos de onda utilizados entre 4\% e 9\%. Para explicar essa grande absorção é necessário considerar as diferentes morfologias das nanoestruturas formadas (estruturas granulares, agulhas, nanocones, etc.). Como é possível perceber na análise por MEV demonstrada na FIG. 377 tais estruturas possuem dimensões que variam entre nanométricas até micrométricas. As estruturas menores, nanométricas, contribuem com a absorção através das interações destrutivas das ondas eletromagnéticas que refletem nos LIPSS (GHMARI et al., 2004). As estruturas maiores contribuem com a absorção através do aprisionamento de ondas eletromagnéticas nas cavidades formadas e através da 
dependência do ângulo de Fresnel para a reflexão. A soma desses processsos levam à uma forte absorção de luz que torna o metal escuro.

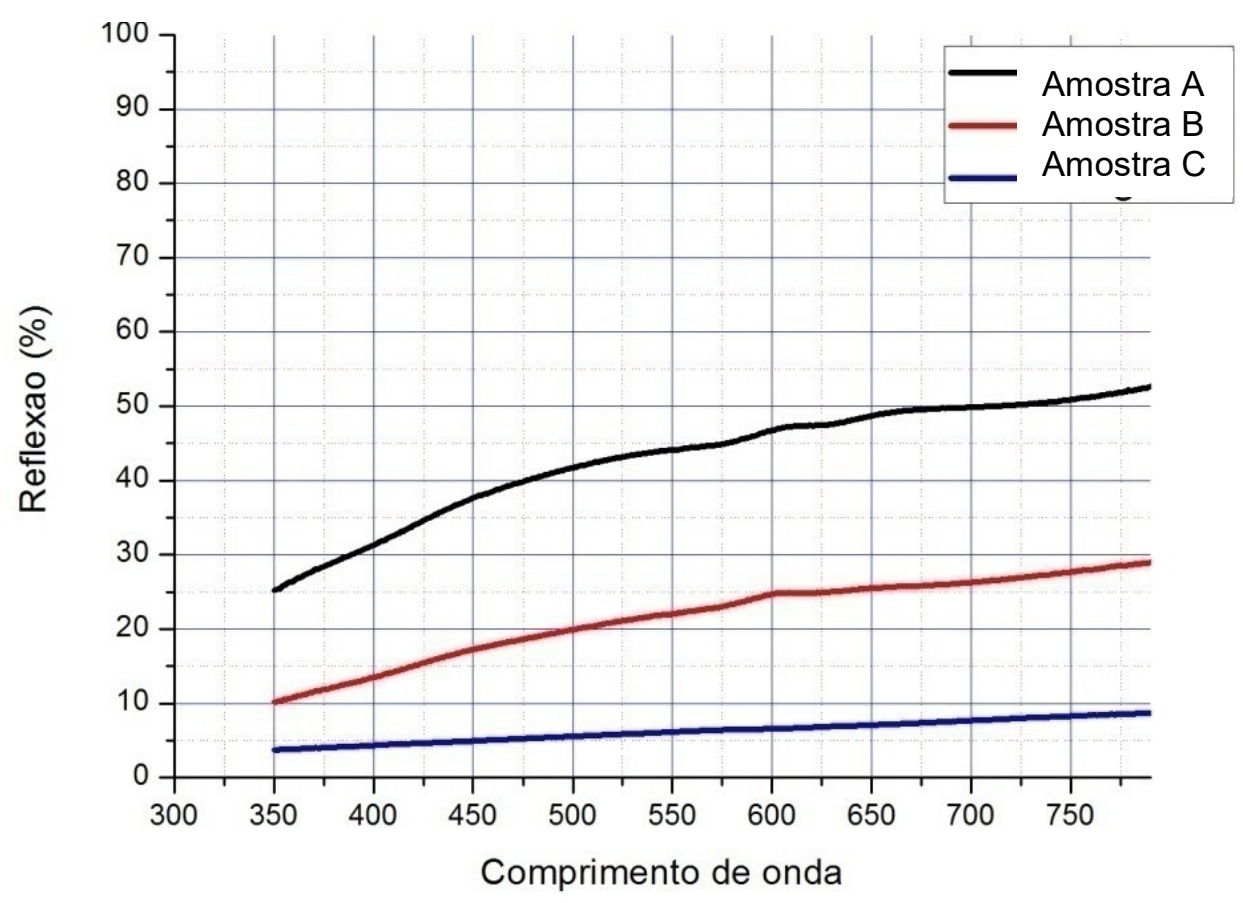

FIGURA 39 - Espectro de reflexão nas regiões 1, 4 e 8. Nota-se que na região com maior taxa de sobreposição de pulsos a absorção de luz alcança $5 \%$.

Esse resultado demonstra a possibilidade de marcação a laser utilizando altas taxas de sobreposição de pulsos, tendo alcançado os mesmos $5 \%$ de reflexão obtidos por Ou et al. (OU; HUANG; ZHAO, 2016)

A análise da intensidade dos comprimentos de onda refletidos obtidos após uma série de medidas está resumida na FIG. 40 onde mostra que nas duas condições de sobreposição de pulsos houve um deslocamento do espectro emitido do refletido, quantificando o efeito visual de mudança de cor. É possível concluir também que, na condição com maior sobreposição de pulsos a intensidade da luz refletida foi em média $60 \%$ menor. 


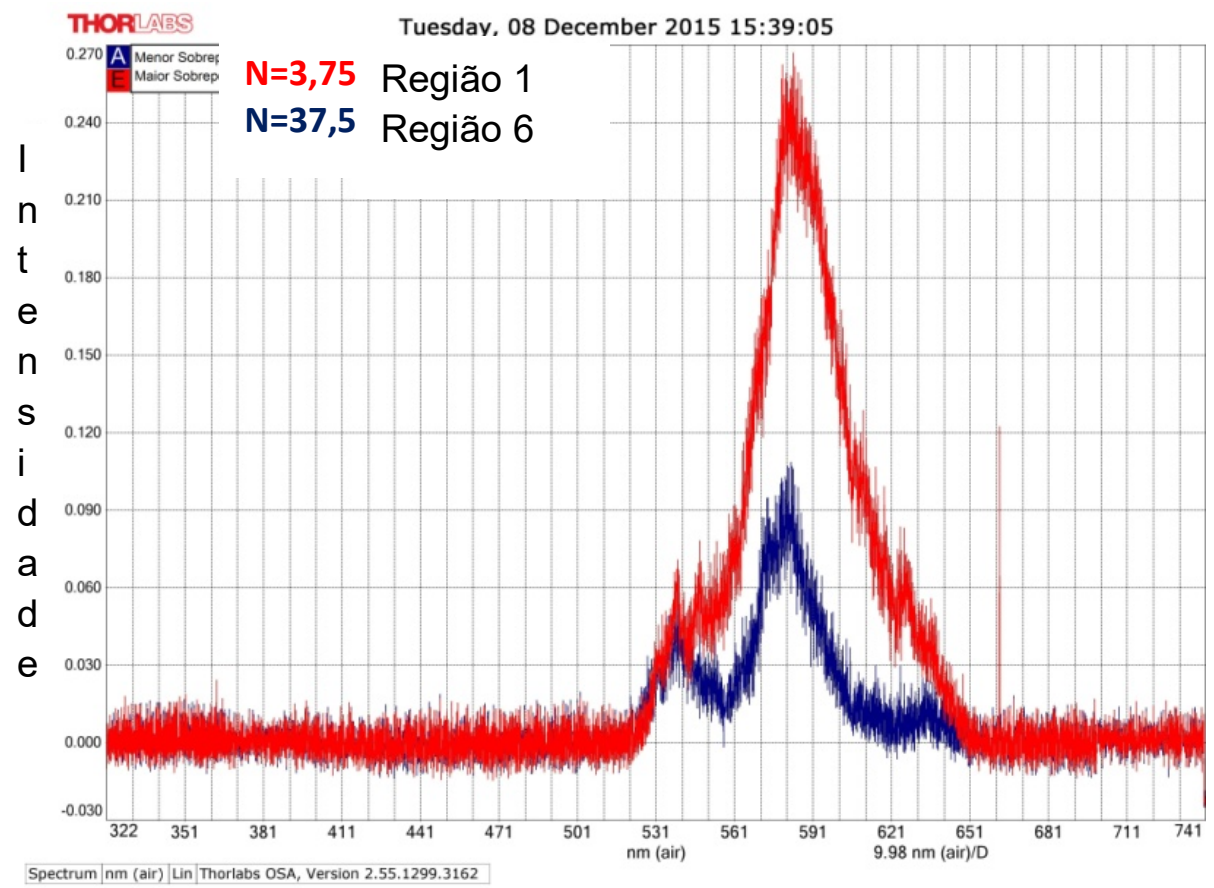

FIGURA 40 - Comparação da emissão em função da taxa de sobreposição de pulsos

\subsection{Avaliação de Dispositivo de Aquecimento}

Após análise dos resultados obtidos no item anterior, percebeu-se a possibilidade de se aproveitar a grande absorção de luz alcançada na amostra para a criação de um micro-aquecedor. Ou seja, a energia luminosa absorvida pelo material se converteria em energia térmica, aquecendo algum sistema de interesse, neste caso, o sistema de interesse é um circuito micro fluídico que será utilizado para crescimento controlado de cristais.

Após a irradiação da amostra foi realizada a análise de reflexão da área irradiada para verificar a capacidade teórica de absorção do dispositivo. Os resultados mostraram um comportamento idêntico ao apresentado na .

Os resultados das temperaturas alcançadas pelo dispositivo estão representados na FIG. 41 , onde é possível verificar um rápido aquecimento do material logo após o início da incidência do laser, até que ocorre uma estabilização da temperatura. Da mesma forma, no momento em que o feixe laser 
de He-Ne é interrompido a temperatura cai rapidamente, voltando a se estabilizar na temperatura ambiente.

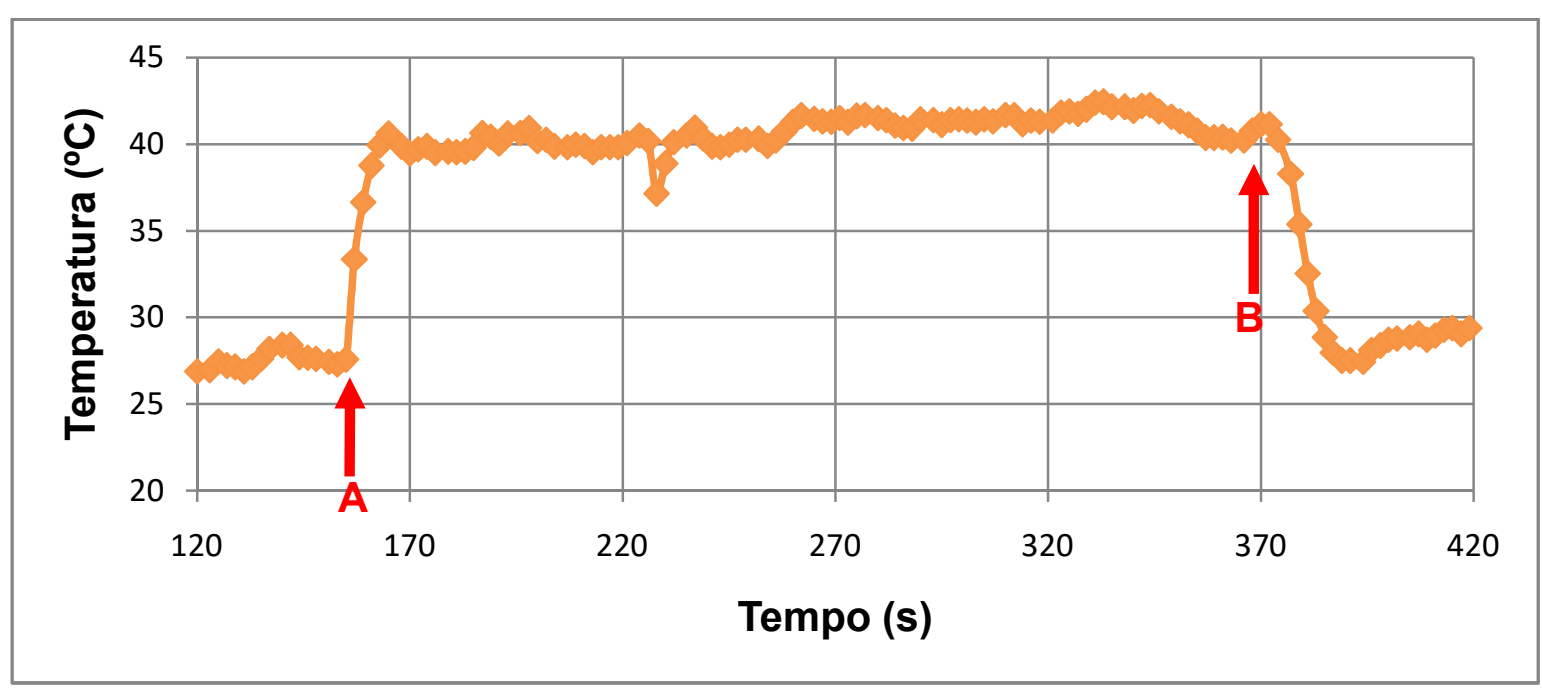

FIGURA 41 - Gráfico de Temperatura x Tempo obtido durante a utilização do dispositivo de aquecimento. Ponto (A): Início da incidência do Laser He-Ne, ponto (B): Término da incidência do Laser He-Ne.

Esta rápida variação da temperatura mostra uma inércia térmica multo baixa, o que é altamente desejável em aplicações de microfluídica. Aqui, não se pretendeu atingir temperaturas mais altas, mas apenas demonstrar a utilizada destas superfícies para este uso. Neste experimento, a temperatura máxima atingida está limitada não somente pela baixa potência do laser, mas também pela grande massa do termopar (comparada com a da placa) e pela falta de isolamento térmico.

Com esse experimento foi possível concluir que é possível construir as bases do dispositivo para aquecimento de circuitos microfluídicos, fazendo o uso da técnica de escurecimento, onde é necessário um dispositivo com dimensões na ordem micrométrica e que tenha um fácil controle da temperatura alcançada. Detalhes do dispositivo estão no pedido de patente que está sendo submetido ao INPI. 


\section{CONCLUSÕES}

Com base no que foi apresentado, foi possível concluir que a produção de LIPSS é influenciada pela fluência do laser, polarização do feixe e utilização de gases protetivos. Notou-se também que, o período dos LIPSS não é alterado por nenhum dos parâmetros alterados nesse trabalho, pois tal propriedade está intimamente ligada com o comprimento de onda do laser utilizado.

A partir da análise visual das amostras irradiadas com laser de femtossegundo nas condições apresentadas no decorrer do trabalho, é possível comprovar que a formação das nanoestruturas periódicas causa uma alteração na coloração do metal. Entretanto, o aspecto visual não é alterado para uma cor fixa, e sim para um conjunto de cores correspondentes ao espectro de luz visível ao olho humano. Esse efeito ocorre pelo fato de as nanoestruturas periódicas atuarem como uma grade de difração na superfície do metal refletindo cores que são uma função do ângulo de incidência e do ângulo de visualização.

Pode-se também observar que ao modificar as condições de irradiação, é possível criar uma superfície absorvedora de luz, ou seja, a superfície do metal fica com coloração preta, onde se pode tomar proveito da grande absorção da superfície para a criação de dispositivos aquecedores com alto rendimento e amplitude térmica. 


\section{REFERÊNCIAS BIBLIOGRÁFICAS}

1. AHMMED, K. M. T.; LING, E. J. Y.; SERVIO, P.; KIETZIG, A.-M. Introducing a new optimization tool for femtosecond laser-induced surface texturing on titanium, stainless steel, aluminum and copper. Optics and Lasers in Engineering, v. 66, p. 258-268, 2015.

2. AHSAN, M. S.; AHMED, F.; KIM, Y. G.; LEE, M. S.; JUN, M. B. G. Colorizing stainless steel surface by femtosecond laser induced micro/nano-structures. Applied Surface Science, v. 257, n. 17, p. 7771-7777, 2011.

3. B.N. CHICBKOV, C. MOMMA, S. NOLTE, F. YON ALVENSLEBEN, A. T. Femtosecond, picosecond and nanosecond laser ablation of solids. Applied Physics A, v. 115, p. 109-115, 1996.

4. BIRNBAUM, M. Semiconductor Surface Damage Produced by Ruby Lasers. Journal of Applied Physics, v. 36, n. 11, p. 3688-3689, 1965.

5. BONSE, J.; KOTER, R.; HARTELT, M.; SPALTMANN, D.; PENTZIEN, S.; HÖHM, S.; ROSENFELD, a.; KRÜGER, J. Tribological performance of femtosecond laser-induced periodic surface structures on titanium and a high toughness bearing steel. Applied Surface Science, v. 336, p. 21-27, 2015.

6. BONSE, J.; ROSENFELD, A.; KRÜGER, J. On the role of surface plasmon polaritons in the formation of laser-induced periodic surface structures upon irradiation of silicon by femtosecond-laser pulses. Journal of Applied Physics, v. 106, n. 10, p. 104910, 2009.

7. BOROWIEC, A.; HAUGEN, H. K. Subwavelength ripple formation on the surfaces of compound semiconductors irradiated with femtosecond laser pulses. Applied Physics Letters, v. 82, n. 25, p. 4462-4464, 2003. 
8. CANGUEIRO, L. T.; VILAR, R. Mechanisms of formation of low spatial frequency LIPSS on Ni / Ti reactive multilayers. Journal of Physics D: Applied Physics, v. 49, n. 36, 2016.

9. CASSIE, A. B. D.; BAXTER, S. Wettability of porous surface. Transactions of the Faraday Society, v. 40, p. 546-551, 1944.

10. CUNHA, A. Multiscale femtosecond laser surface texturing of titanium and titanium alloys for dental and orthopaedic implants multiscale femtosecond laser surface texturing of titanium and titanium alloys for dental and orthopaedic implants. 2015. Tese - Universidade de Lisboa, Lisboa.

11. CUNHA, A.; SERRO, A. P.; OliVEIRA, V.; ALMEIDA, A.; VILAR, R.; DURRIEU, M.-C. Wetting behaviour of femtosecond laser textured Ti-6Al-4V surfaces. Applied Surface Science, v. 265, p. 688-696, 2013.

12. DUSSER, B.; SAGAN, Z.; SODER, H.; FAURE, N.; COLOMBIER, J. P.; JOURLIN, M.; AUDOUARD, E. Controlled nanostructrures formation by ultra fast laser pulses for color marking. Optics express, v. 18, n. 3, p. 2913-2924, 2010.

13. EICHSTADT, J.; ROMER, G. R. B. E.; HUIS IN 'T VELD, A. J. Determination of irradiation parameters for laser-induced periodic surface structures. Applied Surface Science, v. 264, p. 79-87, 2013.

14. EMMONY, D. C. Laser mirror damage in germanium at $10.6 \mu \mathrm{m}$. Applied Physics Letters, v. 23, n. 11, p. 598, 1973.

15. GHMARI, F.; GHBARA, T.; LAROCHE, M.; CARMINATI, R.; GREFFET, J. J. Influence of microroughness on emissivity. Journal of Applied Physics, v. 96, n. 5, p. 2656-2664, 2004. 
16. GNILITSKYI, I.; ROTUNDO, F.; MARTINI, C.; PAVLOV, I.; ILDAY, S.; VOVK, E.; ÖMER, F.; ORAZI, L. Tribology International Nano patterning of AISI 316L stainless steel with Nonlinear Laser Lithography : Sliding under dry and oil-lubricated conditions. Tribiology International, v. 99, p. 67-76, 2016.

17. GUO, C.; VOROBYEV, A. Y. Black Metals Produced by Femtosecond Laser Pulses.In International Symposium on High Power Laser Ablation. American Institute of Physics 2010.

18. GUREVICH, E. L.; GUREVICH, S. V. Laser Induced Periodic Surface Structures induced by surface plasmons coupled via roughness. Applied Surface Science, v. 302, p. 118-123, 2014.

19. UANG, M.; ZHAO, F.; CHENG, Y.; XU, N.; XU, Z. Origin of Laser-Induced Near-Subwavelength Ripples: Interference between Surface Plasmons and Incident Laser. ACS Nano, v. 3, n. 12, p. 4062-4070, 2009.

20. HWANG, T. Y.; GUO, C. Angular effects of nanostructure-covered femtosecond laser induced periodic surface structures on metals. Journal of Applied Physics, v. 108, n. 7, p. 1-5, 2010.

21. IONIN, A. a.; KUDRYASHOV, S. I.; MAKAROV, S. V.; SELEZNEV, L. V.; SINITSYN, D. V.; GOLOSOV, E. V.; GOLOSOVA, O. a.; KOLOBOV, Y. R.; LIGACHEV, A. E. Femtosecond laser color marking of metal and semiconductor surfaces. Applied Physics A, v. 107, n. 2, p. 301-305, 2012.

22. JOHNSTON JR., T. F. M2 concept characterizes beam qualit. Laser Focus World, v. 26, p. 173-183, 1990

23. KEILMANN, F.; BAI, Y. H. Periodic surface structures frozen into CO2 lasermelted quartz. Applied Physics A Solids and Surfaces, v. 29, n. 1, p. 9-18, 1982. 
24. LI, G.; LI, J.; HU, Y.; ZHANG, C.; LI, X.; CHU, J.; HUANG, W. Realization of diverse displays for multiple color patterns on metal surfaces. Applied Surface Science, v. 316, p. 451-455, $2014 a$.

25. LI, G.; LI, J.; HU, Y.; ZHANG, C.; LI, X.; CHU, J.; HUANG, W. Femtosecond Laser Color Marking Stainless Steel Surface with Different Wavelengths. Applied Physics A, v. 118, n. 4, p. 1189-1196, 9 nov. 2014b.

26. MACHADO, L. M. Microusinagem de dielétricos com pulsos laser de femtossegundos. 2012. Universidade de São Paulo, 2012.

27. MIRIM, D. de C. Desenvolvimento de processos de microusinagem com laser de pulsos ultracurtos. 2016. 2016.

28. MIZUNO, A.; HONDA, T.; KIUCHI, J.; IWAI, Y.; YASUMARU, N.; MIYAZAKI, K. Friction Properties of the DLC Film with Periodic Structures in Nano-scale. v. 2, p. 44-48, 2006.

29. NAYAK, B. K.; GUPTA, M. C.; KOLASINSKI, K. W. Formation of nanotextured conical microstructures in titanium metal surface by femtosecond laser irradiation. Applied Physics A, v. 90, n. 3, p. 399-402, 2008.

30. NOLTE, S. Micromachining. In: FERMAN, M. E.; GALVANAUSKAS, A.; GREGG SUCHA (Ed.). Ultrafast Lasers: Technology and Applications. [s.I.] Marcel Denker, 2003. p. 359-395.

31. NOLTE, S.; MOMMA, C.; JACOBS, H.; TU, A.; CHICHKOV, B. N.; WELLEGEHAUSEN, B.; WELLING, H. Ablation of metals by ultrashort laser pulses. Journal of the Optical Society of America B, v. 14, n. 10, p. 27162722, 1997. 
32. OKAMURO, K.; HASHIDA, M.; MIYASAKA, Y.; IKUTA, Y.; TOKITA, S.; SAKABE, S. Laser fluence dependence of periodic grating structures formed on metal surfaces under femtosecond laser pulse irradiation. Physical Review B, v. 82, n. 16, p. 165417, 2010.

33. OLIVEIRA, V.; CUNHA, a.; VILAR, R. Multi-scaled femtosecond laser structuring of stationary titanium surfaces. Journal of Optoelectronics and Advanced Materials, v. 12, n. 3, p. 654-658, 2010.

34. OU, Z.; HUANG, M.; ZHAO, F. Colorizing pure copper surface by ultrafast laser-induced near-subwavelength ripples. Optics Express, v. 22, n. 14, p. $17254,2014$.

35. OU, Z.; HUANG, M.; ZHAO, F. The fluence threshold of femtosecond laser blackening of metals: The effect of laser-induced ripples. Optics and Laser Technology, v. 79, p. 79-87, 2016.

36. QI, J.; WANG, K. L.; ZHU, Y. M. A study on the laser marking process of stainless steel. Journal of Materials Processing Technology, v. 139, n. 1-3 SPEC, p. 273-276, 2003.

37. REIF, J.; MARTENS, C.; UHLIG, S.; RATZKE, M.; VARLAMOVA, O.; VALETTE, S.; BENAYOUN, S. On large area LIPSS coverage by multiple pulses. Applied Surface Science, v. 336, p. 249-254, 2015.

38. RODRÍGUEZ, A.; MORANT-M NANA, M. C.; DIAS-PONTE, A.; MARTÍNEZCALDERÓN, M.; GÓMEZ-ARANZADI, M.; OLAIZOLA, S. M. Femtosecond laser-induced periodic surface nanostructuring of sputtered platinum thin films. Applied Surface Science, v. 351, p. 135-139, 2015.

39. SAMAD, R. E.; MACHADO, L. M.; JUNIOR, N. D. V.; DE ROSSI, W. Ultrashort Laser Pulses Machining. 2012. 
40. SAVOLAINEN, J.-M.; CHRISTENSEN, M. S.; BALLING, P. Material swelling as the first step in the ablation of metals by ultrashort laser pulses. Physical Review B, v. 84, n. 19, p. 193410, 2011.

41. SILVA, L. G. da. Caracterização da liga super duplex uns32750 soldada por laser pulsado de Nd:YAG. Faculdade de Tecnologia de São Paulo - FATECSP, 2013.

42. SIPE, J. E.; YOUNG, J. F.; PRESTON, J. S.; VAN DRIEL, H. M. Laserinduced periodic surface structure. I. Theory. Physical Review B, v. 27, n. 2, p. 1141-1154, 1983.

43. TSIBIDIS, G. D.; FOTAKIS, C.; STRATAKIS, E. From ripples to spikes: A hydrodynamical mechanism to interpret femtosecond laser-induced selfassembled structures. Physical Review B, v. 92, n. 4, p. 041405, 2015.

44. UMM-I-KALSOOM; BASHIR, S.; ALI, N.; AKRAM, M.; MAHMOOD, K.; AHMAD, R. Effect of ambient environment on excimer laser induced micro and nano-structuring of stainless steel. Applied Surface Science, v. 261, p. 101-109, 2012.

45. UPADHYAY, A. K.; INOGAMOV, N. a.; RETHFELD, B.; URBASSEK, H. M. Ablation by ultrashort laser pulses: Atomistic and thermodynamic analysis of the processes at the ablation threshold. Physical Review B, v. 78, n. 4, p. $045437,2008$.

46. VARLAMOVA, O. Evolution of Femtosecond Laser Induced Surface Structures at Low Number of Pulses near the Ablation Threshold. Journal of Laser Micro/Nanoengineering, v. 8, n. 3, p. 300-303, 2013.

47. VOROBYEV, a. Y.; GUO, C. Colorizing metals with femtosecond laser pulses. Applied Physics Letters, v. 92, n. 4, p. 041914, 2008a. 
48. VOROBYEV, a. Y.; GUO, C. Multifunctional surfaces produced by femtosecond laser pulses. Journal of Applied Physics, v. 117, n. 3, p. $033103,2015$.

49. VOROBYEV, a. Y.; MAKIN, V. S.; GUO, C. Periodic ordering of random surface nanostructures induced by femtosecond laser pulses on metals. Journal of Applied Physics, v. 101, n. 3, p. 034903, 2007.

50. VOROBYEV, A. Y.; GUO, C. Femtosecond laser structuring of titanium implants. Applied Surface Science, v. 253, n. 17, p. 7272-7280, 2007.

51. VOROBYEV, A. Y.; GUO, C. Femtosecond laser-induced periodic surface structure formation on tungsten. Journal of Applied Physics, v. 104, n. 6, p. 17-20, 2008b.

52. VOROBYEV, A. Y.; GUO, C. Direct femtosecond laser surface nano/microstructuring and its applications. Laser \& Photonics Reviews, v. 7 , n. 3, p. 385-407, 2013.

53. WENZEL, R. N. Resistance of solid surfaces to wetting by water. Journal of Industrial and Engineering Chemistry (Washington, D. C.), v. 28, p. 988-994, 1936.

54. YAO, J.; ZHANG, C.; LIU, H.; DAI, Q.; WU, L.; LAN, S.; GOPAL, A. V.; TROFIMOV, V. a.; LYSAK, T. M. Selective appearance of several laserinduced periodic surface structure patterns on a metal surface using structural colors produced by femtosecond laser pulses. Applied Surface Science, v. 258, n. 19, p. 7625-7632, 2012.

55. YOUNG, J. F.; PRESTON, J. S.; DRIEL, H. M. Van; SIPE, J. E. Laserinduced periodic surface structure. II. Experiments on $\mathrm{Ge}, \mathrm{Si}, \mathrm{Al}$, and brass. Physical Review B, v. 27, n. 2, 1983. 
56. ZAYATS, A. V.; SMOLYANINOV, I. I. Near-field photonics: surface plasmon polaritons and localized surface plasmons. Journal of Optics A: Pure and Applied Optics, v. 5, n. 4, p. S16-S50, 2003 